UNIVERSIDADE TECNOLÓGICA FEDERAL DO PARANÁ PROGRAMA DE PÓS-GRADUAÇÃO EM ENGENHARIA ELÉTRICA E INFORMÁTICA INDUSTRIAL

FERNANDO CÉSAR BARAVIERA TOSTA

\title{
ANÁLISE E CARACTERIZAÇÃO DE LUMINÁRIA LED APLICADA EM COMUNICAÇÃO POR LUZ VISÍVEL
}

DISSERTAÇÃO

\section{CURITIBA}




\section{ANÁLISE E CARACTERIZAÇÃO DE LUMINÁRIA LED APLICADA EM COMUNICAÇÃO POR LUZ VISÍVEL}

Dissertação apresentada como requisito parcial à obtenção do título de Mestre em Ciências em Engenharia Elétrica e Informática Industrial, do Programa de Pós-Graduação em Engenharia Elétrica e Informática Industrial, da Universidade Tecnológica Federal do Paraná.

Orientador: Prof. Dr. Alexandre de Almeida Prado Pohl

\section{CURITIBA}




\section{Dados Internacionais de Catalogação na Publicação}

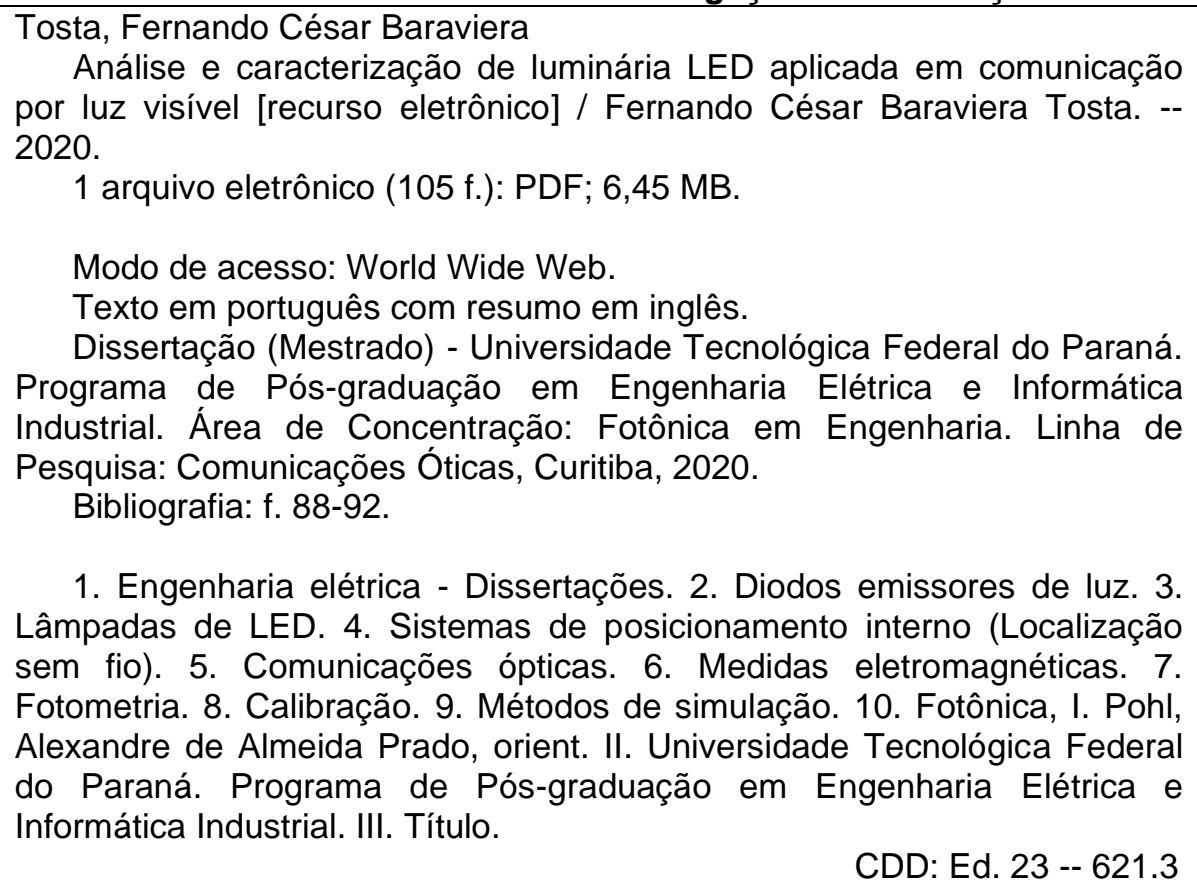

Dissertação (Mestrado) - Universidade Tecnológica Federal do Paraná. Programa de Pós-graduação em Engenharia Elétrica e Informática Industrial. Área de Concentração: Fotônica em Engenharia. Linha de Pesquisa: Comunicações Óticas, Curitiba, 2020.

Bibliografia: f. 88-92.

1. Engenharia elétrica - Dissertações. 2. Diodos emissores de luz. 3. Lâmpadas de LED. 4. Sistemas de posicionamento interno (Localização sem fio). 5. Comunicações ópticas. 6. Medidas eletromagnéticas. 7. Fotometria. 8. Calibração. 9. Métodos de simulação. 10. Fotônica, I. Pohl, Alexandre de Almeida Prado, orient. II. Universidade Tecnológica Federal do Paraná. Programa de Pós-graduação em Engenharia Elétrica e Informática Industrial. III. Título.

CDD: Ed. 23 -- 621.3 


\section{TERMO DE APROVAÇÃO DE DISSERTAÇÃO}

A Dissertação de Mestrado intitulada "Análise e Caracterização de Luminária LED Aplicada em Comunicação por Luz Visível” defendida em sessão pública pelo(a) candidato(a) Fernando Cesar Baraviera Tosta, no dia 30 de junho de 2020, foi julgada para a obtenção do título de Mestre em Ciências, Área de Concentração: Fotônica Em Engenharia, Linha de Pesquisa: Comunicações Óticas, e aprovada em sua forma final, pelo Programa de Pós-Graduação em Engenharia Elétrica e Informática Industrial - CPGEI.

BANCA EXAMINADORA:

Prof. Dr. Alexandre de Almeida Prado Pohl - Presidente - UTFPR

Prof. Dr. César Augusto Dartora - UFPR

Prof. Dr. Arismar Cerqueira Sodré Junior - INATEL

A via original deste documento encontra-se arquivada na Secretaria do Programa, contendo a assinatura da Coordenação após a entrega da versão corrigida do trabalho.

Curitiba, 30 de junho de 2020. 
Dedico este trabalho a minha família. 


\section{AGRADECIMENTOS}

São muitos que contribuíram para realização deste trabalho. Agradeço aos meus pais e professores, Joel e Marisa, pelo amor e dedicação, e por terem me ajudado a trilhar este caminho, sempre me apoiando e motivando em todos os momentos. Agradeço também à minha esposa Adriana e aos meus filhos: Vinícius Eduarda e Rafael, pela paciência e apoio na superação dos momentos difíceis dessa jornada.

Ao meu orientador, Professor Dr. Alexandre Pohl, por todo o tempo e conhecimento doado para que fosse possível a superação de mais este desafio em minha vida.

Aos colegas do Curso Técnico em Telecomunicações do Instituto Federal do Paraná (IFPR), da Agência Nacional de Telecomunicações (Anatel), e do Programa de Pós-Graduação em Engenharia Elétrica e Informática Industrial (CPGEI) da Universidade Tecnológica Federal do Paraná (UTFPR) pelo apoio dado à pesquisa aqui retratada, em especial ao Me. Marcelo de Oliveira pela ajuda no desenvolvimento deste trabalho.

O presente trabalho foi realizado com apoio da Coordenação de Aperfeiçoamento de Pessoal de Nível Superior - Brasil (CAPES) - Código de Financiamento 001.

Enfim, a todos os que de alguma forma contribuíram para a realização deste trabalho. 
A velocidade das ondulações transversais em nosso meio hipotético, calculada a partir dos experimentos eletromagnéticos dos Srs. Kohlrausch e Weber, concorda tão exatamente com a velocidade da luz, calculada a partir dos experimentos ópticos do Sr. Fizeau, que é difícil evitar a inferência de que a luz consiste em ondulações transversais do mesmo meio que é a causa dos fenômenos elétricos e magnéticos.

(MAXWELL, James Clerk, 1862). 


\section{RESUMO}

TOSTA, Fernando César Baraviera. ANÁLISE E CARACTERIZAÇÃO DE LUMINÁRIA LED APLICADA EM COMUNICAÇÃO POR LUZ VISÍVEL. 2020. 105 f. Dissertação (Mestrado em Engenharia Elétrica e Informática Industrial) - Universidade Tecnológica Federal do Paraná. Curitiba, 2020.

Este trabalho apresenta análises de desempenho de uma luminária LED, aplicada simultaneamente para iluminação e comunicação em sistemas de comunicação por luz visível (VLC), em ambientes internos (indoor). Apresenta-se a análise de desempenho de um concentrador óptico acoplado à luminária por meio de medidas fotométricas e radiométricas, com suas características reproduzidas e simuladas nos softwares SolidWorks ${ }^{\circledR}$ e APEX ${ }^{\circledR}$. As simulações foram comparadas com medições em laboratório, objetivando a utilização desses softwares em predições mais realistas de sistemas VLC e na análise de componentes ópticos. Os resultados ressaltam a importância do detalhamento das características ópticas dos materiais empregados nas simulações, bem como a necessidade de calibração de potência dos LEDs. Nas simulações realizadas a 1,70 m de distância foram obtidos níveis de iluminância de até 1351,59 lx e estimativas de

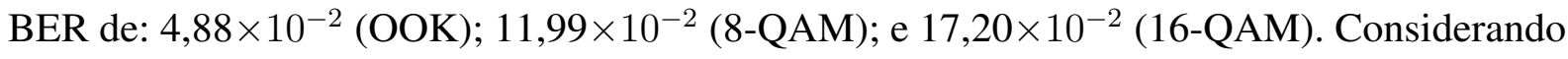
um ganho de 3,82 dB no front - end de recepção, as estimativas de BER melhoram para:

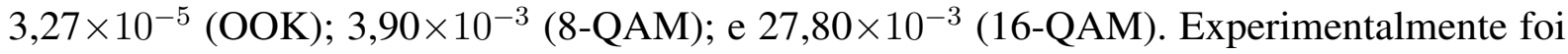
alcançado ganho de até $8,59 \mathrm{~dB}$ na transmissão com o uso do concentrador óptico.

Palavras-chave: Comunicação em luz visível. LED. VLC. 


\begin{abstract}
TOSTA, Fernando César Baraviera. ANALYSIS AND CHARACTERIZATION OF LUMINAIRE APPLIED IN COMMUNICATION BY VISIBLE LIGHT. 2020. 105 p.

Dissertation (Master's Degree in Course Name) - Universidade Tecnológica Federal do Paraná. Curitiba, 2020.

This work presents performance analysis of an LED luminaire, applied simultaneously for lighting and communication in visible light communication systems (VLC), indoors ( emphindoor). The performance analysis of an optical concentrator coupled to the luminaire by means of photometric and radiometric measurements is presented, with its characteristics reproduced and simulated in the SolidWorks ${ }^{\circledR}$ and APEX ${ }^{\circledR}$ pieces of software. The simulations were compared with measurements in the laboratory, aiming to use this software in more realistic predictions of VLC systems and in the analysis of optical components. The results highlight the importance of detailing the optical characteristics of the materials used in the simulations, as well as the need for power calibration of the LEDs. In simulations carried out at $1.70 \mathrm{~m}$ distance, illuminance levels of up to $1351.59 \mathrm{~lx}$ and BER estimates of: $4.88 \times 10^{-2}$ (OOK); $11.99 \times 10^{-2}$ (8-QAM); and $17.20 \times 10^{-2}(16-\mathrm{QAM})$. Considering a $3.82 \mathrm{~dB}$ gain in the reception front-end, the BER estimates improve to: $3.27 \times 10^{-5}(\mathrm{OOK}) ; 3.90 \times 10^{-3}(8-\mathrm{QAM})$; and $27.80 \times 10^{-3}$ (16-QAM). Experimentally, a gain of up to $8.59 \mathrm{~dB}$ was achieved in the transmission with the use of the optical concentrator.
\end{abstract}

Keywords: Visible light Communication. LED. VLC. 


\section{LISTA DE ILUSTRAÇÕES}

Figura 1 - Espectro Eletromagnético. . . . . . . . . . . . . . . . . . . . 19

Figura 2 - Diagrama em blocos de um sistema de comunicação em luz visível. . . . . . 20

Figura 3 - Campos E e H. Os vetores indicam valores instantâneos (setas vermelhas e

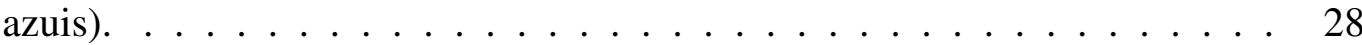

Figura 4 - Curva da sensibilidade espectral relativa do olho humano. . . . . . . . . . . 30

Figura 5 - Ângulo sólido dado pela relação entre a área iluminada da superfície e o raio da esfera. . . . . . . . . . . . . . . . . . .

Figura 6 - Projeção da densidade de fluxo incidente em uma superfície na qual um foco puntiforme ao angulo solido elementar ilumina um elemento de superfície,

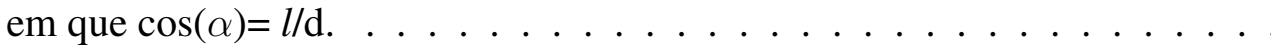

Figura 7 - Na absorção a energia é capturada de um feixe de luz para excitar o átomo, enquanto na emissão espontânea, a energia é liberado pelo átomo. . . . . . . . .

Figura 8 - Relação entre a potência óptica radiada e a corrente elétrica que passa pela junção p-n. . . . . . . . . . . . . . . . . . . . . . .

Figura 9 - Características lambertianas normalizadas. De acordo com a ordem do lambertiano são observadas diferentes FOVs. . . . . . . . . . . . . . . . 38

Figura 10 - Distribuição espectral do LED Lumileds, modelo LXML-PW31. . . . . . . 39

Figura 11 - Propagação em um enlace de comunicação sem fio. Além do sinal recebido em visada direta, também são recebidas parcelas do sinal sem linha de visada. Os ângulos $\alpha$ e $\beta$ denotam os ângulos de irradiação e incidência, respectivamente. . . . . . . . . . . . . . . 40

Figura 12 - Configurações de enlaces LOS e NLOS em comunicações ópticas sem fio.

Figura 13 - Transferência de energia radiante. As superfícies separadas por uma distância "d"e com ângulos em relação à normal $(\mathrm{n})$ definidos por $\theta_{1}$ e $\theta_{2} \ldots$. . . . . . .

Figura 14 - Absorção, reflexão e transmissão de um fluxo luminoso ao incidir em uma determinada superfície. No detalhe é representada a reflexão dos raios em uma superfície lambertiana. . . . . . . . . . . . . . . . .

Figura 15 - A PSD de um LED (linha sólida, que corresponde ao eixo esquerdo) é comparada à refletância espectral medida (que corresponde ao eixo direito) das paredes de gesso e de plástico (linhas tracejadas e pontilhadas), piso (linha tracejada) e teto (linha pontilhada). . . . . . . . . . . . . . .

Figura 16 - Percentual de absorção do espectro eletromagnético pela atmosfera em função do comprimento de onda.

Figura 17 - Luminária com base circular contendo sete elementos LED. A imagem da esqueda mostra a disposição dos LEDs na base, enquanto a imagem da direita apresenta a luminária montada com o elemento concentrador encaixado sobre os LEDs dispostos na base. . . . . . . . . . . . . . . . . . . . . . . 5 5

Figura 18 - Fluxo de trabalho no APEX ${ }^{\circledR} \ldots \ldots \ldots \ldots$. . . . . . . . . . . 52

Figura 19 - Elemento de acoplamento do LED ao conjunto óptico que compõe a luminária. No detalhe é apresentada a vista lateral da peça. . . . . . . . . . . . . . . .

Figura 20 - Luminária reproduzida no Solidworks ${ }^{\circledR}$ e utilizada nas simulações no APEX ${ }^{\circledR}$. $\mathrm{Na}$ imagem da esquerda podem ser observados os LEDs encaixados no elemento concentrador. $\mathrm{Na}$ imagem da direita o conjunto acomodado sobre a base. 
Figura 21 - Fonte de luz LED modelo LXML-PW31 disponível na biblioteca do aplicativo $\mathrm{APEX}^{\circledR} \ldots \ldots \ldots \ldots \ldots \ldots \ldots \ldots$

Figura 22 - Ajuste do fluxo radiométrico do LED modelo LXML-PW31 obtida na simulação do $\mathrm{APEX}^{\circledR}$. O perfil circular nas imagens é devido à própria geometria da superfície irradiante do LED. . . . . . . . . . . . . . . . . . . .

Figura 23 - Montagem para posicionamento da fonte de luz LED e verificação da estabilização do traçado de raios. . . . . . . . . . . . . . . . . . . . . .

Figura 24 - Secção da distribuição da densidade de potência. As setas indicam pontos onde ocorre deformidade na curva de distribuição. Até 2 milhões de raios a distribuição não atinge o valor de $0,009 \mathrm{~W} / \mathrm{mm}^{2}$ que passa a ocorrer à partir do uso de 3 milhões de raios. . . . . . . . . . . . . . . . . . . . . . .

Figura 25 - Cenário montado para as simulações, representando uma sala com as medidas de 4,80 x 4,80 x 2,50 m e a fonte de luz centralizada na parte superior. As setas indicam a posição da fonte de luz em relação à sala. . . . . . . . . . . . .

Figura 26 - Perfil de irradiância obtido no piso: (a) Somente LEDs e paredes sem refletância: irradiância mínima de $16,66 \mathrm{nW} / \mathrm{mm}^{2}$ e máxima de $163,72 \mathrm{nW} / \mathrm{mm}^{2}$; (b) Somente LEDs e paredes com refletância: irradiância mínima de 50,24 $\mathrm{nW} / \mathrm{mm}^{2}$ e máxima de $183,34 \mathrm{nW} / \mathrm{mm}^{2}$; (c) Inclusão da base com refletãncia de $80 \%$ : irradiância mínima de $16,62 \mathrm{nW} / \mathrm{mm}^{2}$ e máxima de $162,49 \mathrm{nW} / \mathrm{mm}^{2}$; e (d) Inclusão da base com refletãncia de 95\%: irradiância mínima de 16,91 $\mathrm{nW} / \mathrm{mm}^{2}$ e máxima de $162,49 \mathrm{nW} / \mathrm{mm}^{2}$.

Figura 27 - Distribuição de potência no piso: (a) representação tridimensional pela qual pode ser observada a concentração de potência na parte central; e (b) detalhamento dos níveis de irradiância que varia de $7,37 \mathrm{nW}$ a $1,76 \mu \mathrm{W} / \mathrm{mm}^{2}$. . . .

Figura 28 - Elementos utilizados para simulação. No centro da sala é disposta uma superfície quadrada (mesa) com variação da distância em relação à luminária (eixo y). Elementos: (1) Luminária; (2) Mesa; e (3) detalhe do ressalto circular no centro da mesa. . . . . . . . . . . . . . . . . . . . . . .

Figura 29 - Exemplo de detecção do fluxo radiométrico por superfície sensora de 0,71 $\mathrm{cm}^{2}$. (a) Fluxo radiométrico total de $47,86 \mathrm{~mW}$ para superfície distante $20 \mathrm{~cm}$ da luminária. (b) Fluxo radiométrico de $318,50 \mu \mathrm{W}$ para superfície distante $1,70 \mathrm{~m}$ da luminária . . . . . . . . . . . . . . . . . . . .

Figura 30 - Potência detectada em uma superfície circular com $0,71 \mathrm{~cm}^{2}$ de área em função do afastamento em relação à luminária. As linhas tracejadas indicam o resultado teórico. . . . . . . . . . . . . . . . . 65

Figura 31 - Variação da refletância e do material do elemento concentrador. . . . . . . . 66

Figura 32 - Distribuição da iluminância em uma superfície de $1 m^{2}\left(\Phi_{v}\right.$ de 725,90 lm). . 67

Figura 33 - Distribuição da iluminância em uma superfície de $1 m^{2}\left(\Phi_{v}\right.$ de 205,50 lm). . 68

Figura 34 - Distribuição das luminárias numeradas de 1 a 9 e das mesas (A, B, C, D e E) no cenário. Vista superior (esquerda) e vista isométrica (direita). . . . . . .

Figura 35 - Distribuição da Irradiância incidente no piso da sala com o uso de nove luminárias. Os níves de variam entre $104 \mathrm{nW} / \mathrm{mm}^{2}$ e $2,62 \mu \mathrm{W} / \mathrm{mm}^{2}$. No detalhe é apresentada a visualização tridimensional da distribuição da irradiância.

Figura 36 - Distribuição da iluminância incidente no piso da sala com o uso de nove luminárias. Os níves de variam entre $104 \mathrm{nW} / \mathrm{mm}^{2}$ e $2,62 \mu \mathrm{W} / \mathrm{mm}^{2} \ldots$. . .

Figura 37 - Montagem do setup para medidas de laboratório. O arranjo de medidas pode ser modificado pela alteração da posição da fonte de luz (luminária) e dos instrumentos de medida sobre a mesa óptica. . . . . . . . . . . . . . . . 
Figura 38 - Picos de emissão na faixa da cor azul e amarela detectados pelo analisador. $\mathrm{O}$ pico à esquerda $(454 \mathrm{~nm})$ demonstra a emissão no espectro de cor azul. $\mathrm{O}$ pico à direita $(580 \mathrm{~nm})$ encontra-se na faixa a cor amarela. . . . . . . . . . . 72

Figura 39 - Curva de responsividade do fotodiodo S121C disponibilizada pela ThorLabs ${ }^{\circledR} .73$

Figura 40 - Potência óptica e Iluminância medidas em função da variação da potência elétrica consumida pela luminária a $1 \mathrm{~m}$ de distância. . . . . . . . . . . . . 74

Figura 41 - Potência óptica função da variação da potência elétrica consumida pela luminária a mantida a $1,70 \mathrm{~m}$ de distância. Nesse experimento foram medidos valores com e sem o concentrador. . . . . . . . . . . . . . . 74

Figura 42 - Procedimento para variação da distância durante a execução do experimento. 75

Figura 43 - Potência medida no fotodetector em função da distância de afastamento em relação à luminária. . . . . . . . . . . . . . . . . . . . . . . . 75

Figura 44 - Desalinhamento lateral do fotodetector a cada $5 \mathrm{~cm}$ em relação ao eixo de alinhamento entre luminária e fotodetector. . . . . . . . . . . . . 76

Figura 45 - Potência medida no fotodetector em função do desalinhamento lateral em relação ao eixo de alinhamento da luminária. . . . . . . . . . . . . . . . . . 77

Figura 46 - Subdivisões da distribuição das medições de iluminância em uma superfície de $1 \mathrm{~m}^{2} \ldots \ldots \ldots \ldots \ldots \ldots \ldots \ldots \ldots \ldots \ldots$

Figura 47 - Distribuição das medições de iluminância em uma superfície de $1 \mathrm{~m}^{2}$. Nas figuras pode ser observada a concentração da iluminância na região central. As medidas foram realizadas com as potências consumidas pela luminária de

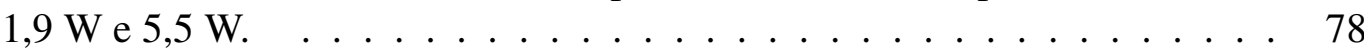

Figura 48 - Comparação entre resultados experimentais, simulados pelo APEX ${ }^{\circledR}$ e teóricos. 81

Figura 49 - Estimativas de SNR e BER para diferentes modulações, na condição de baixa luminosidade $(205,50 \mathrm{~lm}) \ldots \ldots$. . . . . . . . . . . . . . 82

Figura 50 - Variação da SNR em função da distância. As linhas tracejadas demonstram a SNR sem a aplicação de ganho na recepção. Os resultados experimentais consideram as potências elétricas consumidas pela luminária. . . . . . . . .

Figura 51 - Variação da BER para as modulações OOK e M-QAM devido ao desalinhamento lateral do fotodiodo em relação à luminária distante $1 \mathrm{~m}$ quando alinhada ao eixo central $(\mathrm{g}(\beta)=3,82 \mathrm{~dB}) . \ldots \ldots 83$

Quadro 1 - Estudos e respectivas performances obtidas recentemente. . . . . . . . . . 21

Quadro 2 - Resumo das grandezas radiométricas e fotométricas. . . . . . . . . . . . . 31

Quadro 3 - Seleção de softwares ópticos, por categoria. . . . . . . . . . . . . . . . . 43 


\section{LISTA DE TABELAS}

Tabela 1 - Planejamento de ambientes (áreas), tarefas e atividades com a respectiva especificação da iluminância. . . . . . . . . . . . . . . . . . 33 33

Tabela 2 - Fontes artificiais de luz e suas características, valores típicos. . . . . . . . . 35

Tabela 3 - Performances típicas e características dos fotodiodos. . . . . . . . . . . . 40

Tabela 4 - Características dos LEDs Lumileds (corrente de teste em 350 mA). . . . . 54

Tabela 5 - Variação da área de fotodetecção. . . . . . . . . . . . . . . . . . 58

Tabela 6 - Comparativo entre método determinístico e estocástico. . . . . . . . . . . . 59

Tabela 7 - Refletância em função do comprimento de onda correspondente às paredes de gesso. . . . . . . . . . . . . . . . . . . 60 60

Tabela 8 - Análise da iluminância sobre as mesas da sala e do fluxo radiométrico incidente sobre as respectivas superfícies sensoras com $0,71 \mathrm{~cm}^{2} \ldots \ldots$. . . 71

Tabela 9 - Parâmetros para cálculo da SNR . . . . . . . . . . . . . . 80

Tabela 10 - Estimativas de SNR e BER para diferentes modulações com superfície sensora alinhada à luminária e distante de $1,70 \mathrm{~m}$ ( sem ganho na recepção $-\mathrm{g}(\beta)$ $=0 \mathrm{~dB}) \ldots \ldots \ldots \ldots \ldots \ldots \ldots \ldots \ldots \ldots \ldots \ldots \ldots \ldots \ldots \ldots \ldots$

Tabela 11 - Estimativas de SNR e BER para diferentes modulações com superfície sensora alinhada à luminária e distante de $1,70 \mathrm{~m}$ (com ganho na recepção $-\mathrm{g}(\beta)$ $=3,82 \mathrm{~dB}) \ldots \ldots \ldots \ldots \ldots \ldots \ldots \ldots \ldots \ldots \ldots \ldots \ldots \ldots \ldots \ldots \ldots$

Tabela 12 - Estimativas de SNR e BER para diferentes modulações com superfícies sensoras de $0,71 \mathrm{~cm}^{2}$ distribuídas na sala (com ganho na recepção $-\mathrm{g}(\beta)=$

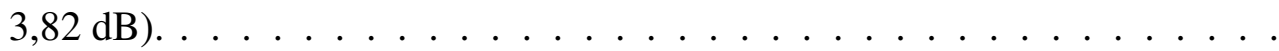




\section{LISTA DE ABREVIATURAS, SIGLAS E ACRÔNIMOS}

SIGLAS

\begin{tabular}{|c|c|}
\hline ABNT & Associação Brasileira de Normas Técnicas \\
\hline APD & Fotodiodo de Avalanche, do inglês Avalanche Photodiode \\
\hline AWGN & Ruído Branco Aditivo Gaussiano, do inglês Additive White Gaussian Noise \\
\hline BER & axa de Erro de Bit, do inglês Bit Error Rate \\
\hline CAD & Desenho Assistido por Computador, do inglês Computer Aided Design \\
\hline CAPES & Coordenação de Aperfeiçoamento de Pessoal de Nível Superior - Brasil \\
\hline CCT & Temperatura de Cor Correlata, do inglês Correlated Color Temperature \\
\hline CPGEI & Programa de Pós-Graduação em Engenharia Elétrica e Informática Industrial \\
\hline CRI & Índice de Reprodução de Cor, do inglês Color Rendering Index \\
\hline DFT-S & $\begin{array}{l}\text { Transformada de Fourier Discreta - Distribuída, do inglês Discrete Fourier Trans- } \\
\text { form - Spread }\end{array}$ \\
\hline ERB & Estação Rádio Base \\
\hline FOV & Ângulo de Visão, do inglês Field Of View \\
\hline IEEE & $\begin{array}{l}\text { Instituto de Engenheiros Eletricistas e Eletrônicos, do inglês Institute of Electrical } \\
\text { and Electronic Engineers }\end{array}$ \\
\hline IFPR & Instituto Federal do Paraná \\
\hline $\mathrm{IM} / \mathrm{DD}$ & $\begin{array}{l}\text { Modulação de Intensidade com Detecção Direta, do inglês Intensity Modulation } \\
\text { with Direct Detection }\end{array}$ \\
\hline IRC & Comunicação Infravermelha, do inglês Infrared Communication \\
\hline ISI & Interferência Intersimbólica, do inglês Intersymbol interference \\
\hline LATE & Laboratório Avançado de Telecomunicações \\
\hline LD & Diodo Laser, do inglês Laser Diode \\
\hline LED & Diodo Emissor de Luz, do inglês Light Emitting Diode \\
\hline LOS & Linha de Visada, do inglês Line Of Sight \\
\hline M-CPAM & $\begin{array}{l}\text { Modulação por Amplitude de Pulso Colorido Multinível, do inglês Multi-level } \\
\text { Color Pulse Amplitude Modulation }\end{array}$ \\
\hline M-QAM & $\begin{array}{l}\text { Modulacão de Amplitude em Quadratura Multinível, do inglês MultiLevel - Qua- } \\
\text { drature Amplitude Modulation }\end{array}$ \\
\hline MAC & Camada de Enlace, do inglês Media Access Control \\
\hline MCRT & Traçado de Raios Monte Carlo, do inglês Monte Carlo Ray-Tracing \\
\hline MIMO & Múltiplas Entradas, Múltiplas Saídas, do inglês Multiple Input, Multiple Output \\
\hline NLOS & Sem Linha de Visada, do inglês Non-line-of-sight \\
\hline OFDM & $\begin{array}{l}\text { Multiplexação por Divisão de Freqüências Ortogonais, do inglês Orthogonal } \\
\text { Frequency Division Multiplexing }\end{array}$ \\
\hline
\end{tabular}


OOK Chaveamento Liga-Desliga, do inglês On-Off Keying

OWC

Comunicações Ópticas Sem Fio, do inglês Optical Wireless Communication

PAM

Modulação por Amplitude de Pulso, do inglês Pulse Amplitude Modulation

PAPR Razão entre a Potência de Pico e a Potência Média, do inglês Peak to Average Power Ratio

PHY Camada Física, do inglês Physical Layer

PIN P-Intrínseco-N

PPM Modulação por Posição de Pulso, do inglês Pulse Position Modulation

PSD Distribuição Espectral de Potência, do inglês Power Spectral Distribution

PWM Modulação por Largura de Pulso, do inglês Pulse Width Modulation

QPSK Modulação por Chaveamento de Fase em Quadratura, do inglês Quadrature Phase-Shift Keying

RGB Red, Green and Blue

SNR Relação Sinal Ruído, do inglês Signal-to-Noise Ratio

UTFPR Universidade Tecnológica Federal do Paraná

UVC Comunicação Ultravioleta, do inglês Ultraviolet Communication

VLC Comunicação por Luz Visível, do inglês Visible Light Communication

WDM Multiplexação por Divisão de Comprimento de Onda, do inglês Wavelength Division Multiplexing

WiFi Wireless Fidelity

\section{ACRÔNIMOS}

Anatel Agência Nacional de Telecomunicações 


\section{LISTA DE SÍMBOLOS}

\section{LETRAS LATINAS}

$\begin{array}{llr}A & \text { Área } & {\left[\mathrm{m}^{2}\right]} \\ B & \text { Largura de banda } & {[\mathrm{Hz}]} \\ C & \text { Capacidade do canal } & {[\mathrm{bps}]} \\ \mathrm{c} & \text { Velocidade de propagação da luz } & {[\mathrm{m} / \mathrm{s}]} \\ c_{0} & \text { Velocidade de propagação da luz no vácuo } & {[\mathrm{m} / \mathrm{s}]} \\ d & \text { Distância } & {[\mathrm{m}]} \\ \vec{E} & \text { Vetor intensidade de campo elétrico } & {[\mathrm{V} / \mathrm{m}]} \\ \mathscr{E} & \text { Energia } & {[\mathrm{J}]} \\ f & \text { Frequência } & {[\mathrm{Hz}]} \\ G & \text { Ganho de tensão em malha aberta } & {[\text { admensional] }} \\ g(\beta) & \text { Ganho da lente na recepção } & {[\text { admensional] }} \\ g_{m} & \text { Transcondutância do FET } & {[\mathrm{S}]} \\ \vec{H} & \text { Vetor intensidade de campo magnético } & {[\mathrm{A} / \mathrm{m}]} \\ h & \text { Constante de Plank } & {[\mathrm{Js}]} \\ I_{b g} & \text { Fotocorrente devido à luz ambiente } & {[\mathrm{A}]} \\ I_{o} & \text { Intensidade óptica } & {\left[\mathrm{W} / \mathrm{m}^{2}\right]} \\ I_{2} & \text { Fator de ruído de banda para pulso retangular } & {[\text { admensional }]} \\ I_{3} & \text { Fator de ruído de banda para pulso cosseno levantado equalizado [admensional] } \\ \vec{J} & \text { Vetor densidade de corrente elétrica } & {\left[\mathrm{A} / \mathrm{m}^{2}\right]} \\ k & \text { Constante de Boltzmann } & {\left[\mathrm{m}^{2} \mathrm{kgs}^{-2} \mathrm{~K}^{-1}\right]} \\ l & \text { Altura } & {[\mathrm{m}]} \\ m & \text { Ordem da emissão lambertiana } & {[\text { admensional] }} \\ P_{r I S I} & \text { Potência recebida referente à interferência intersimbólica } & {[\mathrm{W}]} \\ P_{r S i n a l} & \text { Potência óptica do sinal recebido } & {[\mathrm{W}]} \\ q & \text { Carga do elétron } & {[\mathrm{C}]} \\ R & \text { Raio } & {[\mathrm{m}]} \\ \vec{S} & \text { Vetor de Poynting } & {\left[\mathrm{W} / \mathrm{m}^{2}\right]} \\ T_{k} & \text { Temperatura absoluta } & {[\mathrm{K}]} \\ T_{s}(\beta) & \text { Ganho do filtro óptico na recepção } & \text { admensional] }\end{array}$

\section{LETRAS GREGAS}

$\begin{array}{llr}\rho & \text { Densidade de cargas elétricas } & {\left[\mathrm{C} / \mathrm{m}^{3}\right]} \\ \varepsilon_{0} & \text { Permissividade elétrica no vácuo } & {[\mathrm{F} / \mathrm{m}]} \\ \mu_{0} & \text { Permeabilidade magnética no vácuo } & {[\mathrm{H} / \mathrm{m}]} \\ \omega & \text { Frequência angular } & {[\mathrm{rad} / \mathrm{s}]} \\ \Omega & \text { Unidade de ângulo sólido } & {[\mathrm{sr}]} \\ \lambda & \text { Comprimento de onda } & {[\mathrm{m}]} \\ \eta & \text { Eficiência luminosa } & {[\mathrm{lm} / \mathrm{W}]}\end{array}$




\section{SUMÁRIO}

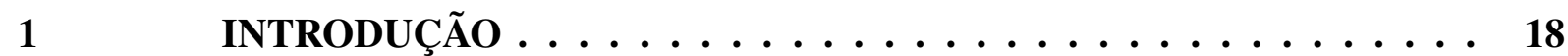

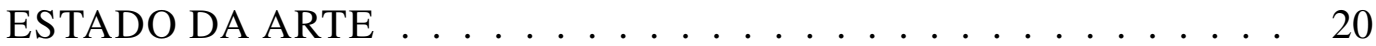

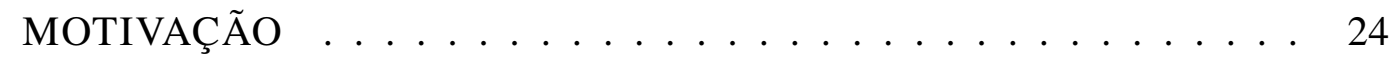

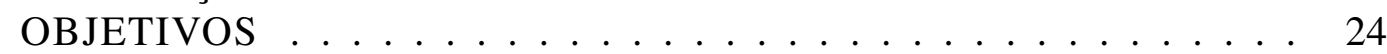

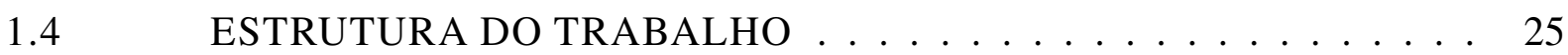

2 FUNDAMENTAÇÃO TEÓRICA $\ldots \ldots \ldots \ldots \ldots \ldots \ldots$

$2.1 \quad$ A FÍSICA DA LUZ $\ldots \ldots \ldots \ldots \ldots \ldots \ldots \ldots$

2.2 GRANDEZAS E PARÂMETROS RADIOMÉTRICOS E FOTOMÉ-

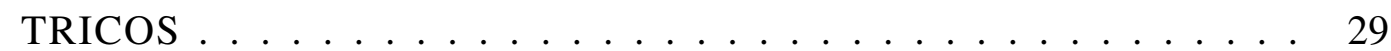

2.3 REQUISITOS PARA ILUMINAÇÃO . . . . . . . . . . . . . 32

$2.4 \quad$ FONTES ARTIFICIAIS DE LUZ $\ldots \ldots \ldots \ldots \ldots \ldots$

2.5 FOTODETECTORES . . . . . . . . . . . . . . . . 39

2.6 ÓPTICA GEOMÉTRICA E TRAÇADO DE RAIOS . . . . . . . . . . 41

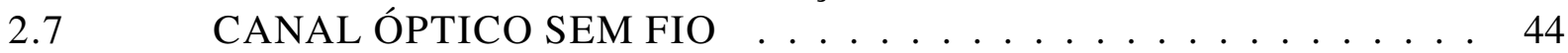

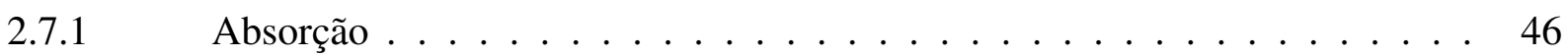

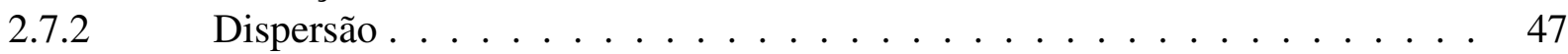

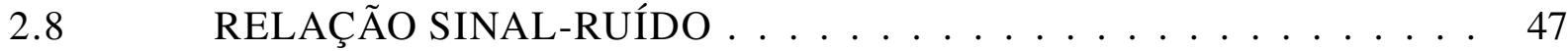

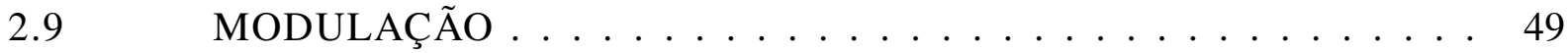

3 MATERIAL E MÉTODOS $\ldots \ldots \ldots \ldots \ldots \ldots \ldots \ldots$

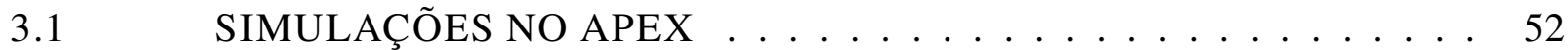

3.1.1 Reprodução da Luminária no Solidworks ${ }^{\circledR} \ldots \ldots \ldots \ldots$. . . . . . 53

3.1.2 Fonte de Luz LED utilizada . . . . . . . . . . . . . . . . . . . 54

3.1.3 Definição da quantidade de raios $\ldots \ldots \ldots \ldots \ldots \ldots$

$3.1 .4 \quad$ Cenário . . . . . . . . . . . . . . . . . . . . . . 59

3.1.5 Inclusão de peças na luminária $\ldots \ldots \ldots \ldots$. . . . . . . . 61

3.1.6 Variação da distância de deteç̧ão . . . . . . . . . . . . . . 63

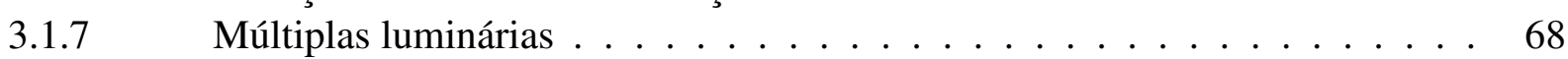

3.2 ENSAIOS PARA CARACTERIZAÇÃO DA LUMINÁRIA . . . . . . . 71

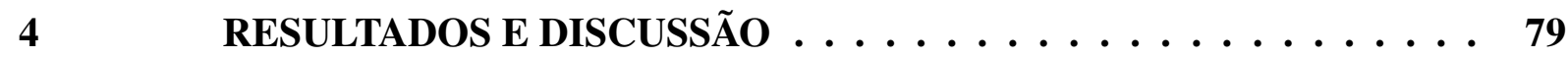

5 CONCLUSÕES E PERSPECTIVAS $\ldots \ldots \ldots \ldots \ldots$

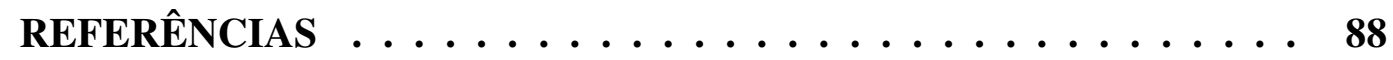

$\begin{array}{ll}\text { ANEXO } & 93\end{array}$

ANEXO A - DATASHEET LED LXML-PW31 . . . . . . . . 94

ANEXO B - DATASHEET LED LX18-P150 _ . . . . . . . . . . 99

ANEXO C - DETALHAMENTO TÉCNICO DO CONCENTRADOR

PL121140 . . . . . . . . . . . . . . . 104 


\section{INTRODUÇÃo}

A popularização dos sistemas de comunicação sem fio têm aumentado a demanda de uso do espectro radioelétrico que, no Brasil, é definido como a faixa compreendida entre $8,3 \mathrm{kHz}$ a 3000 GHz (ANATEL, 2020b). Segundo a Anatel, o Serviço Móvel Pessoal, que utiliza faixas do espectro licenciado, registrou mais de 226,7 milhões de linhas móveis no mês de janeiro de 2020 (ANATEL, 2020a).

Há ainda a demanda pelo uso de dispositivos sem fio dos mais diversos e que operam na faixa do espectro não licenciado, como os equipamentos de radiação restrita (ANATEL, 2017) que embarcam tecnologias como Wireless Fidelity (WiFi) e Bluetooth, contudo, os fabricantes ou importadores desses dispositivos que utilizam radiofrequências necessitam passar por processos de certificação e homologação compulsória (ANATEL, 2019).

No tocante às aplicações de comunicação, observa-se que, segundo o Inciso XIV do art. $3^{\circ}$ do anexo da Resolução Anatel $n^{\circ}$ 671, de 3/11/2016, o espectro de radiofrequências é um bem público, de fruição limitada, administrado pela Anatel, correspondente ao espectro eletromagnético abaixo de $3000 \mathrm{GHz}$. A porção do espectro eletromagnético associado à luz visível (430 THz a $790 \mathrm{THz}$ ) não está na atual jurisdição do ente regulador ${ }^{1}$.

Assim, como o espectro de radiofrequências é um recurso finito, e o uso de altas frequências (ondas milimétricas) sofre com o aumento da atenuação no espaço livre e efeitos de sombreamento (HAAS HARALD ; YIN, 2016), buscar alternativas para o provimento de comunicação sem fio fora dessas faixas de frequências torna-se importante e é nesse contexto que as comunicações que usam a banda do espectro óptico surgem como opção.

As Comunicações Ópticas Sem Fio, do inglês Optical Wireless Communication (OWC) (GHASSEMLOOY et al., 2013) tornam-se uma tecnologia complementar e de alta capacidade às radiocomunicações, como, por exemplo, futuras soluções de comunicação móvel de quinta geração (5G - New Radio), não apenas devido à enorme quantidade oferecida de espectro não regulamentado, mas, também, devido à maturidade tecnológica dos componentes ópticos, que pode ser explorada em conjunto com as infra-estruturas de iluminação baseadas no Diodo Emissor de Luz, do inglês Light Emitting Diode (LED), já existentes (SHI et al., 2018).

1 De acordo com o art. 131 da Lei n n $^{9.472}$, de 16/7/1997, Lei Geral de Telecomunicações, a exploração de serviços de telecomunicações dependerá de prévia autorização da Anatel, ou seja, trata-se de ato discricionário que independe do meio de comunicação utilizado, abrangendo a exploração por meios guiados (cabos ópticos, metálicos, etc) ou comunicações sem fio, mesmo que em faixas acima de $3000 \mathrm{GHz}$. 
Sistemas OWC utilizam comprimentos de onda no domínio óptico do espectro eletromagnético que inclui as faixas do infravermelho, da luz visível e do ultravioleta, denominadas, respectivamente, por: Comunicação Infravermelha, do inglês Infrared Communication (IRC); Comunicação por Luz Visível, do inglês Visible Light Communication (VLC); e Comunicação Ultravioleta, do inglês Ultraviolet Communication (UVC) (KARUNATILAKA et al., 2015; XU; SADLER, 2008). A Figura 1 ilustra um intervalo do espectro eletromagnético com destaque para a faixa da luz visível compreendida entre $380 \mathrm{~nm}$ e $750 \mathrm{~nm}$, localizada em frequências muito superiores às utilizadas nas radiocomunicações (DIMITROV; HAAS, 2015).

Figura 1 - Espectro Eletromagnético.

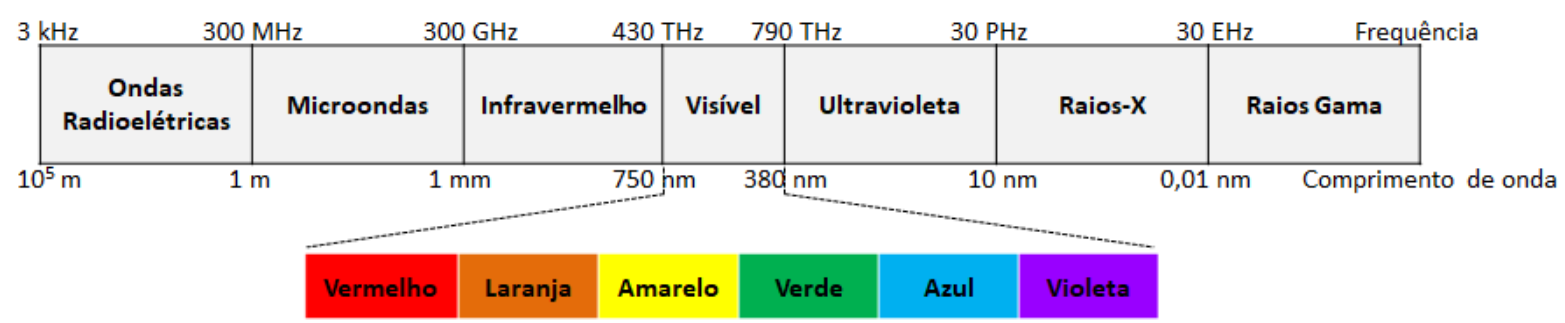

Fonte: Adaptado de BAO (2015).

A luz visível possui maior disponibilidade de espectro $(\approx 360 \mathrm{THz})$ que as ondas de rádio $(\approx 300 \mathrm{GHz})$ e não causa ou sofre interferência dos sinais de radiocomunicação. Outro aspecto associado às frequências é a capacidade de propagação. Enquanto emissões de radiofrequência podem atravaessar paredes, a luz fica confinada em espaços cercados por divisórias opacas. Apesar da limitação quanto à propagação, essa característica permite uma maior privacidade nas comunicações e possibilita a coexistência de links operando sem interferência (reuso espacial) (KARUNATILAKA et al., 2015).

O diagrama em blocos apresentado na Figura 2 ilustra como um sistema de comunicação por luz vizível pode ser implementado. A informação a ser transmitida é inserida em um circuito modulador que modula a corrente aplicada a uma fonte de luz LED. A luz irradiada no espaço livre deve chegar ao fotodetector (fotodiodo) com nível de potência suficiente para que seja convertida em fotocorrente pelo fotodiodo. No espaço livre, além da atenuação, estão presentes outras fontes de luz do próprio ambiente que agregam ruído na fotodetecção. Estando a relação sinal ruído em níveis adequados na saída do fotodiodo, a informação pode ser demodulada e recuperada na saída do receptor.

Segundo Chen et al. (2014), o uso da VLC oferece a oportunidade de criação de uma rede celular em pequena escala que pode ser incorporada em uma sala com várias luminárias. 
Figura 2 - Diagrama em blocos de um sistema de comunicação em luz visível.

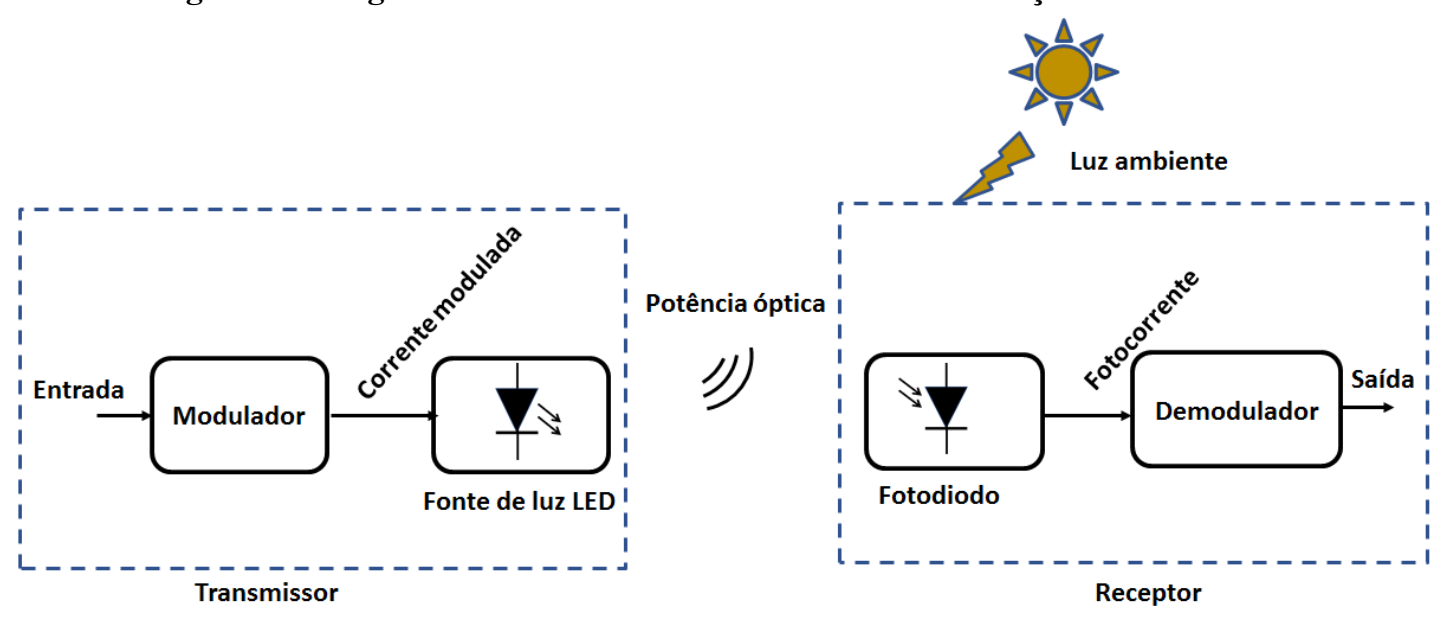

Fonte: Adaptado de Ghassemlooy et al. (2013).

Neste tipo de rede celular, cada elemento de iluminação espacialmente separado é usado como uma Estação Rádio Base (ERB), que abrange os usuários em uma pequena área (tipicamente entre 1 e $10 \mathrm{~m}^{2}$ ) abaixo dela. Esta pequena célula é referida como atto-célula óptica.

\subsection{ESTADO DA ARTE}

O uso de sinais luminosos visíveis para promover comunicação à distância não é algo novo para a humanidade. Nossa civilização utilizava-se de recursos rudimentares para enviar avisos a uma distância maior que a alcançada pela voz ou por gestos: tambores, sinais de fumaça, sinais visíveis, inclusive com bandeirolas (semáforo). Ao final do século XVIII (1793), foi inventado, na França, um "telégrafo semafórico", que transmitia sinais visíveis e que continuou sendo utilizado mesmo depois da invenção do telégrafo elétrico, deixando de ser empregado apenas após a invenção do rádio (CARVALHO, 2014). Após a invenção do código Morse em 1836, os navios da Marinha se comunicavam por meio de uma lâmpada de sinalização com faróis em terra para navegação.

Em 1880, Alexander Graham Bell demonstrou a primeira implementação de um enlace óptico na faixa do espectro visível na forma de um fotofone, modulando a luz solar com a mensagem de voz por meio da vibração de um espelho, transmitindo-a cerca de $200 \mathrm{~m}$ de distância. O receptor era formado por um espelho parabólico com uma célula de selênio no ponto focal para detecção (BELL, 1880).

O primeiro sistema OWC indoor foi relatado por Gfeller e Bapst (1979). Operando na faixa do IR (comprimento de onda central de $950 \mathrm{~nm}$ ), o sistema era capaz de atingir 1 
Mbps usando modulação do tipo Chaveamento Liga-Desliga, do inglês On-Off Keying (OOK) e radiação difusa para a cobertura de uma sala de escritório. Carruther e Kahn (2000) apresentaram uma implementação mais rápida do sistema IR OOK com taxa de dados de $70 \mathrm{Mbps}$ e potencial para atingir até 100 Mbps. Tanaka et al. (2000) foram pioneiros no uso de LEDs brancos para transmitir informações, além de servir para iluminação em uma configuração interna. Eles propuseram um sistema de comunicação óptica sem fio com LEDs de cor branca para um enlace (link) doméstico e, no ano de 2003, apresentaram uma configuração do sistema OOK VLC com taxa de dados de até $400 \mathrm{Mbps}$ (TANAKA et al., 2003).

No ano de 2011 o Instituto de Engenheiros Eletricistas e Eletrônicos, do inglês Institute of Electrical and Electronic Engineers (IEEE), publicou o padrão 802.15.7-2011 para a Camada Física, do inglês Physical Layer (PHY) e Camada de Enlace, do inglês Media Access Control (MAC), nas comunicações óticas sem fio de curto alcance na faixa do espectro da luz visível (IEEE, 2011). Este padrão foi atualizado em 2018 e substituído pelo 802.15.7-2018 que contempla faixas do infravermelho e do ultravioleta, se estendendo de $190 \mathrm{~nm}$ a $10.000 \mathrm{~nm}$ (IEEE, 2018). Com o passar do tempo novas tecnologias e técnicas de modulação vêm sendo propostas para as comunicações VLC. O Quadro 1 apresenta alguns estudos realizados na área, detalhados a seguir.

Quadro 1 - Estudos e respectivas performances obtidas recentemente.

\begin{tabular}{|c|c|c|c|c|c|c|}
\hline \multirow{2}{*}{ Autores } & \multicolumn{4}{|c|}{ Desempenho } & \multirow{2}{*}{ Transmissor } & \multirow{2}{*}{ Receptor } \\
\hline & Taxa de dados & BER & $\begin{array}{l}\text { Distância } \\
\text { (m) }\end{array}$ & $\begin{array}{l}\text { Iluminância } \\
\text { (Ix) }\end{array}$ & & \\
\hline $\begin{array}{l}\text { Tsonev et al. } \\
\text { (2015) }\end{array}$ & $\begin{array}{ll}\text { i. } & 14 \mathrm{Gbps} \\
\text { ii. } & 105,41 \mathrm{Gbps} \\
\text { iii. } & 3,43 \mathrm{Gbps}\end{array}$ & $\begin{array}{ll}\text { i. } & 6,07 \times 10^{-4} \\
\text { ii. } & 2,04 \times 10^{-3} \\
\text { iii. } & 2,33 \times 10^{-3}\end{array}$ & $\begin{array}{ll}\text { i. } & 0,3 \\
\text { ii. } & 0,93 \\
\text { iii. } & 2,88\end{array}$ & $\begin{array}{ll}\text { i. } & 843,69 \\
\text { ii. } & 971,28 \\
\text { iii. } & 21,25\end{array}$ & RGB (LD) & PIN \\
\hline $\begin{array}{l}\text { Ferreira et al. } \\
(2016)\end{array}$ & $\begin{array}{l}\text { 3,5 Gbps (PAM-4) } \\
5 \text { Gbps (OFDM) }\end{array}$ & $3,8 \times 10^{-3}$ & Apx. 0,5 & Não consta & $\mu \mathrm{LED}(\mathrm{GaN})$ & PIN \\
\hline $\begin{array}{l}\text { Wu et al. } \\
\text { (2017) }\end{array}$ & $\begin{array}{l}1 \text { Gbps (16-QAM) } \\
877,7 \mathrm{Mbps}(64-\mathrm{QAM})\end{array}$ & $\begin{array}{l}2,7 \times 10^{-3} \\
1,6 \times 10^{-3}\end{array}$ & $\begin{array}{l}\text { Sala } \\
5 \times 5 \times 3\end{array}$ & Não consta & RGB LED & PIN \\
\hline $\begin{array}{l}\text { Shi et al. } \\
\text { (2018) }\end{array}$ & $14,4 \mathrm{Mbps}$ & EVM de $4,78 \%$ & 0,55 & Não consta & LED & APD \\
\hline $\begin{array}{l}\text { Burton et al. } \\
\text { (2019) }\end{array}$ & $>10 \mathrm{Mbps}$ & $\leq 10^{-6}$ & 0,5 & Não consta & RGB LED & PIN com ganho \\
\hline $\begin{array}{l}\text { Celik e Çolak } \\
\text { (2020) }\end{array}$ & 4 bits por uso do canal & $\begin{array}{l}10^{-4} \text { para uma } \\
\text { menor SNR. }\end{array}$ & $\begin{array}{l}\text { Sala } \\
4 \times 4 \times 3,5\end{array}$ & Não consta & $\begin{array}{l}\text { LEDs VLC - } \\
\text { MIMO }\end{array}$ & $\begin{array}{l}\text { Quatro detectores } \\
\text { genéricos }\end{array}$ \\
\hline
\end{tabular}

Fonte: Autoria própria. 
Tsonev et al. (2015) propuseram o uso de Diodo Laser, do inglês Laser Diode (LD), como alternativa aos LEDs, por serem mais eficientes na conversão da eletricidade em luz, combinando três cores: vermelho, verde e azul - Red, Green and Blue (RGB) -, emitidas separadamente por três LDs para gerar luz branca. Apesar de obterem desempenhos superiores a $100 \mathrm{Gbps}$ em uma área de cobertura de $1 \mathrm{~m}^{2}$ (atto-célula óptica típica), na configuração em que a distância foi de 2,88 m, a taxa de dados alcançada foi de 3,43 Gbps com uma Taxa de Erro de

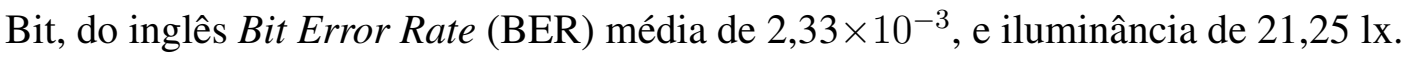

LEDs convencionais possuem larguras de banda de modulação eletro-óptica na ordem de 10 a 20 MHz. Ferreira et al. (2016), propuseram o uso de micro-LED para aumento dessa largura de banda de operação, excedendo-a em $800 \mathrm{MHz}$, aplicando três diferentes esquemas de modulação: OOK, Modulação por Amplitude de Pulso, do inglês Pulse Amplitude Modulation (PAM) e Multiplexação por Divisão de Freqüências Ortogonais, do inglês Orthogonal Frequency Division Multiplexing (OFDM). Os desempenhos alcançados de até 5 Gbps foram à distância de aproximadamente 0,5 m com o esquema de modulação OFDM.

O estudo apresentado por Wu et al. (2017), aplica a técnica de modulação denominada Transformada de Fourier Discreta - Distribuída, do inglês Discrete Fourier Transform - Spread (DFT-S), em subportadoras OFDM para reduzir a Razão entre a Potência de Pico e a Potência Média, do inglês Peak to Average Power Ratio (PAPR). O estudo aplicou luminárias formadas por matrizes de contendo 24 LEDs RGB e distribuídas nos quatro cantos do teto (sala de $5 \mathrm{~m} \times$ $5 \mathrm{~m} \times 3 \mathrm{~m}$ ), com uma lâmpada fluorescente funcionando ao mesmo tempo para iluminação complementar. Segundo os autores, foi a primeira vez que um transceptor DFT-S-OFDM em tempo real atingiu taxas de até 1,0 Gbps (BER de $2,7 \times 10^{-3}$ ) em um sistema indoor com múltiplas luminárias, e com um receptor de tamanho compacto.

Shi et al. (2018) testaram a integração do 5G - New Radio com a arquitetura de downlink VLC. Foi realizada a adequação da estrutura dos frames do $5 \mathrm{G}$ para a comunicação VLC e, nos testes com uma lâmpada LED comercial distante $55 \mathrm{~cm}$ do receptor, foi obtida a taxa de transmissão de 14,4 Mbps com aplicação da Modulação por Chaveamento de Fase em Quadratura, do inglês Quadrature Phase-Shift Keying (QPSK).

Burton et al. (2019) relataram que, pela primeira vez, foi demonstrada uma nova Multiplexação por Divisão de Comprimento de Onda, do inglês Wavelength Division Multiplexing (WDM) para comunicações de luz visível usando um esquema de modulação chamado de Modulação por Amplitude de Pulso Colorido Multinível, do inglês Multi-level Color Pulse 
Amplitude Modulation (M-CPAM), aplicada a LEDs RGB. Diferente do WDM tradicional, na recepção não foram utilizados filtros ópticos passa-faixa, tampouco múltiplos fotodiodos. A solução aplicou um único fotodiodo de ganho variável, a $50 \mathrm{~cm}$ de distância, obtendo-se, para cada comprimento de onda (cor), taxas superiores a $10 \mathrm{Mbps}\left(\mathrm{BER} \leq 10^{-6}\right)$ quando utilizados os LEDs azul e vermelho (RB) e acima de $5 \mathrm{Mbps}\left(\mathrm{BER} \leq 10^{-6}\right)$, incluindo o LED verde, ou seja, utilizando a configuração RGB.

Buscando melhorias no campo da eficiência espectral em sistemas VLC-MIMO, Celik e Çolak (2020) apresentaram uma nova técnica de modulação espacial que explora a sinergia entre a modulação espacial em quadratura e a modulação de intensidade de subportadora, chamando-a de QSM-SIM. A abordagem de Múltiplas Entradas, Múltiplas Saídas, do inglês Multiple Input, Multiple Output (MIMO), é adotada nos sistemas VLC com o emprego de vários LEDs como transmissores e vários fotodiodos como receptores, beneficiando-se dos ganhos de multiplexação e diversidade para aumentar a taxa de transferência (DIMITROV; HAAS, 2015).

A modelagem do sistema empregou duas diferentes configurações de LEDs dispostos no teto de uma sala hipotética de $4 \mathrm{~m} \times 4 \mathrm{~m} \times 3,5 \mathrm{~m}$. A primeira configuração distribui quatro LEDs no teto e a segunda oito. No centro da sala foram dispostos quatro fotodetectores (área de fotodetecção de $1,5 \mathrm{~cm}^{2}$ ) para realização das simulações com duas configurações MIMO (4 × 4 e $8 \times 4$ ). No estudo, os autores demonstraram que valores de BER da ordem de $10^{-4}$ foram alcançados com uma menor relação sinal-ruído ( Signal-to-Noise Ratio) na configuração $4 \times 4$. Na configuração $8 \times 4$, outras técnicas de modulação apresentaram melhor desempenho que a QSM-SIM (CELIK; ÇOLAK, 2020).

Estudos sobre o canal óptico sem fio em diferentes condições espaciais e configurações ópticas, com base em medições diretas ou simulações de traçados de raios também são propostas. Os trabalhos de Miramirkhani e Uysal (2015) e de Sarbazi et al. (2014), por exemplo, propõem o uso da técnica do traçado de raios com o software Zemax ${ }^{\circledR}$ para caracterização e modelagem da resposta ao impulso desse canal.

Já Lichtenegger et al. (2019) aplicaram o software de traçado de raios ASAP ${ }^{\circledR}$. Nesse trabalho são utilizadas quatro luminárias hipotéticas compostas, cada uma, por 100 elementos LED com potência radiante individual de $0,45 \mathrm{~W}$, totalizando $180 \mathrm{~W}$ de potência emitida.

Considerando os trabalhos realizados, foi observada a necessidade de elaboração de um estudo que permita a caracterização de uma luminária de uso comercial em conjunto com um elemento óptico, o concentrador, objetivando a melhoria do desempenho da comunicação e seus 
respectivos impactos na iluminação do ambiente.

O estudo das características da luminária em software que possibilite, também, o uso de fontes de luz disponíveis comercialmente, tem como objetivo a criação de cenários mais realísticos para o estudo do desempenho de comunicação VLC.

\subsection{MOTIVAÇÃO}

Uma das principais vantagens do uso de luz visível nas comunicações é a possibilidade de se utilizar dispositivos sem fio operando fora da faixa de radiofrequência. Além disso, a popularização do uso de sistemas de iluminação por meio de lâmpadas LED permite a distribuição de atto-células ópticas nos ambientes iluminados. Contudo, a obtenção do enlace de comunicação torna-se um desafio devido às condições de atenuação do sinal luminoso no espaço livre, principalmente em condições nas quais deseja-se manter a comunicação sem a necessidade, ou o compromisso, de garantir a iluminação do ambiente, como é típico dos sistemas de iluminação no período diurno.

$\mathrm{Na}$ maioria dos estudos, são utilizados arranjos com apenas um LED, ou enlaces dispostos a curtas distâncias. Portanto, a reprodução de luminárias, cenários com múltiplas luminárias, elementos ópticos e fontes de luz mais realísticos para aplicação em predições de sistemas VLC é fator motivador para os estudos aqui realizados, permitindo não só a análise de desempenho de comunicação, mas, também, da iluminação do ambiente.

\subsection{OBJETIVOS}

O objetivo deste trabalho é a reprodução de uma luminária LED real para análise simultânea do desempenho de iluminação e de comunicação para sistemas VLC indoor. Como a análise é realizada tomando-se a luminária como dispositivo transmissor (downlink), não são consideradas as abordagens para implementação do canal de retorno na comunicação (uplink).

A luminária e o ambiente (cenário) de estudos foram reproduzidos no software $\mathrm{CAD}^{2}$ SolidWorks ${ }^{\circledR}$, sendo aplicados os respectivos parâmetros ópticos e inseridas as fontes de luz LED disponíveis na biblioteca do $\mathrm{APEX}^{\circledR}$, um suplemento de design e análise óptica para o SolidWorks ${ }^{\circledR}$, utilizado na simulação pelo método do traçado de raios. Os resultados obtidos nessas simulações são comparados com as medições experimentais da luminária real.

2 Desenho Assistido por Computador, do inglês Computer Aided Design (CAD) 
Assim, os seguintes objetivos específicos foram estabelecidos:

- Reprodução da luminária e validação de parâmetros de projetos de sistemas VLC pelo método de traçado de raios.

- Obtenção de parâmetros operacionais da luminária por meio de medidas em laboratório.

- Análise da BER em função da Relação Sinal Ruído, do inglês Signal-to-Noise Ratio (SNR) do sinal modulado pela aplicação de elemento concentrador passivo na luminária.

- Obter parâmetros relativos às normas de iluminação vigentes no Brasil.

\subsection{ESTRUTURA DO TRABALHO}

O estudo foi organizado em cinco Capítulos. O primeiro Capítulo é dedicado à introdução do tema, bem como seu estado da arte, motivação e objetivos do trabalho. A fundamentação teórica, as características das fontes de luz e dos fotodetectores, os parâmetros do canal óptico sem fio e os respectivos parâmetros para realização dos cálculos de desempenho de comunicação são apresentados no segundo Capítulo. No terceiro Capítulo, os materiais e métodos utilizados para reprodução e simulação da luminária são apresentados, juntamente com a caracterização em laboratório de seus parâmetros operacionais. Posteriormente, no quarto Capítulo, são apresentados os resultados obtidos e, no Capítulo 5, as conclusões sobre os estudos realizados e sugestões para trabalhos futuros. 


\section{FUNDAMENTAÇÃO TEÓRICA}

Neste Capítulo é apresentada a fundamentação teórica sobre propagação das ondas eletromagnéticas, os parâmetros radiométricos e fotométricos necessários para as análises e as características fundamentais dos LEDs e fotodiodos de sistemas VLC.

\subsection{A FÍSICA DA LUZ}

Segundo a Lei de Faraday, sempre que houver um campo magnético $\vec{H}$ variando no tempo, surgirá um campo elétrico $\vec{E}$ induzido. Analogamente, ao ter-se um campo elétrico variando no tempo, surgirá um campo magnético induzido. No caso dinâmico, os campos $\vec{H}$ e $\vec{E}$ são grandezas indissociáveis e o resultado é uma sucessão desses campos que se induzem mutuamente, afastando-se da origem, e constituindo uma onda eletromagnética. O seu deslocamento é conhecido como propagação e garante transferência da energia eletromagnética de um ponto para outro do meio (RIBEIRO, 2006).

Moléculas e átomos excitados também emitem onda eletromagnética em uma vasta faixa de frequências. A origem da onda eletromagnética pode ser também à partir de transições de elétrons entre níveis de energia dos átomos. Quando os elétrons passam de um estado de energia mais alto para um nível inferior, a correspondente diferença é irradiada sob a forma de uma onda eletromagnética (RIBEIRO, 2006). Sob a perspectiva quântica, a luz consiste de partículas chamadas fóton, que transporta energia eletromagnética e momento (SALEH; TEICH, 2007).

Um campo eletromagnético é então descrito por dois campos vetorias relacionados: o campo elétrico $\vec{E}(\mathrm{r}, \mathrm{t})$ e o campo magnético $\vec{H}(\mathrm{r}, \mathrm{t})$. Ambos são funções vetoriais de posição e tempo, de modo que os fenômenos aqui apresentados podem ser descritos pelas equações de Maxwell macroscópicas em meios lineares, isotrópicos e homogêneos. As equações 1 e 2 são, respectivamente, as Leis de Gauss para a eletrostática e para o magnetismo. Já as equações 3 e 4 são, respectivamente, as Leis de Faraday e de Ampére-Maxwell (SALEH; TEICH, 2007).

$$
\begin{aligned}
& \nabla \cdot \vec{E}=\rho, \\
& \nabla \cdot \vec{H}=0,
\end{aligned}
$$




$$
\begin{gathered}
\nabla \times \vec{E}=-\mu_{0} \frac{\partial \vec{H}}{\partial t}, \\
\nabla \times \vec{H}=\vec{J}+\varepsilon_{0} \frac{\partial \vec{E}}{\partial t} .
\end{gathered}
$$

Onde:

$\vec{E}$ é o vetor intensidade de campo elétrico $[\mathrm{V} / \mathrm{m}]$.

$\vec{H}$ é o vetor intensidade de campo magnético $[\mathrm{A} / \mathrm{m}]$.

$\rho$ é a densidade de cargas elétricas no volume $\left[\mathrm{C} / \mathrm{m}^{3}\right]$.

$\vec{J}$ é o vetor densidade de corrente elétrica $\left[\mathrm{A} / \mathrm{m}^{2}\right]$.

Permissividade elétrica no vácuo: $\varepsilon_{0} \approx 8,85 \times 10^{-12}[\mathrm{~F} / \mathrm{m}]$.

Permeabilidade magnética no vácuo: $\mu_{0}=4 \pi \times 10^{-7}[\mathrm{H} / \mathrm{m}]$.

$\mathrm{Na}$ análise do caso dinâmico, no qual os campos elétricos e magnéticos variáveis no tempo interagem, há a condição em que $\rho=0$ e $\vec{J}=0$, de modo que os campos elétrico e magnético no espaço livre satisfazem as seguintes equações (SALEH; TEICH, 2007; SADIKU, 2000):

$$
\begin{gathered}
\nabla \cdot \vec{E}=0, \\
\nabla \cdot \vec{H}=0, \\
\nabla \times \vec{E}=-\mu_{0} \frac{\partial \vec{H}}{\partial t}, \\
\nabla \times \vec{H}=\varepsilon_{0} \frac{\partial \vec{E}}{\partial t} .
\end{gathered}
$$

Uma condição necessária para $\vec{E}$ e $\vec{H}$ satisfazerem as equações de Maxwell é que cada um dos seus componentes satisfaçam a equação de onda (SALEH; TEICH, 2007):

$$
\nabla^{2} u-\frac{1}{c_{0}^{2}} \frac{\partial^{2} u}{\partial t^{2}}=0
$$

A função escalar $u$ representa qualquer um dos três componentes do campo elétrico (Ex, Ey, Ez), ou dos três componentes do campo magnético (Hx, Hy, Hz) e $\mathrm{c}_{0}=1 / \sqrt{\mu_{0} \varepsilon_{0}} \approx 3 \times 10^{8}$ [m/s] é a velocidade de propagação da luz no vácuo (SALEH; TEICH, 2007).

À partir de uma fonte de luz puntual (dimensões infinitesimais) a propagação é caracterizada por meio de uma onda esférica, sendo que a frente de onda na região no campo 
distante pode ser considerada em um referencial local como uma onda plana uniforme. Para o caso de uma região do espaço na qual os Campos $\vec{E}$ e $\vec{H}$ se propagam na direção $z$ e possuem componentes ortogonais nas direções $x$ e $y$, respectivamente, observa-se o comportamento ondulatório da propagação ilustrado pela Figura 3, em um instante de tempo $t$ (ex.: $t=0)$. Sendo suas componentes descritas por (SADIKU, 2000):

$$
\begin{aligned}
& E=E_{0} \operatorname{sen}(\beta z-\omega t) a_{x} ; \\
& H=H_{0} \operatorname{sen}(\beta z-\omega t) a_{y} ;
\end{aligned}
$$

onde $\omega$ é a frequência angular dada em $\mathrm{rad} / \mathrm{s}$.

Figura 3 - Campos E e H. Os vetores indicam valores instantâneos (setas vermelhas e azuis).

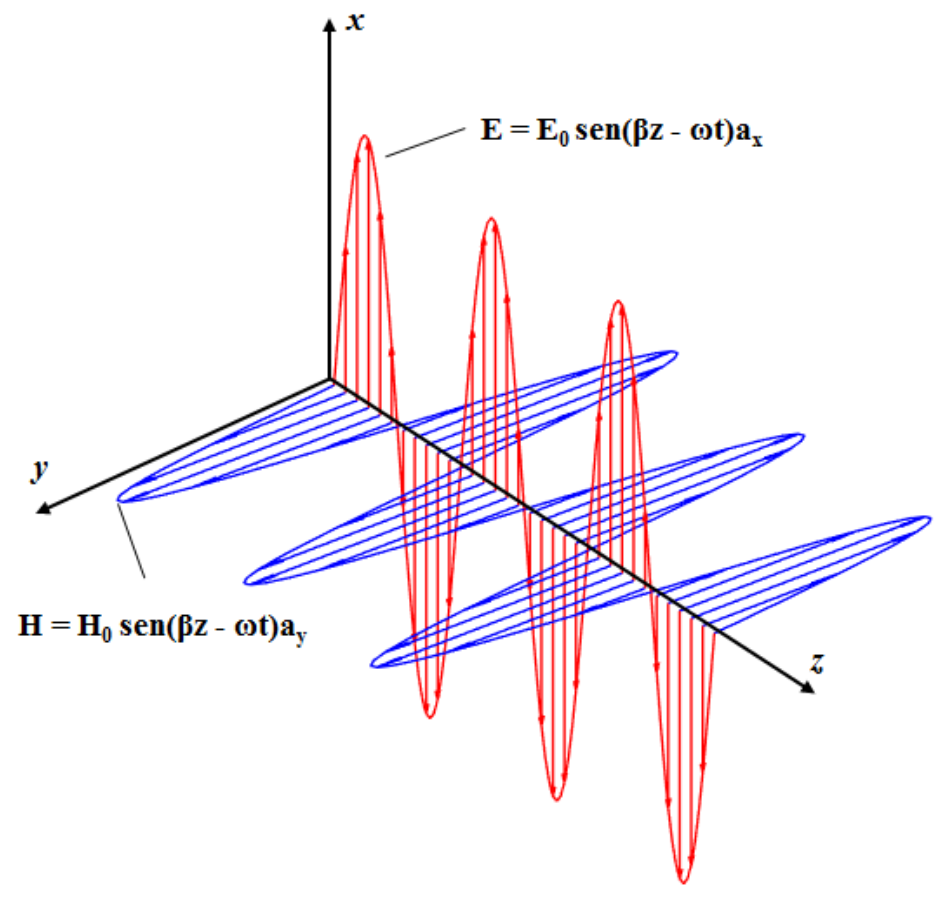

Fonte: Adaptado de Sadiku (2000).

Devido ao fato das componentes das ondas eletromagnéticas planas serem perpendiculares entre si e na direção de propagação da onda, utiliza-se o vetor de Poynting $(\vec{S}=\vec{E} \times \vec{H})$ para definir a densidade de potência, ou seja, a onda irradiada possui direção de propagação e fluxo de potência por unidade de área, também chamado de Intensidade Óptica $\left(\mathrm{I}_{o}\right)$ definidos pela Equação 12 (VISTNES, 2018).

$$
I_{o}=\frac{\text { Energia }}{\text { Área } \times \text { Tempo }}=\frac{\text { Potência }}{\text { Área }} \text {. }
$$


A partir dessas análises é verificada a condição na qual a luz é uma onda eletromagnética e, devido ao comprimento de onda da luz visível ser relativamente curto (entre $380 \mathrm{~nm}$ e $750 \mathrm{~nm}$ ), as técnicas usadas para gerar, transmitir e detectar ondas nessa faixa diferem daquelas usadas em ondas eletromagnéticas de longo comprimento de onda (radiocomunicação) (SALEH; TEICH, 2007).

Além disso, deve ser considerado que os canais de radiocomunicação, operando em frequências mais baixas, são mais robustos aos efeitos de bloqueio e sombreamento, podendo fornecer melhores coberturas, porém, o uso de frequências mais baixas implica em taxas de dados menores devido à dependência do canal à largura de banda disponível. Para um dado canal afetado por Ruído Branco Aditivo Gaussiano, do inglês Additive White Gaussian Noise (AWGN) sua capacidade é dada pelo modelo matemático de Shannon (GOLDSMITH, 2005):

$$
C=B \log _{2}(1+S N R)
$$

Onde:

C - Capacidade do canal [bps];

B - Largura de banda [Hz]; e

SNR - Relação sinal ruído do canal [adimensional].

O custo ao se utilizar faixas de frequências mais altas para obtenção de maiores larguras de banda é que a propagação torna-se cada vez mais em Linha de Visada, do inglês Line Of Sight (LOS) e, portanto, os problemas encontrados são similares àqueles que usam luz para comunicação sem fio (GHASSEMLOOY et al., 2013).

\subsection{GRANDEZAS E PARÂMETROS RADIOMÉTRICOS E FOTOMÉTRICOS}

Um sistema de medição radiométrico é baseado em medições de potência (energia por unidade de tempo) com unidades relacionadas ao watt (W). Por outro lado, o sistema de medição fotométrico é baseado na percepção visual, isto é, na curva de sensibilidade do olho humano, e tem como unidade básica de medida o Lúmen ( $\mathrm{lm}$ ), que é baseado na unidade Candela (cd) (VISTNES, 2018). Na Equação 14, V( $\lambda$ ) é a sensibilidade relativa do olho humano, cuja função é ilustrada pela Figura 4 (THORLABS, 2020).

$$
V(\lambda)=1,019 e^{-285,4(\lambda-0,559)^{2}} .
$$


Figura 4 - Curva da sensibilidade espectral relativa do olho humano.

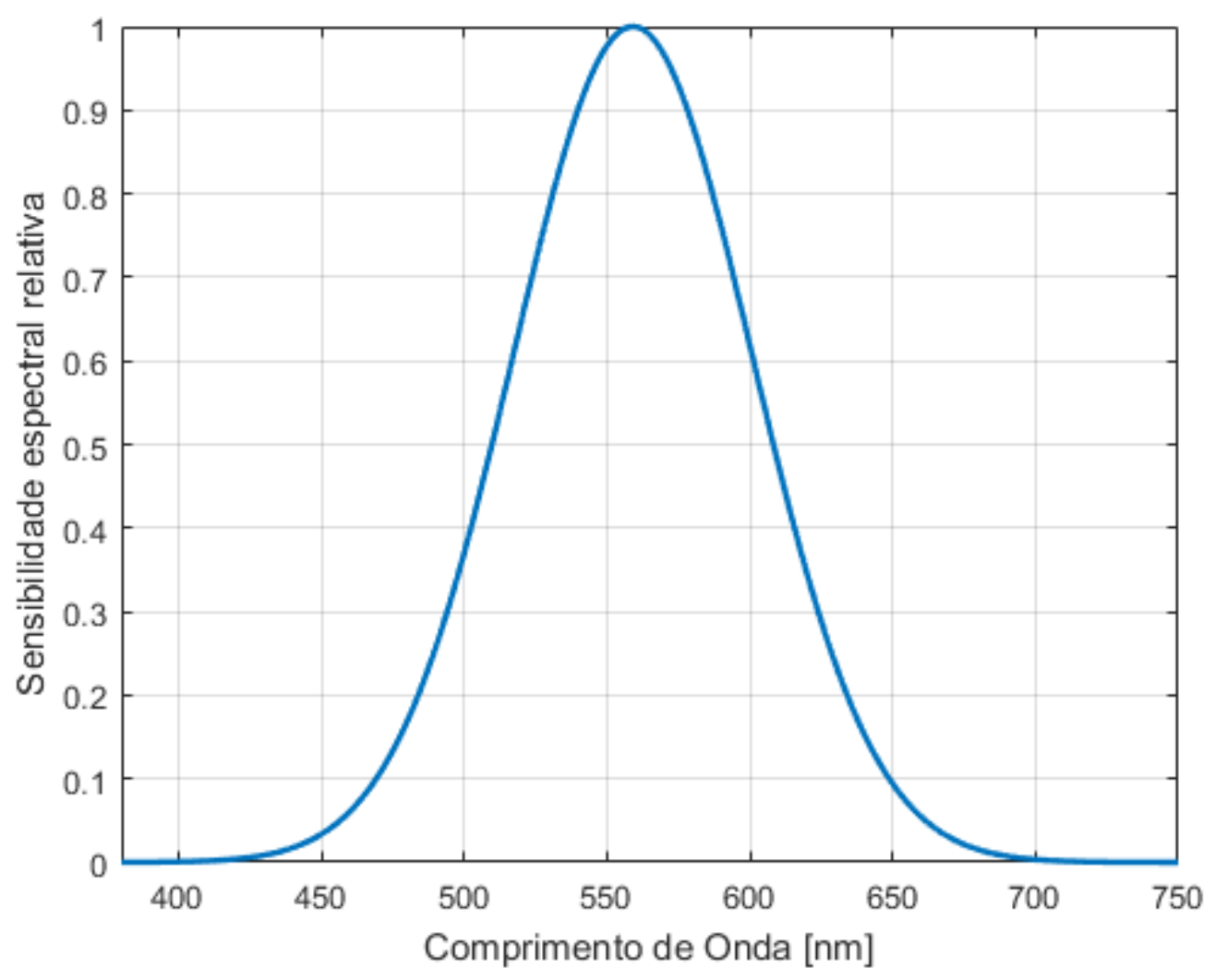

Fonte: Adaptado de Thorlabs (2020).

Devido a necessidade de atendimento dos critérios de iluminação, são definidas as grandezas fotométricas utilizadas, por exemplo, para dimensionamentos e análises de luminotécnica (GUERRINI, 2008). A Equação 15 descreve a luz emitida total ponderada pela sensibilidade relativa do olho humano $\mathrm{V}(\lambda)$ para diferentes comprimentos de onda. $\Phi_{v}$ é a quantidade de energia radiante emitida por unidade de tempo e avaliada de acordo com a sensação luminosa produzida, onde $\Phi e(\lambda)$ é a potência radiada pelo LED em função do comprimento de onda.

A luz monocromática com comprimento de onda de $555 \mathrm{~nm}$ e intensidade radiante 1/683 W/sr, por definição, tem um brilho de 1,0 cd, ou seja, a máxima eficiência luminosa possível é de $683 \mathrm{~lm} / \mathrm{W}$ para a luz monocromática no comprimento de onda de $555 \mathrm{~nm}$ (VISTNES, 2018). O Quadro 2 resume as grandezas radiométricas e fotométricas.

$$
\Phi_{v}=683 \int_{380 \mathrm{~nm}}^{750 \mathrm{~nm}} V(\lambda) \Phi e(\lambda) d \lambda
$$


Quadro 2 - Resumo das grandezas radiométricas e fotométricas.

\begin{tabular}{|c|c|c|}
\hline Grandeza & Radiométrica & Fotométrica \\
\hline Potência & $\boldsymbol{\Phi}_{\mathrm{e}}$ - Fluxo radiante [W] & $\boldsymbol{\Phi}_{\mathrm{v}}-$ Fluxo luminoso $[\mathrm{lm}]$ ou [cd.sr] \\
\hline Potência por unidade de área & $\mathbf{E}_{\mathrm{e}}$ - Irradiância $\left[\mathrm{W} / \mathrm{m}^{2}\right]$ & $\begin{array}{l}\mathbf{E}_{\mathrm{v}} \text { - Iluminância }[\mathrm{x}] \text { ou }\left[\mathrm{cd} . \mathrm{sr} / \mathrm{m}^{2}\right] \text { ou } \\
{\left[\mathrm{lm} / \mathrm{m}^{2}\right]}\end{array}$ \\
\hline $\begin{array}{l}\text { Potência por unidade de ângulo } \\
\text { sólido }\end{array}$ & $\begin{array}{l}\mathbf{I}_{\mathrm{e}}-\text { Intensidade radiante } \\
{[\mathrm{W} / \mathrm{sr}]}\end{array}$ & $\begin{array}{l}\mathbf{I}_{\mathrm{v}} \text { - Intensidade Luminosa }[\mathrm{cd}] \text { ou } \\
{[\mathrm{lm} / \mathrm{sr}]}\end{array}$ \\
\hline $\begin{array}{l}\text { Potência por unidade de área } \\
\text { por unidade de ângulo sólido }\end{array}$ & $\mathbf{L}_{\mathrm{e}}$ - Radiância $\left[\mathrm{W} / \mathrm{m}^{2} . \mathrm{sr}\right]$ & $\mathbf{L}_{\mathrm{v}}$ - Luminância $\left[\mathrm{cd} / \mathrm{m}^{2}\right]$ ou $\left[\mathrm{lm} / \mathrm{m}^{2} \cdot \mathrm{sr}\right]$ \\
\hline
\end{tabular}

Fonte: Adaptado de Thorlabs (2020).

A unidade de ângulo sólido $(\Omega)$, denominada esterradiano, ou esferorradiano (sr), é definida pela razão entre a área da superfície esférica $(A)$ e o raio da esfera $(\mathrm{R})$, conforme descrito pela Equação 16 e ilustrado pela Figura 5 (VISTNES, 2018).

$$
\Omega=\frac{A}{R^{2}}
$$

Figura 5 - Ângulo sólido dado pela relação entre a área iluminada da superfície e o raio da esfera.

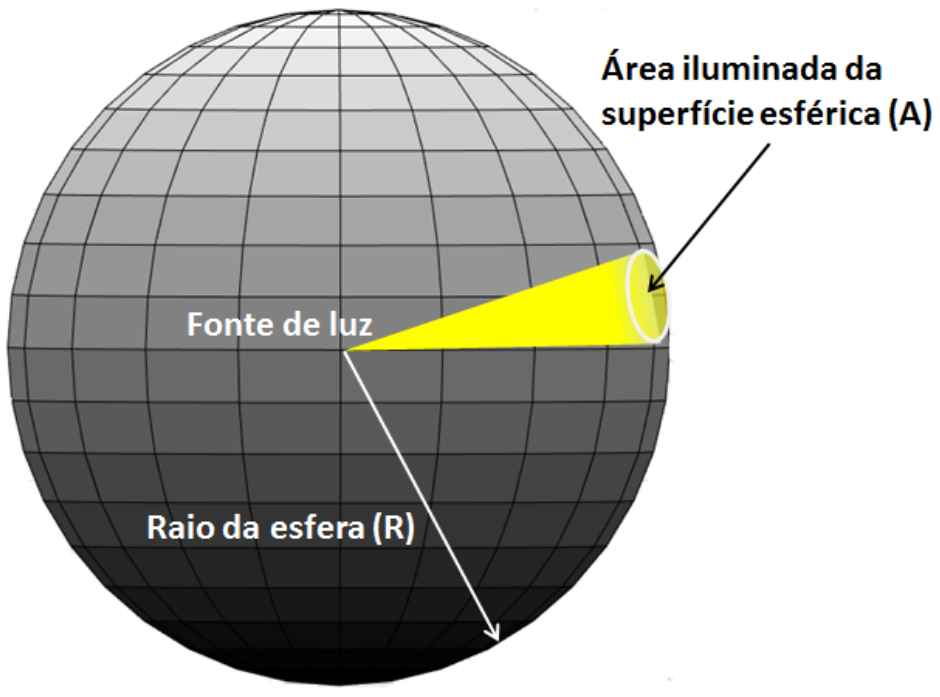

Fonte: Adaptado de Vistnes (2018).

A iluminância de uma determinada superfície pode ser calculada por meio da Lei de Lambert, estabelecendo que esta varia na razão direta da intensidade luminosa $\left(\mathrm{I}_{v}\right)$ e na razão inversa do quadrado da distância (GUERRINI, 2008):

$$
E_{v}=\frac{I_{v} \cos (\alpha)}{d^{2}}
$$


Ainda é possível calcular a iluminância horizontal ponto a ponto a partir de uma altura "l"de uma fonte luminosa, pela expressão (GUERRINI, 2008):

$$
E_{v}=\frac{I_{v} \cos ^{3}(\alpha)}{l^{2}}
$$

A Figura 6 ilustra a relação entre a altura "l"e a distância "d". Verifica-se que, quanto mais inclinado o feixe luminoso estudado, maior será a superfície iluminada e, portanto, menor será a iluminância (GUERRINI, 2008).

Figura 6 - Projeção da densidade de fluxo incidente em uma superfície na qual um foco puntiforme ao angulo solido elementar ilumina um elemento de superfície, em que $\cos (\alpha)=l / d$.

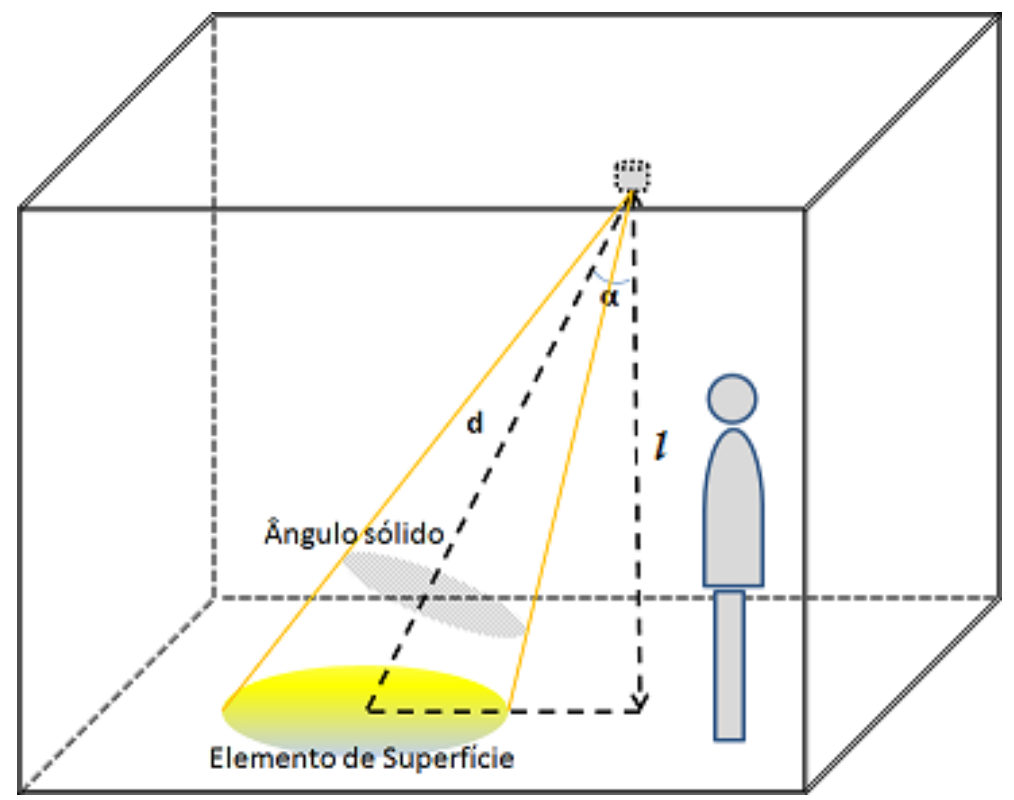

Fonte: Adaptado de Guerrini (2008).

O fluxo de radiação é descrito pela quantidade de energia transferida através de uma superfície ou região do espaço por unidade de tempo. Sempre que a radiação atinge um dispositivo que produz uma corrente eletrônica, tensão, ou outro sinal que é proporcional à magnitude da radiação incidente no dispositivo detector, geralmente é a quantidade total de fluxo sobre o dispositivo inteiro que importa (MCCLUNEY, 2014). Assim, a potência total será dada pela densidade de potência multiplicada pela área de fotodetecção.

\subsection{REQUISITOS PARA ILUMINAÇÃO}

O Instituto Nacional de Metrologia, Qualidade e Tecnologia - Inmetro, define na Portaria ${ }^{\circ}$ 144, de 13 de março de 2015 os requisitos de conformidade para comercialização de Lâmpadas LED com Dispositivo Integrado à Base. Não obstante, as luminárias também devem 
atender às normas que regram a disposição dos pontos de iluminação nos ambientes internos com previsão de parâmetros mínimos de iluminância previstos pela Associação Brasileira de Normas Técnicas (ABNT) na Norma ABNT NBR ISO/CIE 8995-1:2013, iluminação de ambientes de trabalho Parte 1: Interior, pela qual aproximadamente 20 lux de iluminância horizontal é o exigido para diferenciar as características da face humana, sendo este o menor valor considerado para a escala das iluminâncias. A Tabela 1 apresenta parâmetros de iluminância $\left(E_{v}\right)$ a serem considerados para o planejamento de algumas situações.

Tabela 1 - Planejamento de ambientes (áreas), tarefas e atividades com a respectiva especificação da iluminância.

\begin{tabular}{cc}
\hline Tipo de ambiente, tarefa ou atividade & $E_{v}$ (lux) \\
\hline Saguão de entrada & 100 \\
Teatros e salas de concerto & 200 \\
Salas de reunião e conferência (escritório) & 500 \\
Área de leitura (biblioteca) & 500 \\
Salas de desenho técnico & 750 \\
\hline
\end{tabular}

Fonte: ABNT (2013).

Esses valores são considerados para o plano de trabalho, ou seja, em uma sala, por exemplo, a iluminância deve atender à Norma em todo plano horizontal no qual podem ser dispostas mesas e bancadas. Em projetos de iluminação de interiores pode ser utilizado o conceito dos lúmens, que consiste no uso da expressão, que é a própria definição da iluminância:

$$
E_{v}=\frac{\Phi_{v}}{A}
$$

Nela a iluminância (lx) é o resultado da incidência de um determinado fluxo luminoso (lm) sobre uma superfície de área "A". Ocorre, porém, que nem toda luz emitida pelas lâmpadas atinge o plano de trabalho diretamente; parte dela incide sobre as paredes e o teto e é parcialmente absorvida. A luz que incide no plano de trabalho é, em parte, refletida e depois refletida de volta ao plano de trabalho, produzindo uma série infinita de reflexões cruzadas (TREGENZA, 2015).

Também poder ser definido um coeficiente de utilização $(U F)$ em função das características do ambiente. Além disso, a luminária perde sua eficiência com o passar do tempo, emitindo menos luz, e ocorre o acúmulo de sujeira. Para estas perdas é considerado um coeficiente de manutenção $(M C)$.

Para o dimensionamento da quantidade de luminárias $(n)$ a serem utilizadas em um ambiente devem ser considerados ainda os fatores mencionados anteriormente e aplicados à Equação 19, com atendimento ao critério de iluminância da Norma ABNT NBR ISO/CIE 
8995-1:2013. Assim, tem-se:

$$
E_{v}=\frac{n \times \Phi_{v} \times U F \times M C}{A}
$$

$\mathrm{Ou}$,

$$
n=\frac{E_{v} \times A}{\Phi_{v} \times U F \times M C} .
$$

\subsection{FONTES ARTIFICIAIS DE LUZ}

Há uma série de fontes de luz disponíveis. Dentre os parâmetros característicos, tipicamente são utilizados o fluxo luminoso $\left(\Phi_{v}\right)$, a potência elétrica consumida (absorvida) pela fonte, a eficiência luminosa $(\eta)$, a Temperatura de Cor Correlata, do inglês Correlated Color Temperature (CCT) e o Índice de Reprodução de Cor, do inglês Color Rendering Index (CRI).

A eficiência luminosa das fontes de luz pode ser expressa pela relação entre o fluxo luminoso emitido e a potência absorvida pela fonte (GUERRINI, 2008):

$$
\eta=\frac{\text { Fluxo luminoso emitido }}{\text { Potência absorvida pela fonte }} .
$$

A escala de temperatura de cor se relaciona diretamente com o conceito de mudança cromática que ocorre quando um objeto é aquecido (PRäKEL, 2015). Ou seja, CCT é a medida da aparência da cor em uma lâmpada em referência a uma fonte aquecida e medida em Kelvin (K). Normalmente os LEDs brancos frios têm um CCT de $6.000 \mathrm{~K}$, neutro de $4.000 \mathrm{~K}$ e quente de $3.000 \mathrm{~K}$ (KARUNATILAKA et al., 2015).

O IRC de uma fonte luminosa artificial é a medida da cor real de uma superfície e sua aparência a ser iluminada pela fonte artificial. Uma fonte com CRI 100\% é a que apresenta as cores de um objeto com a maxima fidelidade (GUERRINI, 2008).

A Tabela 2 apresenta características típicas de alguns tipos de lâmpadas utilizadas em projetos de iluminação. Para obtenção das características construtivas específicas, devem ser consultados os próprios fabricantes.

As fontes comumente usadas em comunicações ópticas são os LEDs e LDs. Estes últimos não serão objeto de estudos nesse trabalho, com foco em caracterização e simulação de luminária composta por fontes de luz LED. 
Tabela 2 - Fontes artificiais de luz e suas características, valores típicos.

\begin{tabular}{llllll}
\hline Tipo & Potência $(\mathbf{W})$ & $\Phi_{v}(\mathbf{l m})$ & $\eta(\mathbf{l m} / \mathbf{W})$ & CCT $(\mathbf{K})$ & CRI $(\%)$ \\
\hline Incandescente & 40 a 1.500 & 430 a 30.000 & 20 & 2.400 & 100 \\
\hline $\begin{array}{l}\text { Fluorescente co- } \\
\text { mum }\end{array}$ & 15 a 110 & 840 a 8.300 & 60 a 70 & 3.000 a 6.000 & 55 a 85 \\
\hline $\begin{array}{l}\text { Fluorescente com- } \\
\text { pacta }\end{array}$ & 5 a 32 & 250 a 1.650 & 50 a 69 & 2.700 a 4.000 & 85 \\
\hline Vapor de sódio & 70 a 1000 & 5.800 a 130.000 & Até 130 & 3.000 a 6.000 & 20 a 39 \\
\hline LED* & 4,5 a 12 & 480 a 1.311 & 100 a 109 & 3.000 a 6.500 & $>80$ \\
\hline
\end{tabular}

Fonte: Adaptado de Guerrini (2008). *Catálogo Osram - LED SUPERSTAR CLASSIC A.

A absorção de fótons pelo átomo provoca transições de elétrons entre níveis de energia. De modo análogo, a transição de elétrons entre os níveis de energia provoca o efeito da emissão de fótons que transportam energia eletromagnética e momento. Os dispositivos LED e fotodiodos operam a partir deste princípio físico para emissão e detecção de luz, respectivamente. Para determinar a frequência e o comprimento de onda de um fóton emitido ou absorvido deve ser verificada esta diferença entre as bandas de Energia $\left(\mathscr{E}_{1}\right.$ e $\left.\mathscr{E}_{0}\right)$, ou estados de transição dos elétrons, dada por (GHASSEMLOOY et al., 2013):

$$
\mathscr{E}=\mathscr{E}_{1}-\mathscr{E}_{0}=h f=\frac{h c}{\lambda} .
$$

Onde: $\mathscr{E}_{2}$ e $\mathscr{E}_{1}$ - estados de energia [J]

$h$ - constante de Plank $=6,626 \times 10^{-34}[\mathrm{Js}]$

f - frequência $[\mathrm{Hz}]$

c - velocidade da luz $[\mathrm{m} / \mathrm{s}]$

$\lambda$ - Comprimento de onda [m]

Figura 7 - Na absorção a energia é capturada de um feixe de luz para excitar o átomo, enquanto na emissão espontânea, a energia é liberado pelo átomo.

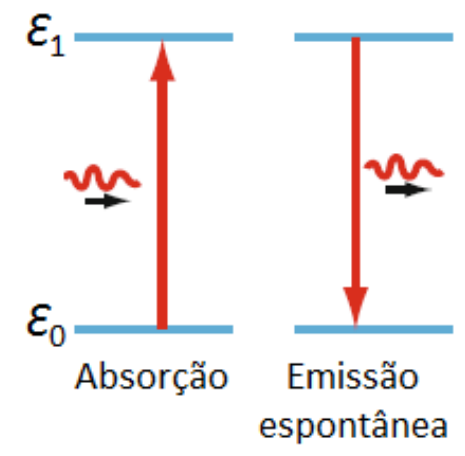

Fonte: Adaptado de Vistnes (2018).

O LED é um dispositivo semicondutor de junção $p-n$ que emite radiação óptica espontânea (fótons) quando sujeito à excitação eletrônica, alcançada aplicando uma tensão de 
polarização direta na junção $p-n$. A radiação dos fótons ocorre aleatoriamente sem correlação de fase entre eles (fonte de luz incoerente). Os fótons emitidos podem estar na porção do ultravioleta, do visível ou do infravermelho do espectro eletromagnético, dependendo da diferença da banda de energia do material semicondutor, conforme apresentado na equação 23 (GHASSEMLOOY et al., 2013).

Figura 8 - Relação entre a potência óptica radiada e a corrente elétrica que passa pela junção p-n.

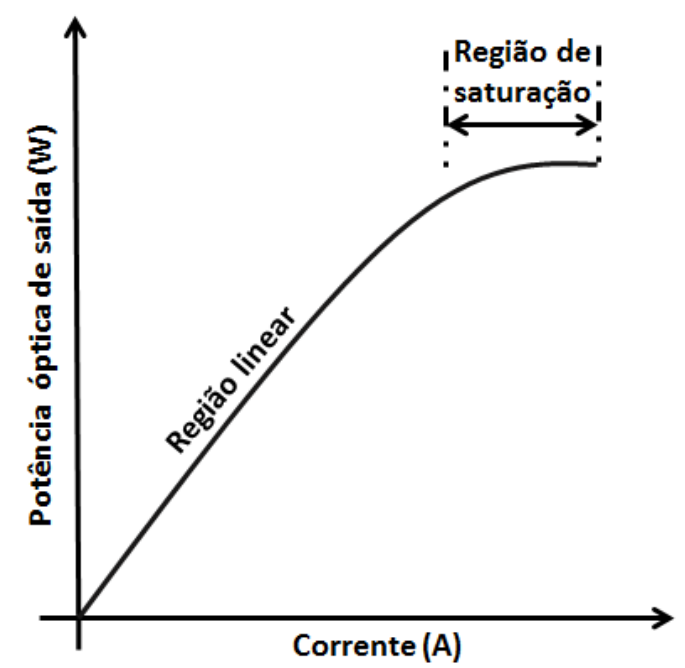

Fonte: Adaptado de Ghassemlooy et al. (2013).

Os LEDs têm duas propriedades básicas, a intensidade luminosa e a intensidade radiante. A intensidade luminosa é usada para expressar seu brilho, já a Intensidade radiante indica a energia total irradiada por um LED e é o parâmetro do ponto de vista da comunicação óptica. O comprimento de onda da luz depende do material utilizado em sua composição que pode ser alumínio, índio, gálio e fósforo ou índio, gálio e nitrogênio, com comprimentos de onda variáveis entre vermelha, amarela, verde e azul. A cor branca é conseguida pela excitação de um fósforo conversor no LED azul, passando da luz amarela para a branca (KOMINE; NAKAGAWA, 2004; GUERRINI, 2008).

Conforme apresentado na Equação 13, um aspecto importante para as comunicações é a largura de banda disponível para modulação da informação a ser transmitida, sendo que a largura de banda de modulação do LED depende de fatores como a corrente injetada e as capacitâncias parasitas e de junção (GHASSEMLOOY et al., 2013). São utilizados dois conceitos principais para gerar luz branca usando LEDs. O primeiro, e mais tradicional, utiliza um chip que emite a luz azul e é recoberto com uma camada de fósforo amarelo. Parte da luz azul emitida é absorvida pelo fósforo e reemitida com um amplo espectro. Esse método é relativamente barato e de fácil 
fabricação, porém alcança bandas limitadas para modulação de aproximadamente $2 \mathrm{MHz}$ devido à lenta resposta temporal do fósforo.

Apesar da largura de banda limitada de modulação dos LEDs revestidos com fósforo, em 2015 foi reportado no estudo de Khalid et al. (2012), a taxa de 1 Gbps (BER de 1,5 $\times 10^{-3}$ ) para um LED branco à base de fósforo, distante $10 \mathrm{~cm}$ do fotodiodo, e utilizando um filtro passa faixa na recepção com resposta no comprimento de onda de $452 \mathrm{~nm}$ (azul) para rejeição das componentes lentas da fosforecência.

O segundo conceito emprega um trio de LEDs RGB, onde a emissão dos três LEDs coloridos é misturada para gerar luz branca, permitindo, inclusive, o uso de Multiplexação por Divisão de Comprimento de Onda. Nesse método são utilizados três LEDs separados que aumentam o custo da luminária em comparação ao uso de LEDs brancos à base de fósforo (PATHAK PARTH H. ; FENG, 2015; KHALID et al., 2012).

Guo et al. (2019) apresentaram em seu trabalho os progressos entre os anos de 2012 e 2018 em sistemas VLC e os respectivos dispositivos LD ou LED utilizados para transmissão. Nele, os três trabalhos de referências que utilizaram LEDs brancos à base de fósforo alcançaram taxas dados entre 2 Gbps e 4 Gbps e os que aplicaram LEDs RGB alcançaram taxas de dados entre 3,22 Gbps e 10,72 Gbps , porém todas as distâncias analisadas eram menores ou iguais a 1 m.

A maioria das fontes LED possui distribuição de feixe Lambertiano, que define o seu padrão de radiação. O campo, ou Ângulo de Visão, do inglês Field Of View (FOV) de um LED é definido como o ângulo entre os pontos no padrão de radiação, onde a diretividade é reduzida para 50\% (DIMITROV; HAAS, 2015). A distribuição espacial da intensidade luminosa é uma função cosseno, apresentada pela Equação 26, na qual $\mathrm{g}_{t}$ é a distribuição da intensidade luminosa espacial normalizada e $m$ é a ordem da emissão lambertiana que depende do ângulo de meia potência do $\operatorname{LED}\left(\phi_{1 / 2}\right)$, onde a intensidade da luz diminui para metade da intensidade axial (FOV) (PATHAK PARTH H. ; FENG, 2015).

$$
\begin{gathered}
m=-\frac{\ln (2)}{\ln \left(\cos \left(\phi_{1 / 2}\right)\right)}, \\
g_{t}(\alpha)=\cos ^{m}(\alpha), \\
I_{0}(\alpha)=I_{0} \cos ^{m}(\alpha) .
\end{gathered}
$$


A Figura 9 mostra um diagrama de radiação polar típico para o emissor Lambertiano, pela qual pode ser observado o ângulo de meia potência $(50 \%)$ em $60^{\circ}$. Neste caso, no ponto em que $\phi_{1 / 2}=\alpha$, tem-se $\mathrm{m}=1, \mathrm{~g}_{t}(\alpha)=0,5$ e $\mathrm{I}_{0}\left(60^{\circ}\right)=\mathrm{I}_{0} / 2$, ou seja, a intensidade luminosa cai para a metade do valor da intensidade axial. Nela também são apresentadas dois padrões lambertianos com ordens $\mathrm{m}=2 \mathrm{e} \mathrm{m}=11$ e seus respectivos $\phi_{1 / 2}$ de $45^{\circ}$ e $20^{\circ}$.

Figura 9 - Características lambertianas normalizadas. De acordo com a ordem do lambertiano são observadas diferentes FOVs.

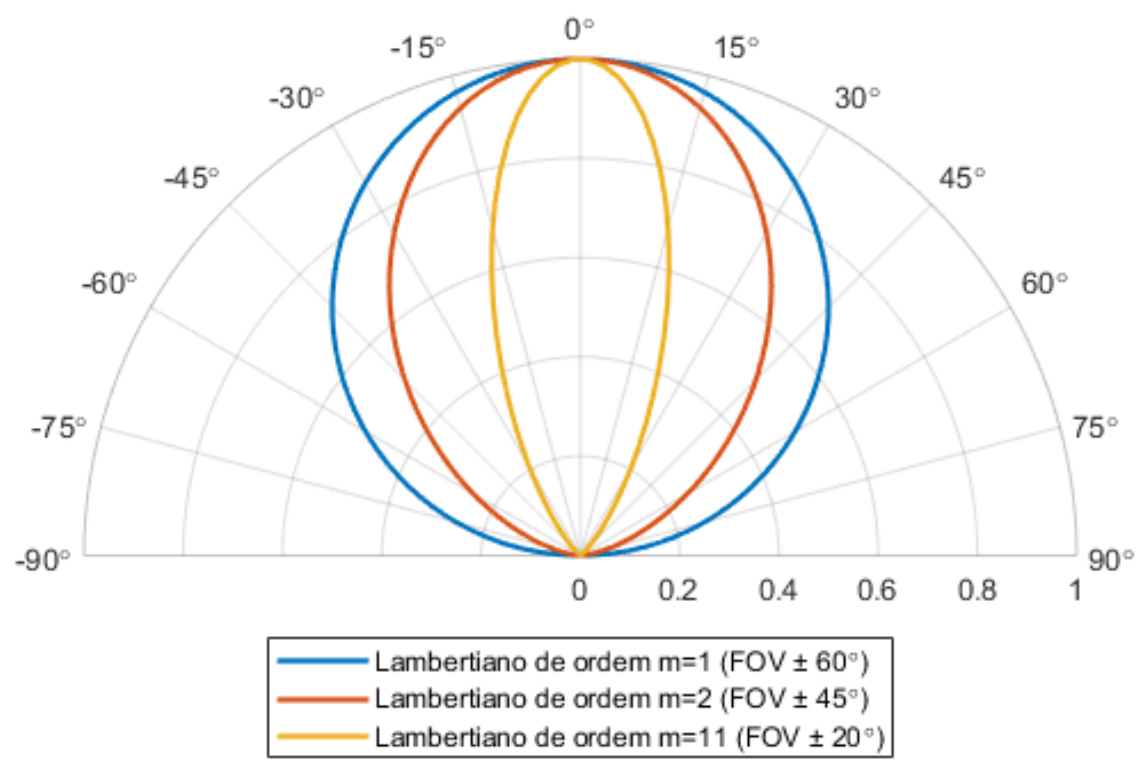

Fonte: Adaptado de Dimitrov e Haas (2015).

Com base nessas informações também é possível calcular o fluxo luminoso do LED $\left(\Phi_{v}\right)$, conforme equação 27 , na qual $\mathrm{I}_{0}$ é a intensidade luminosa axial (cd) e o ângulo $\alpha_{\text {máx }}$ é limitado a $90^{\circ}$ (PATHAK PARTH H. ; FENG, 2015).

$$
\Phi_{v}=I_{0} \int_{0}^{\alpha_{m a ́ x}} 2 \pi g_{t}(\alpha) \operatorname{sen}(\alpha) d \alpha
$$

Em consulta ao datasheet do LED Lumileds, modelo LXML-PW31 pode-se verificar algumas de suas características. A Figura 10 apresenta a Distribuição Espectral de Potência, do inglês Power Spectral Distribution (PSD) do dispositivo. O fluxo luminoso típico para o LED LXML-PW31 é de 105 lm. 
Figura 10 - Distribuição espectral do LED Lumileds, modelo LXML-PW31.

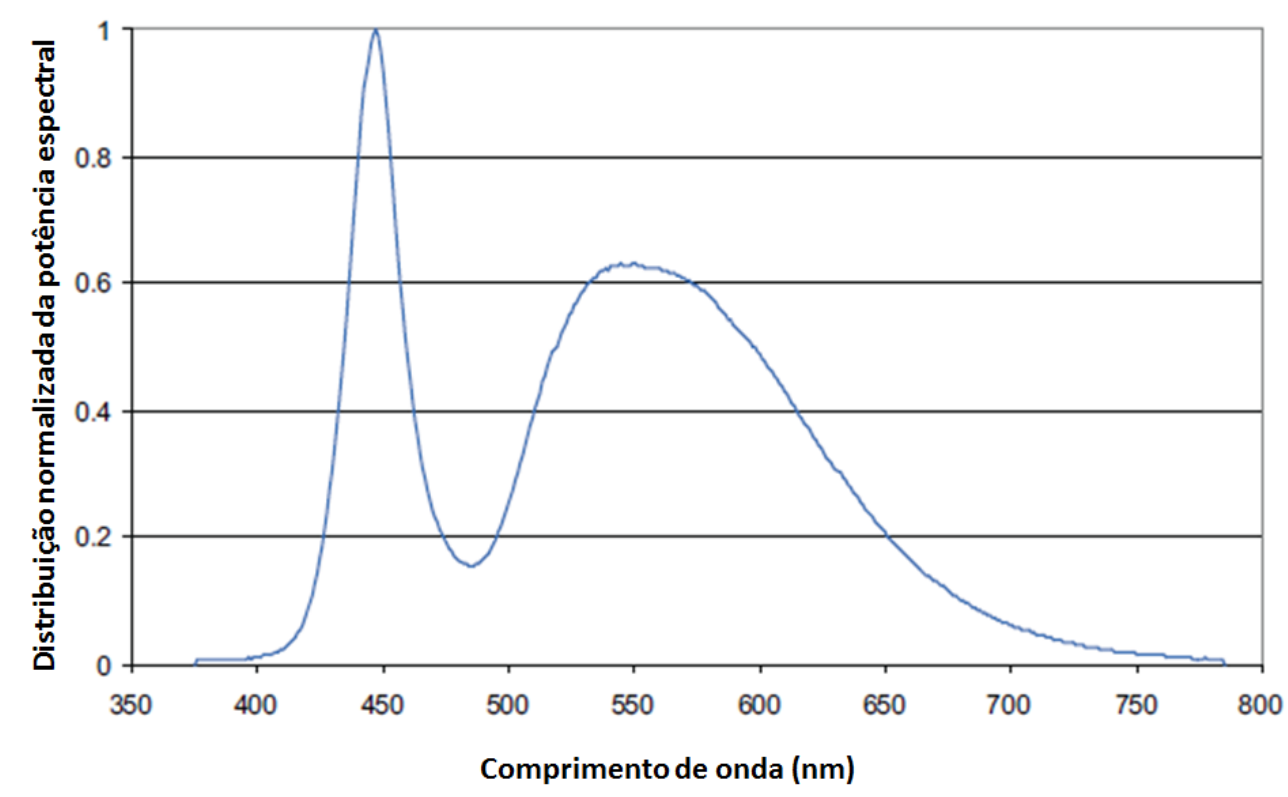

Fonte: Philips Lumileds Lighting Company (2009).

\subsection{FOTODETECTORES}

No lado da recepção o sinal é detectado por meio de um Fotodiodo P-Intrínseco-N (PIN) ou Fotodiodo de Avalanche, do inglês Avalanche Photodiode (APD), que responda na faixa do espectro de luz visível. De modo análogo ao LED, o fotodiodo possui um FOV pelo qual é possível ajustar parâmetros da geometria do enlace de comunicacão e da incidência de sinais interferentes, como a luz ambiente. A Figura 11 ilustra um enlace no qual são representadas as parcelas de raios emitidos por um LED que incidem direta e indiretamente em um dispositivo fotodiodo.

Nos fotodiodos o sinal óptico é convertido em corrente elétrica. Semelhante ao LED, o FOV de um fotodiodo é definido como o ângulo entre os pontos do padrão de detecção, no qual a diretividade é reduzida para 50\% e a resposta espectral do receptor é determinada pela resposta espectral do fotodiodo e de filtros ópticos que venham a ser utilizados. Esta resposta espectral é representada, por exemplo, pelo fator de conversão da potência óptica em corrente elétrica em determinada faixa do espectro óptico, também chamado de responsividade $(\gamma)$.

Tipicamente, os valores máximos de responsividade varia de 0,6 a 0,8 [A/W] para os fotodiodos PIN e de 77 a 130 [A/W] para os APD . Os dispositivos fotodiodos respondem em uma faixa espectral mais ampla que as alcançadas pelos LEDs (GHASSEMLOOY et al., 2013). A Tabela 3 apresenta valores e características típicas para fotodiodos PIN e APD de silício (Si) e 
Figura 11 - Propagação em um enlace de comunicação sem fio. Além do sinal recebido em visada direta, também são recebidas parcelas do sinal sem linha de visada. Os ângulos $\alpha$ e $\beta$ denotam os ângulos de irradiação e incidência, respectivamente.

LED

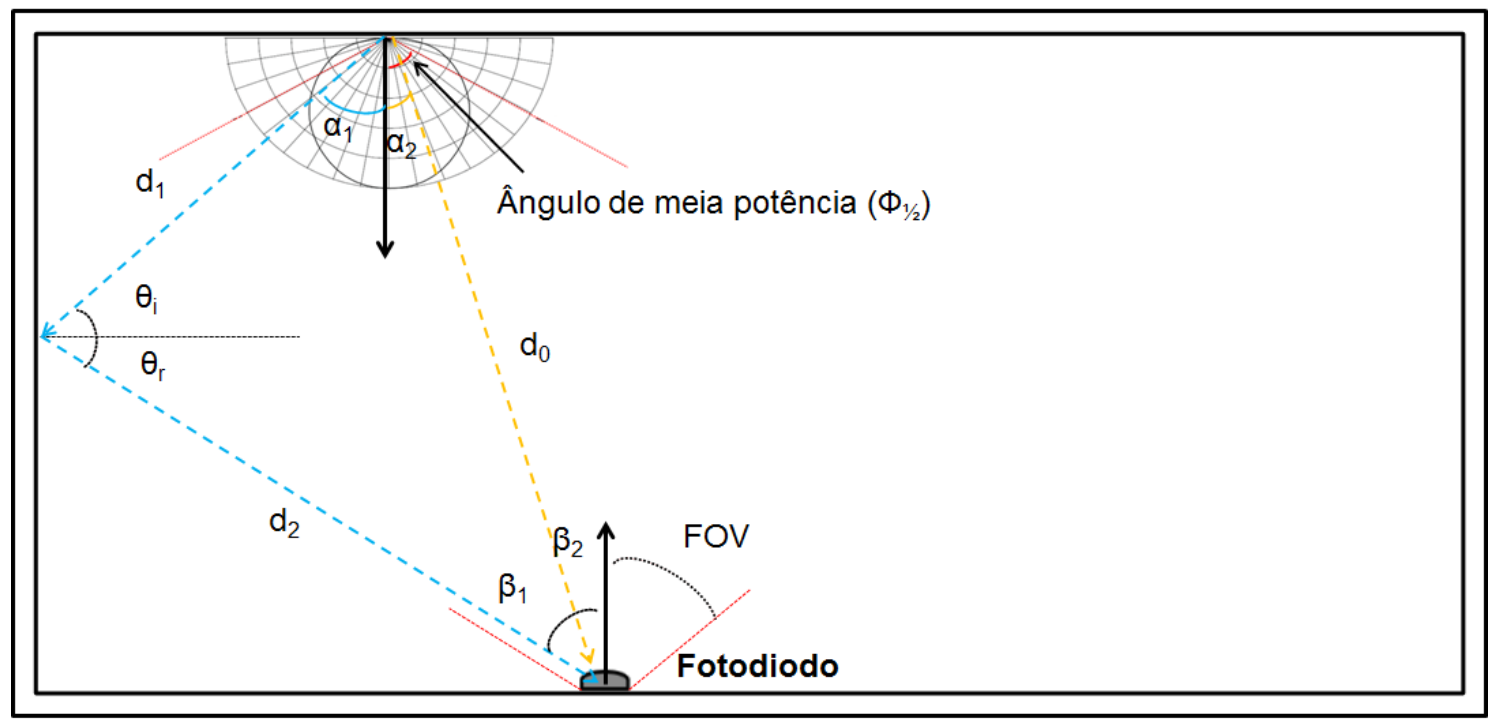

Ponto de referência $(x, y, z)$

Fonte: Adaptado de Pathak Parth H. ; Feng (2015), Komine e Nakagawa (2004).

germânio (Ge). Os dispositivos de arseneto de índio e gálio (InGaAs) foram deixados de fora na tabela por responderem entre 900 e $1700 \mathrm{~nm}$, fora da faixa de interesse desse trabalho (espectro visível). Observa-se, também, que o pico de resposta dos fotodiodos de Si encontra-se na faixa do infravermelho, $900 \mathrm{~nm}$ (PIN) e $830 \mathrm{~nm}$ (APD).

Tabela 3 - Performances típicas e características dos fotodiodos.

\begin{tabular}{ccccc}
\hline Parâmetro & PIN (Si) & APD (Si) & PIN (Ge) & APD (Ge) \\
\hline Faixa de operação (nm) & $400-1000$ & $400-1000$ & $800-1800$ & $800-1800$ \\
$900-1700$ & & & & \\
Pico (nm) & 900 & 830 & 1550 & 1300 \\
Responsividade (A/W) & 0,6 & $77-130$ & $0,65-0,7$ & $3-28$ \\
Fotocorrente de escuro (nA) & $1-10$ & 0,1 a 1,0 & $50-500$ & $10-500$ \\
Capacitância (pF) & 1,2 a 3 & 1,3 a 2 & $2-5$ & $2-5$ \\
\hline
\end{tabular}

Fonte: Adaptado de (GHASSEMLOOY et al., 2013). 


\section{6 ÓPTICA GEOMÉTRICA E TRAÇADO DE RAIOS}

A propagação da luz pode ser analisada pelo método do traçado de raios em determinadas condições. Em um meio, eles se propagam a uma velocidade $v$, dada por $v=c / n$, onde $n$ é o índice de refração que caracteriza o meio em análise. Caso o meio seja homogêneo, o índice de refração será o mesmo em todos os pontos. Essa uniformidade do meio garante que o caminho percorrido pelo raio se dará em linha reta. Segundo o princípio de Fermat, trata-se do caminho de menor tempo entre dois pontos (SALEH; TEICH, 2007).

A análise do traçado de raios tem como base os estudos de óptica geométrica. Com eles há a possibilidade de se observar a trajetória de um ou mais raios de luz, ou sinais luminosos, que iluminam determinado ponto no espaço. Desse modo, deseja-se a formação de enlaces em LOS, mas, como pode ser observado pela Figura 12, há outras possibilidades de formação de enlaces Sem Linha de Visada, do inglês Non-line-of-sight (NLOS), devido às reflexões da luz em objetos presentes no meio de comunicação.

Figura 12 - Configurações de enlaces LOS e NLOS em comunicações ópticas sem fio.

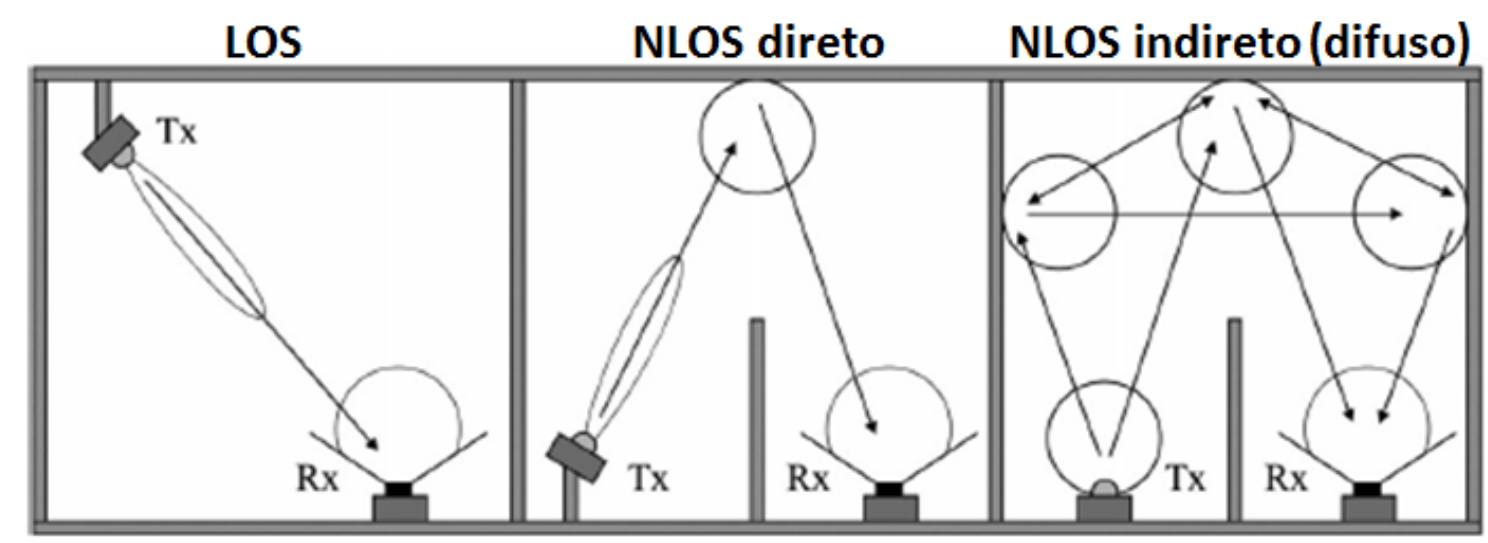

Fonte: Adaptado de Ghassemlooy et al. (2013).

Considerando dois elementos de superfícies com áreas $d A_{1}$ (emissor) e $d A_{2}$ (detector), tem-se a seguinte relação para transferência de energia, ou seja, quanto de energia radiada por $d A_{1}$ é capturada por $d A_{2}$ (BREAULT, 2016).

A transferência de energia entre as superfícies é dada pela Equação 28, de modo que, o fluxo total de um emissor de área $A_{1}$ para um receptor de área $A_{2}$, depende da distância entre eles e dos ângulos entre as superfícies. A potência total na superfície receptora é a soma de toda a energia que pode ser vista em todos os pontos do receptor a partir dos pontos do emissor. Assim, o traçado de raios pode ser considerado como a solução numérica para a integral, em que $\mathrm{L}_{e}$ é a 
Figura 13 - Transferência de energia radiante. As superfícies separadas por uma distância "d"e com ângulos em relação à normal (n) definidos por $\theta_{1} \mathbf{e} \theta_{2}$.

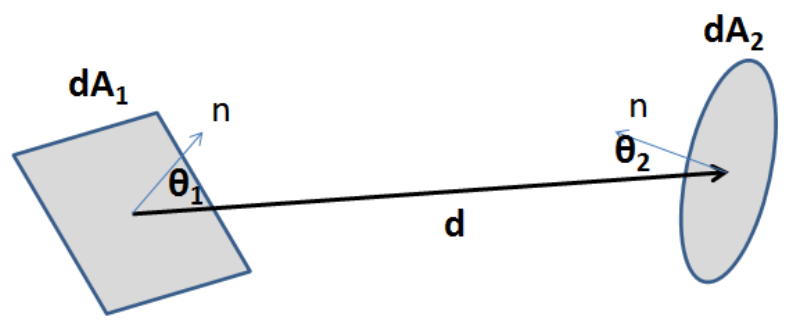

Fonte: Adaptado de Breault (2016).

radiância dada em $\mathrm{W} / \mathrm{m}^{2}$.sr (BREAULT, 2016):

$$
\Phi=\int_{A_{1}} \int_{A_{2}} \frac{L_{e}}{d^{2}} d A_{1} \cos \left(\theta_{1}\right) d A_{2} \cos \left(\theta_{2}\right) .
$$

Existem vários estudos sobre o canal óptico sem fio em diferentes condições espaciais e configurações ópticas, com base em medições diretas ou simulações de traçados de raios (DIMITROV; HAAS, 2015).

Quando um raio atinge uma superfície refletora, a potência é reduzida de acordo com o coeficiente de reflexão, transformando esta superfície em uma fonte de luz de potência igual à potência do raio atenuado (DIMITROV; HAAS, 2015).

Os mecanismos utilizados pelos softwares ópticos geralmente se enquadram em uma dessas três categorias: traçado de raios seqüenciais; traçado de raios não sequenciais; e diferenças finitas no domínio do tempo (STEVENSON, 2006). O Quadro 3 apresenta uma seleção de programas que se enquadram nessas categorias.

Segundo Stevenson (2006), o método de traçado de raios seqüenciais é realizado sequencialmente, interceptando elementos ópticos um de cada vez e em uma ordem predefinida. É frequentemente usado para projetar e otimizar sistemas de lentes aplicados, por exemplo, em câmeras, microscópios e telescópios.

O traçado de raios não sequenciais permite que os raios atinjam as superfícies em qualquer ordem e inúmeras vezes, dividindo-os automaticamente. Esse método é usado para modelar sistemas ópticos complexos em que as características de dispersão e difusão da luz devem ser conhecidas e controladas. Os exemplos de aplicação incluem o estudo de dutos de luz e luminárias. (STEVENSON, 2006). 
Quadro 3 - Seleção de softwares ópticos, por categoria.

\begin{tabular}{|c|c|c|}
\hline Categoria & Programa & Empresa \\
\hline \multirow{4}{*}{$\begin{array}{l}\text { Traçado de raios } \\
\text { sequenciais }\end{array}$} & Code $\mathrm{V}^{\circledR}$ & Optical Research Associates \\
\hline & Optalix $^{\circledR}$ & Optenso \\
\hline & $\mathrm{OSLO}^{\circledR}$ & Lambda Research Corporation \\
\hline & $\mathrm{ZEMAX}^{\circledR}$ & ZEMAX Development Corporation \\
\hline \multirow{7}{*}{$\begin{array}{l}\text { Traçado de raios não } \\
\text { sequenciais }\end{array}$} & $\mathrm{ASAP}^{\circledR}$ & Breault Research Organization \\
\hline & $\mathrm{APEX}^{\circledR *}$ & Breault Research Organization \\
\hline & FRED $^{\mathrm{TM}}$ & Photon Engineering \\
\hline & LightTools ${ }^{\circledR}$ & Optical Research Associates \\
\hline & SPEOS $^{\mathrm{TM}}$ & OPTIS \\
\hline & TracePro ${ }^{\circledR}$ & Lambda Research Corporation \\
\hline & $\mathrm{ZEMAX}^{\circledR}$ & ZEMAX Development Corporation \\
\hline \multirow{5}{*}{$\begin{array}{l}\text { Diferenças finitas no } \\
\text { domínio do tempo }\end{array}$} & FDTD Solutions $^{\mathrm{TM}}$ & Lumerical Solutions \\
\hline & FullWAVE $^{\mathrm{TM}}$ & RSoftDesign Group \\
\hline & JCMsuite $^{\mathrm{TM}}$ & JCMwave \\
\hline & Omnisim $^{\mathrm{TM}}$ & Photon Design \\
\hline & OptiFDTD $^{\mathrm{TM}}$ & Optiwave Systems \\
\hline
\end{tabular}

Fonte: Adaptado de Stevenson (2006). *Breault (2020).

O método das diferenças finitas no domínio do tempo resolve equações de Maxwell para propagar campos eletromagnéticos em estruturas com escalas micrométricas e nanométricas. Alguns exemplos de uso desses códigos são o design e análise de dispositivos ópticos integrados e microcavidades ópticas (STEVENSON, 2006).

A exatidão das simulações dependem do quão precisos são os modelos geométricos e as propriedades ópticas aplicadas (STEVENSON, 2006). Segundo Dimitrov e Haas (2015), uma representação precisa da distribuição da luz em uma instalação interna pode ser obtida por meio da simulação de Traçado de Raios Monte Carlo, do inglês Monte Carlo Ray-Tracing (MCRT), ou por meio de algoritmos determinísticos.

No algoritmo determinístico, a característica de radiação do LED é discretizada em uma quantidade de raios com potência "P"e os raios são traçados seqüencialmente, por caminhos aleatórios, dentro da geometria. No algoritmo MCRT, uma quantidade de raios $\mathrm{N}_{r}$, com potência $\mathrm{P} / \mathrm{N}_{r}$, são gerados aleatoriamente de acordo com uma distribuição seguindo a característica de radiação do LED Dimitrov e Haas (2015). 
As simulações de Monte Carlo são usadas nos casos em que, devido à complexidade do sistema, não é possível se obter uma solução analítica. Essa abordagem baseia-se na probabilidade na qual a ocorrência de um evento pode ser determinada pela observação do número de vezes em que o evento ocorre, em um grande número de tentativas. Assim, a probabilidade de um evento ocorrer é a probabilidade de o raio atingir ou não ao plano do detector. O número de vezes que o evento ocorre é o número de raios que chegam ao plano do detector, e o grande número de tentativas é o número total de raios utilizados na simulação (BRO, 2007). De um modo geral, o algoritmo MCRT atinge uma determinada precisão estocástica, com um esforço computacional significativamente menor (DIMITROV; HAAS, 2015).

Dessa forma, o método de traçado de raios pode ser aplicado na análise do fluxo de energia em um sistema de iluminação, interagindo com as características geométricas do cenário e as propriedades ópticas dos materiais, bem como das fontes de luz aplicadas, objetivando o estudo de enlaces em comunicações ópticas sem fio para predição de coberturas dessas comunicações.

\subsection{CANAL ÓPTICO SEM FIO}

A análise dos sinais de luz a serem transmitidos pelo meio óptico necessita de uma caracterização da resposta ao impulso de seu canal, que é usada para analisar e combater os efeitos das distorções do canal (GHASSEMLOOY et al., 2013). O meio de comunicação a ser analisado é o ar e o uso da luz nas comunicações vêm sendo objeto de estudos que passam pelo modelamento do canal para a propagação de sinais ópticos no espaço livre (KARP S. ; O'NEILL, 1970). O modelo de canal pode ser descrito pelo modelo contínuo no tempo para um enlace de comunicação ruidoso:

$$
Y(t)=\gamma X(t) \star h(t)+N(t)
$$

onde $Y(t)$ representa a réplica distorcida do sinal transmitido $X(t)$ e $\gamma$ é a responsividade do detector. O sinal é convolucionado com a resposta ao impulso do canal, $h(t)$, e distorcido pelo ruído AWGN, $N(t)$, no receptor (GHASSEMLOOY et al., 2013).

O ganho DC do canal para comunicação VLC é apresentado por Tanaka et al. (2000), Chowdhury H. (2017), Komine e Nakagawa (2004), como:

$$
H(0)=\frac{(m+1) A}{2 \pi d^{2}} \cos ^{m}(\alpha) T_{s}(\beta) g(\beta) \cos (\beta)
$$


Onde A representa a área física sensível do fotodetector, d é a distância entre o transmissor e o receptor, $\alpha$ é o ângulo de irradiância, $\beta$ o ângulo de incidência, $\mathrm{T}_{s}(\beta)$ é o ganho do filtro óptico localizado na recepção e $\mathrm{g}(\beta)$ o ganho da lente (concentrador óptico) na recepção que pode ter a ordem de 2,41 vezes $(3,82 \mathrm{~dB})$, conforme considerado no trabalho de Tanaka et al. (2000).

Ao atingir determinada superfície a luz pode sofrer absorção, reflexão ou transmissão. A consideração desses parâmetros faz-se necessária, pois isso afetará a caracterização do canal de comunicação com, por exemplo, a ocorrência de propagação da luz por múltiplos percursos. Os fatores de absorção, reflexão e transmissão são obtidos pela relação entre o fluxo luminoso incidente em uma superfície e o percentual desse fluxo que é absorvido, refletido e transmitido, como ilustra a Figura 14. Assim, tem-se que:

$$
\Phi_{\text {incidente }}=\Phi_{\text {refletido }}+\Phi_{\text {absorvido }}+\Phi_{\text {transmitido }}+\Phi_{\text {espalhado }}
$$

Dessa forma podem ser definidos os parâmetros de absorção $(a)$, reflexão ou refletância (r) e transmissão $(t)$, como:

$$
a+r+t=1 .
$$

Figura 14 - Absorção, reflexão e transmissão de um fluxo luminoso ao incidir em uma determinada superfície. No detalhe é representada a reflexão dos raios em uma superfície lambertiana.

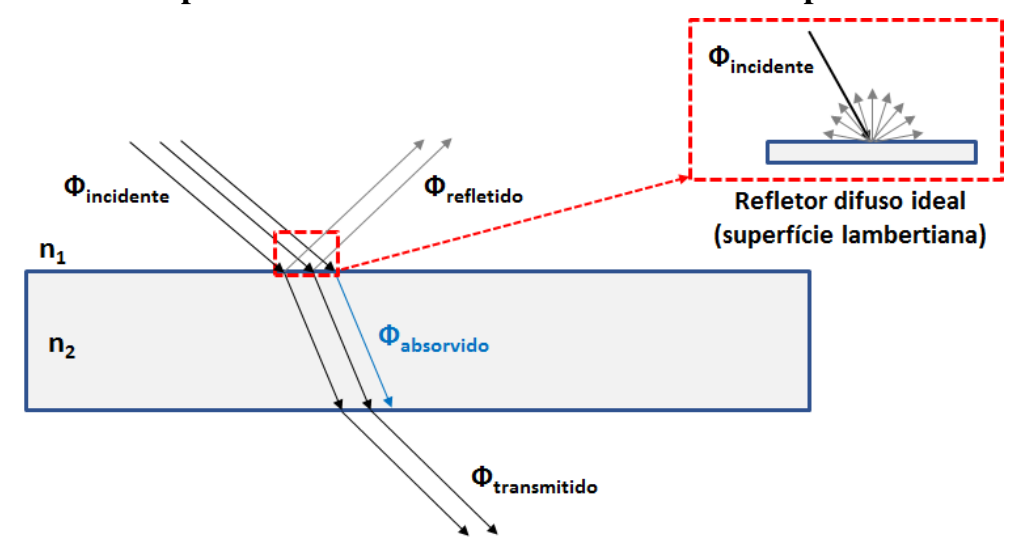

Fonte: Autoria própria.

As características de reflexão das superfícies dos objetos em uma sala dependem de vários fatores, incluindo o comprimento de onda do sinal incidente, o material da superfície, o ângulo de incidência e a rugosidade da superfície em relação ao comprimento de onda (GHASSEMLOOY et al., 2013). Em superfícies perfeitamente planas, com reflexão especular, o ângulo 
de reflexão é igual ao de incidência. Em superfícies rugosas, se ocorre reflexão perfeitamente difusa, é chamada lambertiana ideal.

Essas características variam de acordo com o comprimento da onda (frequência) incidente, ou seja, para uma determinada superfície haverá diferentes refletâncias em função dos diferentes comprimentos de onda na faixa do espectro da luz vísivel que nela incidem. No trabalho sobre caracterização de canal para comunicações indoor Lee et al. (2011) apresentam a curva de distribuição espectral de potência em função do comprimento de onda $\Phi(\lambda)$, medida a partir de uma fonte de luz LED, e as respectivas refletâncias medidas por meio de espectrofotômetro, para alguns materiais típicos (Figura 15). Foi obtida uma variação de reflectância entre 0,1 e 0,8 gerada pelas combinações de cores, padrões de textura e características físicas das superfícies (LEE et al., 2011).

Figura 15 - A PSD de um LED (linha sólida, que corresponde ao eixo esquerdo) é comparada à refletância espectral medida (que corresponde ao eixo direito) das paredes de gesso e de plástico (linhas tracejadas e pontilhadas), piso (linha tracejada) e teto (linha pontilhada).

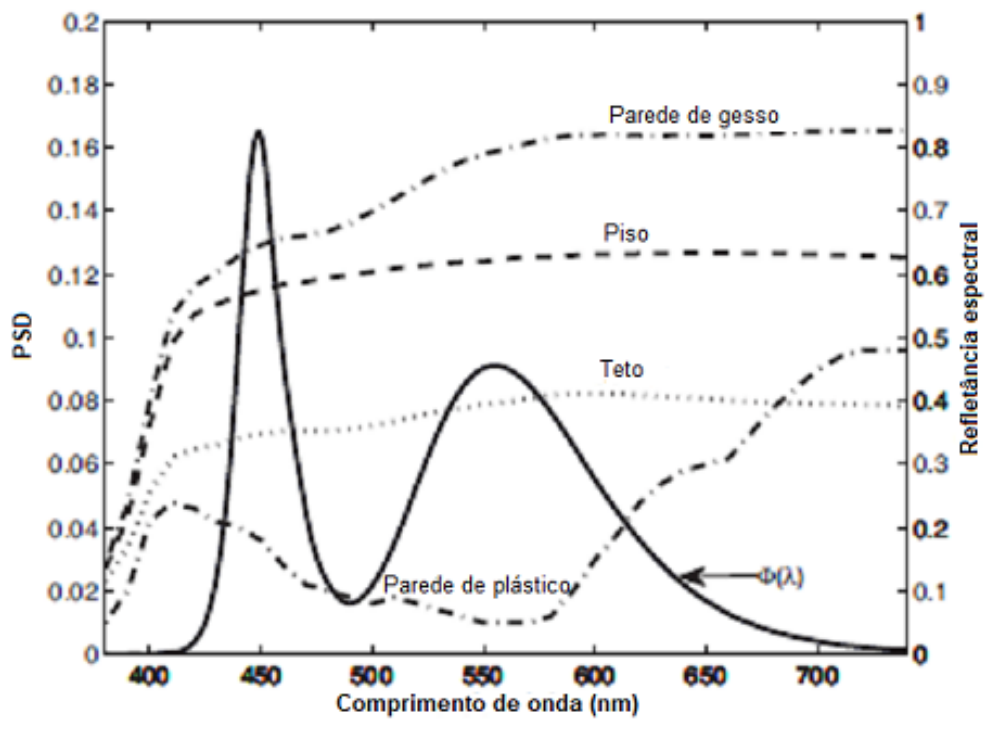

Fonte: Adaptado de Lee et al. (2011).

\subsubsection{Absorção}

Para aplicações externas em visada direta, o principal desafio são as condições atmosféricas que limitam o alcance e a disponibilidade do link, como, por exemplo, a absorção. A absorção ocorre ao longo do caminho de propagação devido à interação entre a onda propagante e moléculas presentes na atmosfera, de modo que o coeficiente de absorção depende do tipo de molécula de gás e de sua concentração, bem como do comprimento de onda utilizado, surgindo 
janelas de menor absorção na propagação atmosférica (GHASSEMLOOY et al., 2013), conforme ilustrado pela Figura 16

Figura 16 - Percentual de absorção do espectro eletromagnético pela atmosfera em função do comprimento de onda.

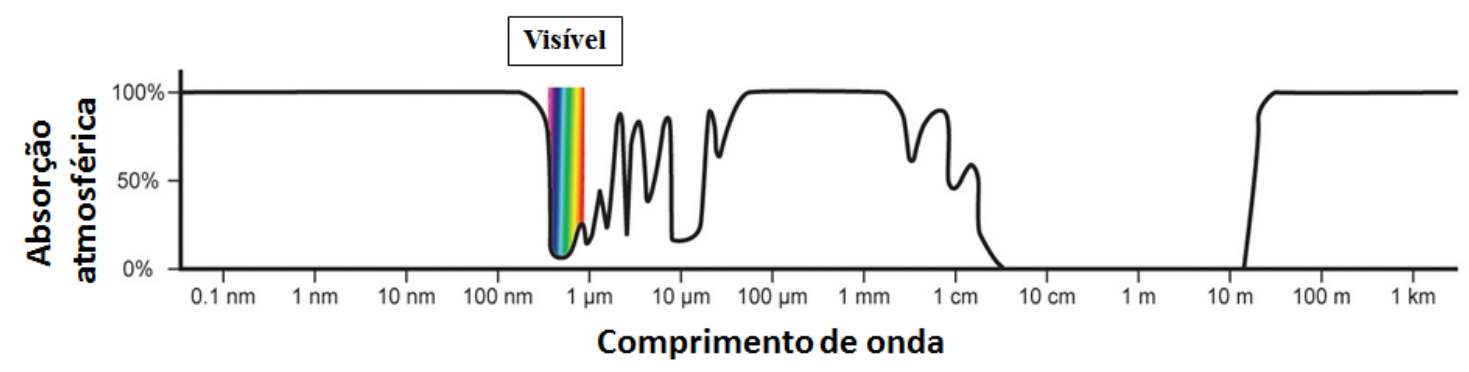

Fonte: Adaptado de NASA (2007).

Existem modelos para caracterizar a natureza estatística do canal atmosférico, porém estes não serão discutidos neste trabalho com foco em estudos indoor. O comprimento do link para OWC em ambientes internos é relativamente curto, portanto a atenuação devido a absorção é muito baixa (GHASSEMLOOY et al., 2013).

\subsubsection{Dispersão}

Na dispersão temporal o sinal pode sofrer uma dispersão severa devido aos múltiplos caminhos pelos quais os pulsos são transmitidos, pois percorrem rotas com comprimentos diferentes, induzindo a ocorrência de Interferência Intersimbólica, do inglês Intersymbol interference (ISI) e, consequentemente, degradando a BER e limitando assim a taxa de bits máxima (DIMITROV; HAAS, 2015). Em altas taxas de dados, onde a largura de banda do sinal excede a largura de banda da coerência do canal, este pode ser caracterizado como um canal seletivo em frequência devido à dispersão (GHASSEMLOOY et al., 2013).

\subsection{RELAÇÃO SINAL-RUÍDO}

Como pode ser verificado na Equação 13, a relação entre a potência do sinal recebido e o ruído presente no meio são fundamentais para se obter parâmetros de dimensionamento da capacidade de comunicação do canal. Enlaces de comunicação estão sujeitos a ruídos de interferências e a SNR pode expressar a qualidade da comunicação. Segundo Komine e Nakagawa (2004), para o cálculo da SNR são consideradas três fontes de ruído: térmico, balístico e a interferência intersimbólica. A variância total $N$, que é a soma das contribuição dos ruídos, é 
descrita pela Equação 33 (KOMINE; NAKAGAWA, 2004).

$$
N=\sigma_{\text {térmico }}^{2}+\sigma_{\text {balistico }}^{2}+\gamma^{2} P_{r I S I}^{2} .
$$

As parcelas referentes aos ruídos térmico e balístico são caracterizadas pelas equações 34 e 35 (KOMINE; NAKAGAWA, 2004).

$$
\begin{gathered}
\text { sigma }_{\text {térmico }}^{2}=\frac{8 \pi k T_{k}}{G} \eta_{c} A I_{2} B^{2}+\frac{16 \pi^{2} k T_{k} \Gamma}{g_{m}} \eta_{c}^{2} A^{2} I_{3} B^{3}, \\
\text { sigma }_{\text {balístico }}^{2}=2 q \gamma\left(P_{r \text { Sinal }}+P_{r I S I}\right) B+2 q I_{b g} I_{2} B .
\end{gathered}
$$

Onde:

$\mathrm{k}$ - constante de Boltzmann $=1,38064852 \times 10^{-23}\left[\mathrm{~m}^{2} \mathrm{kgs}^{-2} \mathrm{~K}^{-1}\right]$;

$\mathrm{T}_{k}$ - temperatura absoluta $[\mathrm{K}]$;

G - ganho de tensão em malha aberta;

$\eta_{c}$ - capacitância fixa do fotodiodo por unidade de área $\left[\mathrm{F} / \mathrm{cm}^{2}\right]$;

A - superfície de fotodetecção do fotodiodo $\left[\mathrm{cm}^{2}\right]$;

$\mathrm{I}_{2}$ - fator de ruído de banda para pulso retangular;

B - largura de banda [Hz];

$\Gamma$ - fator de ruído do canal FET;

$\mathrm{g}_{m}$ - transcondutância do FET [S];

$\mathrm{I}_{3}$ - fator de ruído de banda para pulso cosseno levantado equalizado;

q - carga do elétron $=1,60217662 \times 10^{-19}[\mathrm{C}]$;

$\gamma$ - responsividade do fotodetector $[\mathrm{A} / \mathrm{W}]$;

$\mathrm{P}_{r \text { Sinal }}$ - potência do sinal recebido [W];

$\mathrm{P}_{r I S I}$ - potência recebida referente à interferência intersimbólica [W]; e

$\mathrm{I}_{b g}$ - fotocorrente devido à luz ambiente [A].

Para cálculo da SNR são considerados os fatores de ruído apresentados pela Equação 33 e a potência óptica recebida e convertida em fotocorrente pelo dispositivo fotodetector $\left(\gamma^{2} P_{r}^{2}\right)$.

$$
S N R=\frac{\gamma^{2} P_{r}^{2}}{N}
$$




\subsection{MODULAÇÃO}

Sistemas de comunicação por meio da luz visível podem ser realizados pela implementação de um sistema de Modulação de Intensidade com Detecção Direta, do inglês Intensity Modulation with Direct Detection (IM/DD). Trata-se da maneira mais simples de modulação, na qual é variada a corrente de alimentação de uma fonte de luz LED por meio de um sinal modulante, de valor real e unipolar (não negativo), de modo que a informação é codificada no envelope do sinal transmitido e não há informações de fase (DIMITROV; HAAS, 2015).

Técnicas como Modulação por Largura de Pulso, do inglês Pulse Width Modulation (PWM), Modulação por Posição de Pulso, do inglês Pulse Position Modulation (PPM), OOK e PAM podem ser aplicadas de uma maneira relativamente direta. No entanto, à medida que as velocidades de modulação são aumentadas, esses esquemas de modulação específicos começam a sofrer os efeitos indesejados da ISI devido à seletividade em frequência do canal óptico sem fio. Portanto, uma técnica mais resiliente como a OFDM pode ser requerida (DIMITROV; HAAS, 2015).

Na modulação OOK-NRZ a luz é transmitida para codificar o bit "1"e nenhuma luz é transmitida para codificar bit "0". Assumindo uma forma de pulso retangular cuja duração é igual ao período de bits, a BER é dada por (KOMINE; NAKAGAWA, 2004):

$$
B E R=Q(\sqrt{S N R})
$$

Em sistemas OFDM a performance da BER por subportadora (índice "SC") moduladas em Modulacão de Amplitude em Quadratura Multinível, do inglês MultiLevel - Quadrature Amplitude Modulation (M-QAM), pode ser calculada pela equação 38, na qual "k"indica a subportadora analisada (NARMANLIOGLU et al., 2017).

$$
B E R_{S C}[k] \approx \frac{(\sqrt{M}-1)}{\sqrt{M} \log _{2} \sqrt{M}} \operatorname{erfc}\left[\sqrt{\frac{3 S N R[k]}{(2(M-1))}}\right] .
$$

A SNR obtida em um dado enlace de comunicação VLC é utilizada nas estimativas de BER para, por exemplo, os esquemas de modulação OOK e M-QAM acima descritos. Assim, o próximo capítulo trata dos materiais e métodos aplicados na obtenção da potência recebida por um elemento sensor. 


\section{MATERIAL E MÉTODOS}

Com o objetivo de verificar as condições de propagação e a distribuição espacial dos feixes de luz, propõe-se o uso o método de traçado de raios, pelo qual será construído cenário indoor (ambiente confinado). Para construção e realização das simulações de traçados de raios da luminária foram utilizados os seguintes materiais:

- Computador: processador Intel ${ }^{\circledR}$ Core(TM) i7-4790 CPU @ 3,60GHz, 4 núcleos, 8 processadores lógicos. RAM instalada: 16,0 GB.

- software SolidWorks ${ }^{\circledR} 2016$ x64 Edition SP 2.0

- software $\mathrm{APEX}^{\circledR} 2016$ V5.2.

Por meio de ensaios de laboratório serão caracterizados parâmetros ópticos da luminária. O levantamento das características operacionais da luminária foi realizado no Laboratório Avançado de Telecomunicações (LATE), da UTFPR, Câmpus Curitiba. Nesses ensaios foram utilizados os seguintes materiais:

- Mesa óptica

- Fonte ajustável modelo PS-5000 de duas saídas de 0 - 30 V / 0 - 3 A, da Icel.

- Sensor de potência ThorLabs ${ }^{\circledR}$ contendo: fotodiodo modelo S121C, interface de medida de energia e potência com conexão USB, modelo PM100USB e software de aquisição Optical Power Monitor.

- Espectrômetro de banda modelo CCS200 da Thorlabs ${ }^{\circledR}$.

- Luxímetro modelo Flex com sensor X-08 da Criffer.

Os resultados obtidos pelos raios traçados no ambiente de simulação são analisados em simulações no aplicativo MATLAB ${ }^{\circledR}$, por meio de levantamento do link budget para verificação da capacidade de comunicação do sistema. Nessa proposta é estimada a variação das taxas de erro de bit associadas à modulação OOK e M-QAM.

Para análise da iluminação sobre a área de trabalho foi utilizada a função de medida em isolux disponível no APEX $^{\circledR}$, pela qual o APEX converte automaticamente as unidades do sistema métrico para o cálculo da iluminância (lux $\left.=1 \mathrm{~m} / \mathrm{m}^{2}\right)$. 
A partir de uma peça de referência também utilizada no laboratório de comunicações da UTFPR-Câmpus Curitiba, foi desenhado no Solidworks ${ }^{\circledR}$ um conjunto óptico, base refletora e elementos concentradores, com características e medidas similares. Essa luminária compõe os cenários de simulação de desempenho, ou seja, tendo como referência o modelo de luminária comercial, bem como sua disposição no cenário considerado para análise, foi elaborado um estudo sobre quais as características desejáveis ou necessárias para estabelecer a condição de iluminação conforme a norma vigente e de comunicação baseada na BER mínima à partir de uma dada SNR.

A peça de referência é composta por uma base circular que acomoda sete elementos de luz LED dispostos conforme ilustrado pela Figura 17. Sobreposta à base é encaixada uma outra peça fabricada em material polimérico, marca Khatod Optoelectronic, modelo PL 121140, composta por elementos concentradores. Assim, o conjunto montado tem o objetivo de direcionar o feixe luminoso.

Figura 17 - Luminária com base circular contendo sete elementos LED. A imagem da esqueda mostra a disposição dos LEDs na base, enquanto a imagem da direita apresenta a luminária montada com o elemento concentrador encaixado sobre os LEDs dispostos na base.
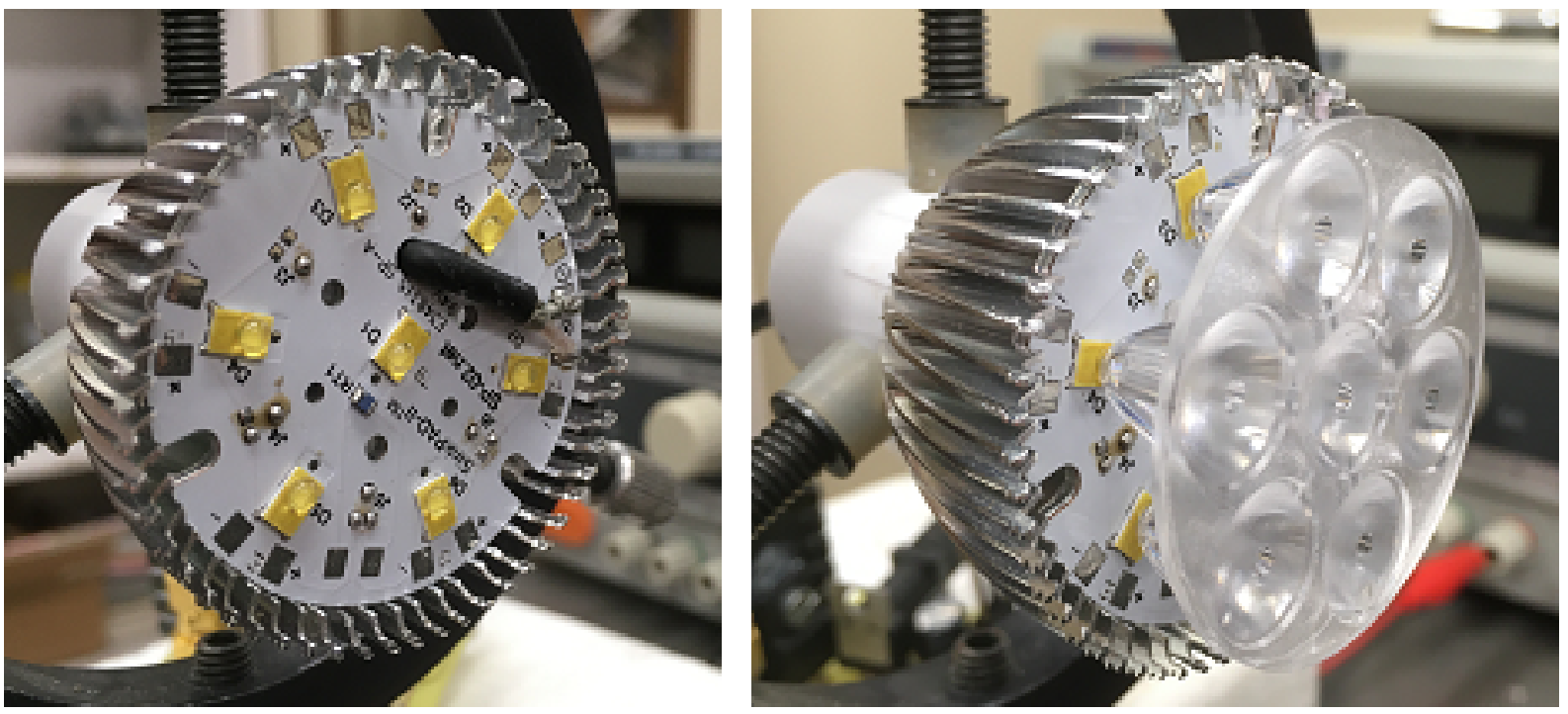

Fonte: Autoria própria. 


\subsection{SIMULAÇÕES NO APEX}

O APEX ${ }^{\circledR}$ combina os recursos de análise óptica em complemento ao ambiente de modelagem 3D do software SOLIDWORKS ${ }^{\circledR}$. Baseado no núcleo (kernel) do software ASAP ${ }^{\circledR}$, desenvolvido pelo fabricante Breault Research Organization, o APEX $^{\circledR}$ lida com a criação de geometria óptica especializada, definindo e atribuindo propriedades ópticas, e análise óptica via traçado de raios não sequenciais (BREAULT, 2016), conforme fluxo de trabalho ilustrado pela Figura 18.

O ASAP ${ }^{\circledR}$ é uma ferramenta de modelagem de sistema óptico, capaz de simular por técnicas MCRT. A precisão da simulação depende de quão bem um número finito de raios aleatórios representa a situação real que está se tentando modelar e essa é a essência do MCRT (BRO, 2006).

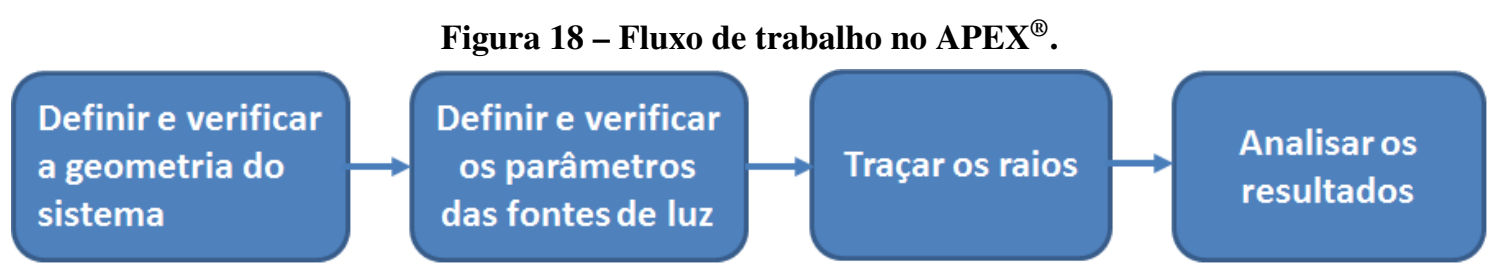

Fonte: Adaptado de Breault (2016).

Uma maneira de se realizar o cálculo da luz difusa é a simulação computacional direta do modo como a luz se propaga através de um sistema óptico. Essa simulação direta, ou simulação de força-bruta, consiste em se construir um modelo computacional de um sistema óptico e traçar muitos raios pelo sistema até que alguns deles cheguem ao detector (PETERSON, 1999).

O meio de propagação padrão (utilizado nas simulações) é o ar os resultados são apresentados em $\mathrm{W} / \mathrm{mm}^{2}$, ou, para uma superfície pré-determinada obtém-se os resultados devido ao fluxo radiométrico total incidente na superfície e dado diretamente em watts. As análises de irradiância são realizadas nos subconjuntos de geometria e raio selecionados. Os resultados desses cálculos são exibidos em forma gráfica pelo $\mathrm{APEX}^{\circledR}$.

Objetivando-se a realização de análises de desempenho de comunicação, baseadas na capacidade de conversão de potência óptica em fotocorrente por meio de um fotodetector, os resultados obtidos foram parametrizados pela densidade de potência óptica, ou irradiância, dada pela razão da potência radiada incidente em uma determinada superfície $\left(\mathrm{W} / \mathrm{m}^{2}\right)$, apresentada pela Equação 28, que é solucionada numericamente pelo $\mathrm{APEX}^{\circledR}$. 


\subsubsection{Reprodução da Luminária no Solidworks ${ }^{\circledR}$}

Todo o conjunto óptico apresentado na Figura 17 foi reproduzido no Solidworks ${ }^{\circledR}$ tendo como base as medidas do projeto do modelo PL 121140. Ao concentrador translúcido foram aplicados materiais poliméricos disponíveis na biblioteca do aplicativo. À base sobre a qual são acomodadas as fontes de luz LED foi atribuída a característica de refletor perfeito.

A sequência de montagem da luminária tem início pela necessidade de construção de sete peças nas quais as fontes de luz LED LXML-PW31 são encaixadas em uma peça para acoplamento do feixe luminoso (Figura 19). Estas peças recebem um outro elemento superior para agregação do conjunto óptico. A todos estes elementos foram aplicados o material policarbonado (PLCARB) ou poli(metacrilato de metila (PMMA) . Por fim, o conjunto é disposto sobre a base circular, conforme ilustra a Figura 20.

Figura 19 - Elemento de acoplamento do LED ao conjunto óptico que compõe a luminária. No detalhe é apresentada a vista lateral da peça.

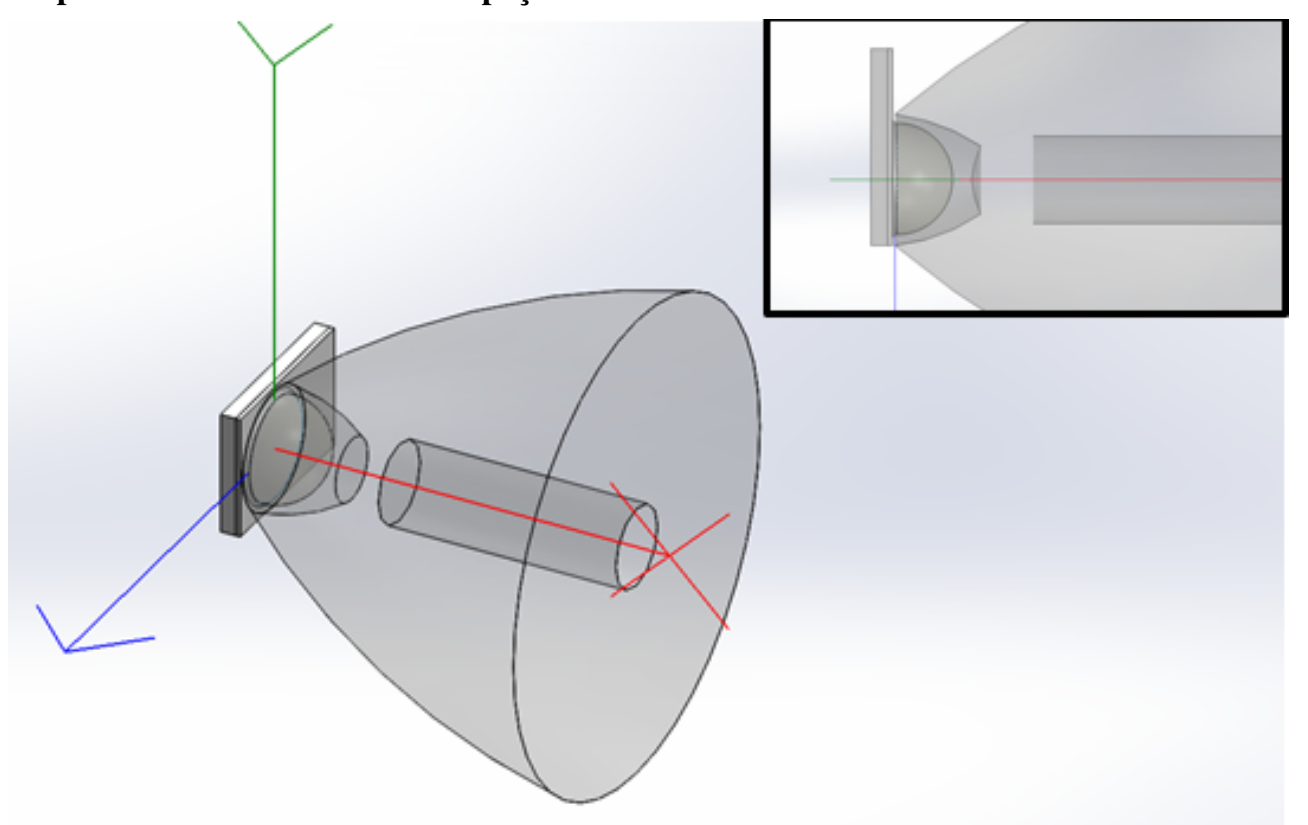

Fonte: Autoria própria. 
Figura 20 - Luminária reproduzida no Solidworks ${ }^{\circledR}$ e utilizada nas simulações no APEX $^{\circledR}$. Na imagem da esquerda podem ser observados os LEDs encaixados no elemento concentrador. Na imagem da direita o conjunto acomodado sobre a base.
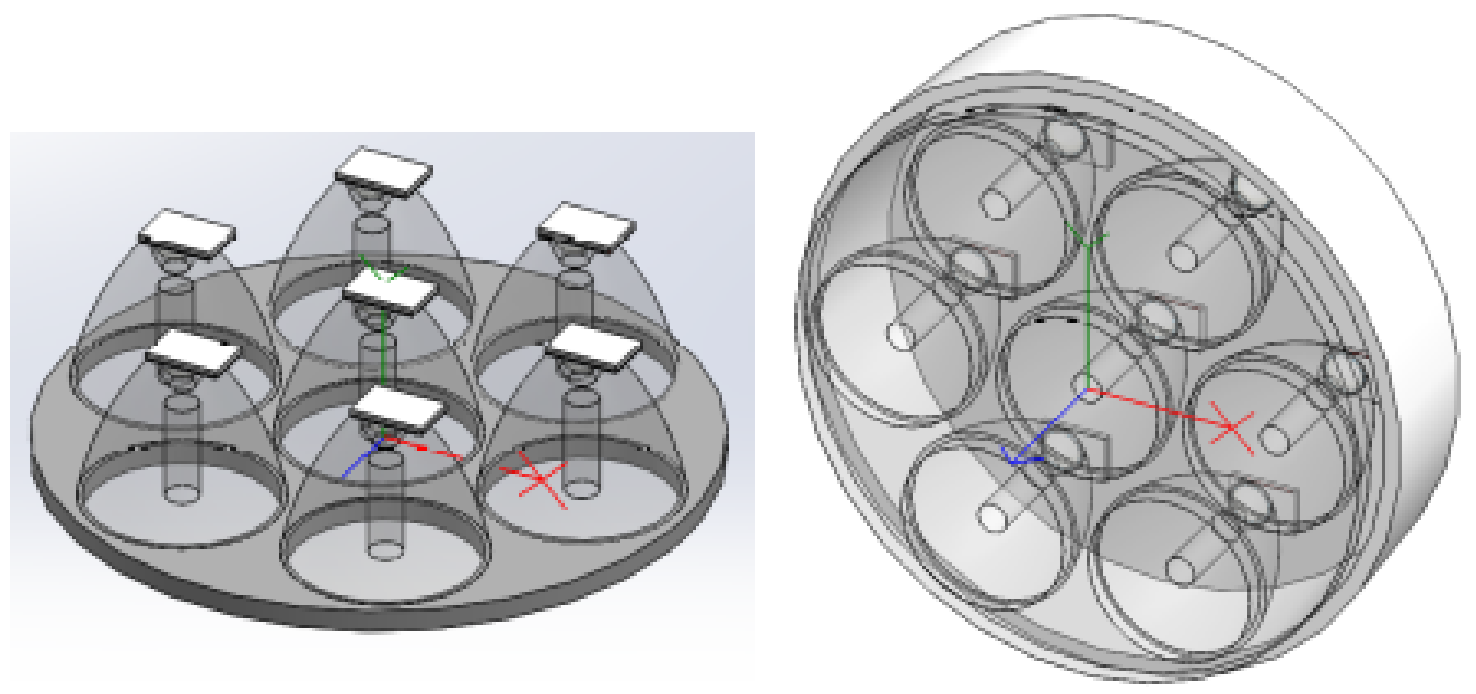

Fonte: Autoria própria.

\subsubsection{Fonte de Luz LED utilizada}

Para as simulações no APEX ${ }^{\circledR}$ foi selecionada a fonte de luz LED modelo LXML-PW31 da empresa Lumileds, por estar disponível na biblioteca do aplicativo e ser um modelo com características similares às do LED modelo LX18-P150, também da Lumileds, utilizado em montagens práticas no laboratório de comunicações da UTFPR-Câmpus Curitiba. Na Figura 17 é observada a presença das sete fontes de luz LED modelo LX18-P150 dispostos na base da luminária utilizada como referência para as simulações.

Tabela 4 - Características dos LEDs Lumileds (corrente de teste em $350 \mathrm{~mA}$ ).

\begin{tabular}{cccc}
\hline LED & CCT & IRC & Fluxo luminoso típico $(\mathrm{lm})$ \\
\hline LXML-PW31 & $5000 \mathrm{~K}$ & 65 & 105 \\
LX18-P150 & $5000 \mathrm{~K}$ & 80 & 106 \\
\hline
\end{tabular}

Fonte: Autoria própria.

Os fluxos luminosos típicos para os LEDs utilizados são apresentados na Tabela 4. Segundo o datasheet do LED modelo LXML-PW31, o fluxo luminoso típico de $105 \mathrm{~lm}$ é obtido ao ser aplicada tensão direta de 3,0 V e corrente de teste de $350 \mathrm{~mA}$, ou seja, este LED possui eficiência luminosa típica de 100 lm/W. Já para o LED LX18-P150 (utilizado nos experimentos) o fluxo luminoso típico é de $106 \mathrm{~lm}$, ao ser aplicada tensão direta de 2,8 V e corrente de teste de $350 \mathrm{~mA}$, apresentando, assim, uma eficiência luminosa de 108,16 lm/W.

O LED modelo LXML-PW31 utilizado nas simulações foi configurado para a geração 
de 3 milhões de raios em múltiplos comprimentos de onda. Como pode ser observado na Figura 21, o espectro da fonte de luz é compreendido entre $350 \mathrm{~nm}$ e $800 \mathrm{~nm}$, tendo como maior pico de emissão em aproximadamente $450 \mathrm{~nm}$ (região da cor azul) e o menor pico em aproximadamente $550 \mathrm{~nm}$ (região da cor verde).

Figura 21 - Fonte de luz LED modelo LXML-PW31 disponível na biblioteca do aplicativo APEX ${ }^{\circledR}$

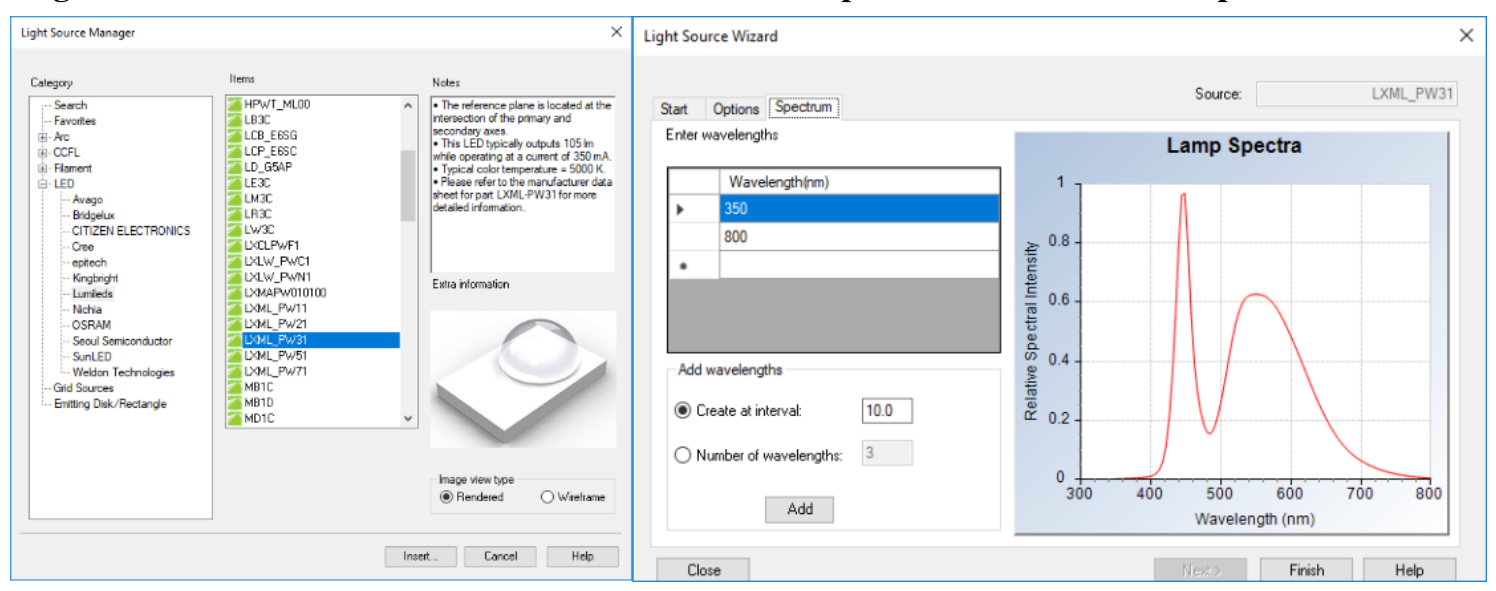

Fonte: Autoria própria.

O fabricante do software orienta o ajuste da potência para fontes policromáticas, de modo a calibrar o fluxo radiante $\Phi_{e}(\mathrm{~W})$ e o respectivo fluxo luminoso $\Phi_{v}(\mathrm{~lm})$. Esta é uma ferramente de análise de fontes de luz disponível no próprio software ("saída radiante") e é executada ao ser selecionada a fonte que se deseja verificar.

Esse processo se inicia com a definição de uma fonte de potência unitária $(1 \mathrm{~W})$ com a ponderação espectral apropriada. Segundo o fabricante, o LED LXML-PW31 possui fluxo luminoso típico de $105 \mathrm{~lm}$. Para o ajuste do fluxo radiante no $\mathrm{APEX}^{\circledR}$, a fonte foi gerada com dez comprimentos de onda no intervalo entre $350 \mathrm{~nm}$ e $800 \mathrm{~nm}$, e ajustado o fluxo radiante total do sistema contendo apenas um LED para $1 \mathrm{~W}$ (valor de referência). Com isso foi obtido um fluxo luminoso total de 282,70 lm, de modo que, para obtenção de um fluxo luminoso de $105 \mathrm{~lm}$, a potência total do sistema deve ser de $371 \mathrm{~mW}$, conforme calculado abaixo:

$$
P=\frac{1 W \times 105 \operatorname{lm}}{282,7 \operatorname{lm}}
$$

O incremento de LEDs nas simulações deve seguir esta premissa, ou seja, sete LEDs LXML-PW31 devem ser calibrados para emissão de um fluxo radiante de 2,6 W (7 x $371 \mathrm{~mW})$. Desse modo, quando os sete LEDs são submetidos ao ajuste de potência irradiada, o resultado foi a obtenção de um fluxo luminoso total de 725,90 lm para os sete LEDs LXML-PW31. 
Figura 22 - Ajuste do fluxo radiométrico do LED modelo LXML-PW31 obtida na simulação do APEX ${ }^{\circledR}$. O perfil circular nas imagens é devido à própria geometria da superfície irradiante do LED.
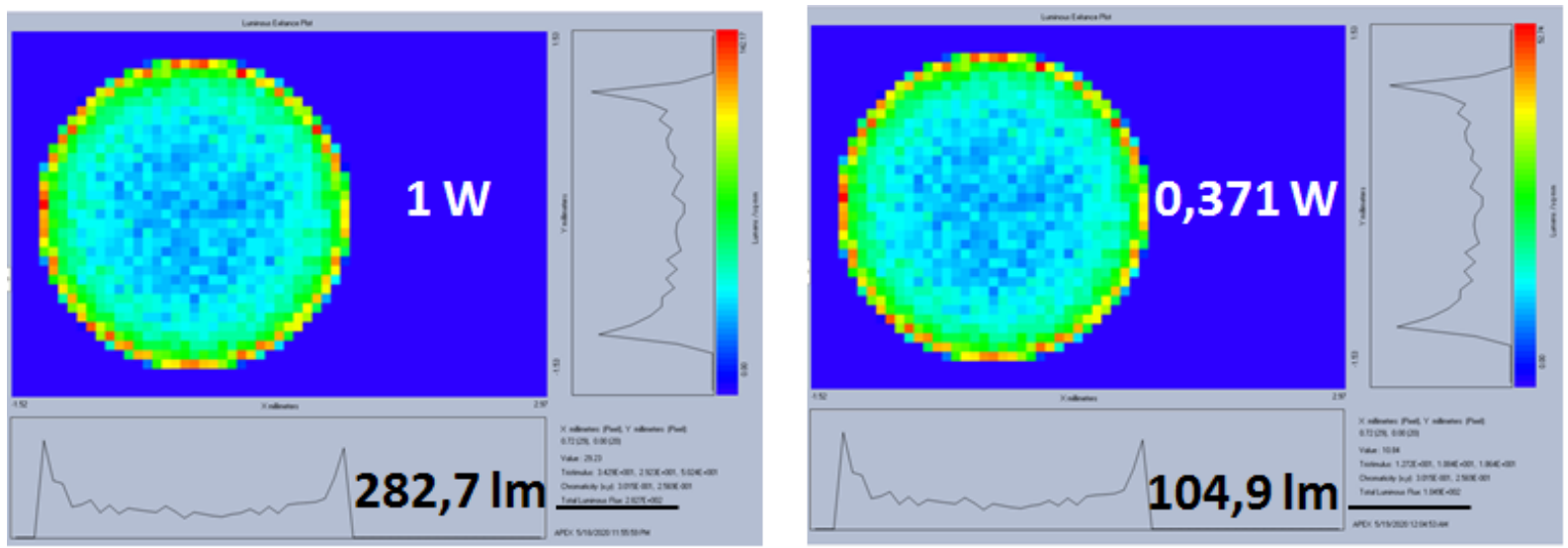

Fonte: Autoria própria.

Ressalva-se, porém, que esta potência radiométrica de 2,6 W não é a potência elétrica consumida pelos LEDs. A potência consumida está relacionada à eficiência luminosa $(1 \mathrm{~m} / \mathrm{W})$.

Nas simulações executados no APEX ${ }^{\circledR}$ verificou-se que os LEDs LXML-PW31 emitem os seguintes fluxos luminosos $\left(\Phi_{v}\right)$ em razão dos ajustes equivalentes de fluxos radionmétricos $\left(\Phi_{e}\right)$ :

- 01 LED: $\Phi_{e}=0,371 \mathrm{~W}$ e $\Phi_{v}=104,9 \mathrm{~lm}$.

- 07 LEDs (01 luminária): $\Phi_{e}=2,6 \mathrm{~W}$ e $\Phi_{v}=725,90 \mathrm{~lm}$.

- 07 LEDs (01 luminária): $\Phi_{e}=736,05 \mathrm{~mW}$ e $\Phi_{v}=205,50 \mathrm{~lm}$ (equivalência com a luminária real consumindo $1,9 \mathrm{~W}$ de potência elétrica).

Para que o LED utilizado nas simulações (LXML-PW31) tenha fluxo luminoso equivalente ao LED LX18-P150, foi efetuado um ajuste da potência proporcional, em função das diferentes eficiências luminosas. Em um dos experimentos a potência elétrica consumida pela luminária foi de 1,9 W e, considerando a eficiência luminosa de 108,16 lm/W dos LEDs LX18P150, obtem-se, teoricamente, 205,50 lm emitidos pelos sete LEDs. Ou seja, são necessários 736,05 $\mathrm{mW}$ de fluxo radiométrico para se ter o equivalente aos 205,50 $\mathrm{lm}$ de fluxo luminoso para o LED LXML-PW31 $(2,6 \mathrm{~W} \times 205,50 \mathrm{~lm} / 725,90 \mathrm{~lm}=736,05 \mathrm{~mW})$.

\subsubsection{Definição da quantidade de raios}

A precisão da simulação é determinada pela quantidade de raios traçados. A orientação contida no $\mathrm{APEX}^{\circledR}$ é para se iniciar as simulações com um pequeno número de raios, para 
verificação do modelo e aumentar esse número para obtenção de análises radiométricas e fotométricas mais precisas (BREAULT, 2016).

Inicialmente foram verificados no aplicativo $\mathrm{APEX}^{\circledR}$ os resultados em função do aumento da quantidade de raios gerados pela fonte de luz. Para isso um LED modelo LXML-PW31 foi selecionado e posicionado à frente de um anteparo medindo $1 \mathrm{~cm}^{2}$ (Figura 23). A quantidades de raios utilizados nas simulações foi de: 100 mil; 1 milhão; 2 milhões; 3 milhões; 4 milhões; e 5 milhões. Observando a Figura 24 é notada a estabilização com o uso de 3 milhões de raios nas análises da distribuição da densidade de potência $\left(\mathrm{W} / \mathrm{mm}^{2}\right)$.

O mesmo teste foi realizado com o LED modelo Star Warm do fabricante bridgelux, com o anteparo quadrado medindo $1 \times 1 \mathrm{~cm}^{2}$ e distante $2 \mathrm{~mm}$ do LED, sendo observada maior estabilidade a partir do uso de 3 milhões de raios na simulação.

Figura 23 - Montagem para posicionamento da fonte de luz LED e verificação da estabilização do traçado de raios.

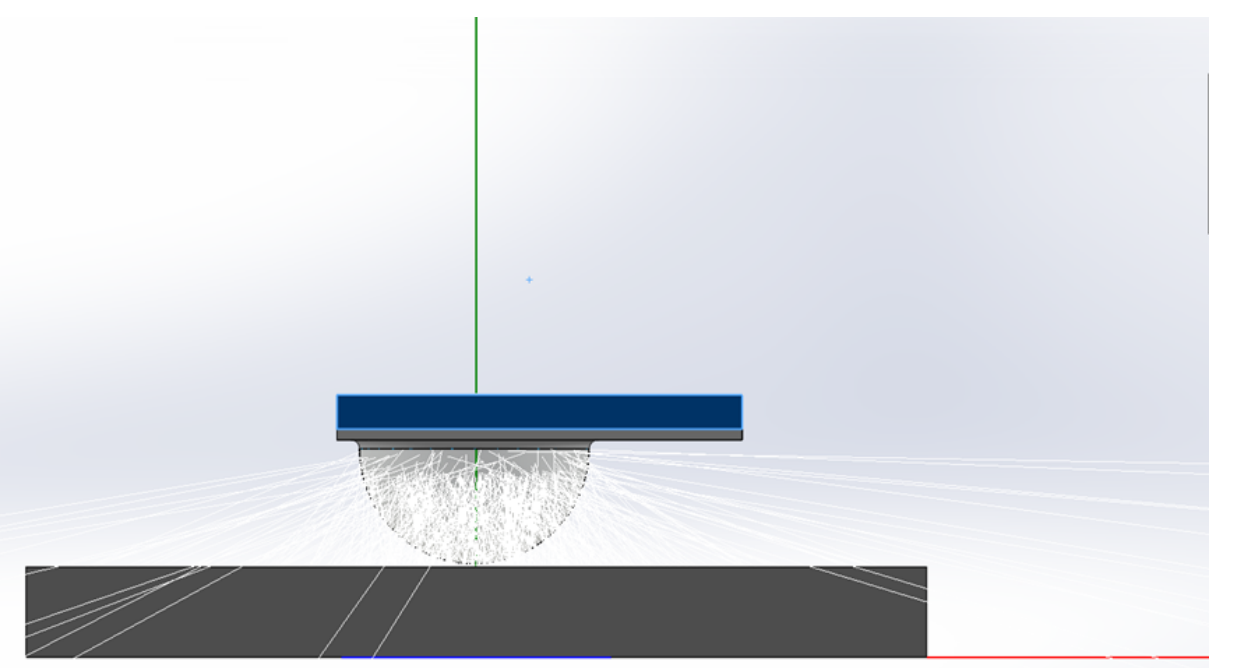

Fonte: Autoria própria.

Em outro teste foi realizada a variação da área de uma superfície circular. O ensaio realizado teve o intuito de verificar qual a mínima superfície possível que pode ser utilizada no aplicativo para avaliação do fluxo radiométrico total, de modo a ser obtida a correspondência com a área de fotodetecção utilizada nos cálculos de desempenho de comunicação. Para tal, foram posicionados dispositivos LED no centro da montagem de referência para análise, distante 2,5m, ou seja, a projeção dos raios de luz em direção à superfície equivale a uma fonte de luz LED posicionada no teto de uma sala, sem obstruções, e alinhada com a superfície delimitada 
Figura 24 - Secção da distribuição da densidade de potência. As setas indicam pontos onde ocorre deformidade na curva de distribuição. Até 2 milhões de raios a distribuição não atinge o valor de 0,009 $\mathrm{W} / \mathrm{mm}^{2}$ que passa a ocorrer à partir do uso de 3 milhões de raios.

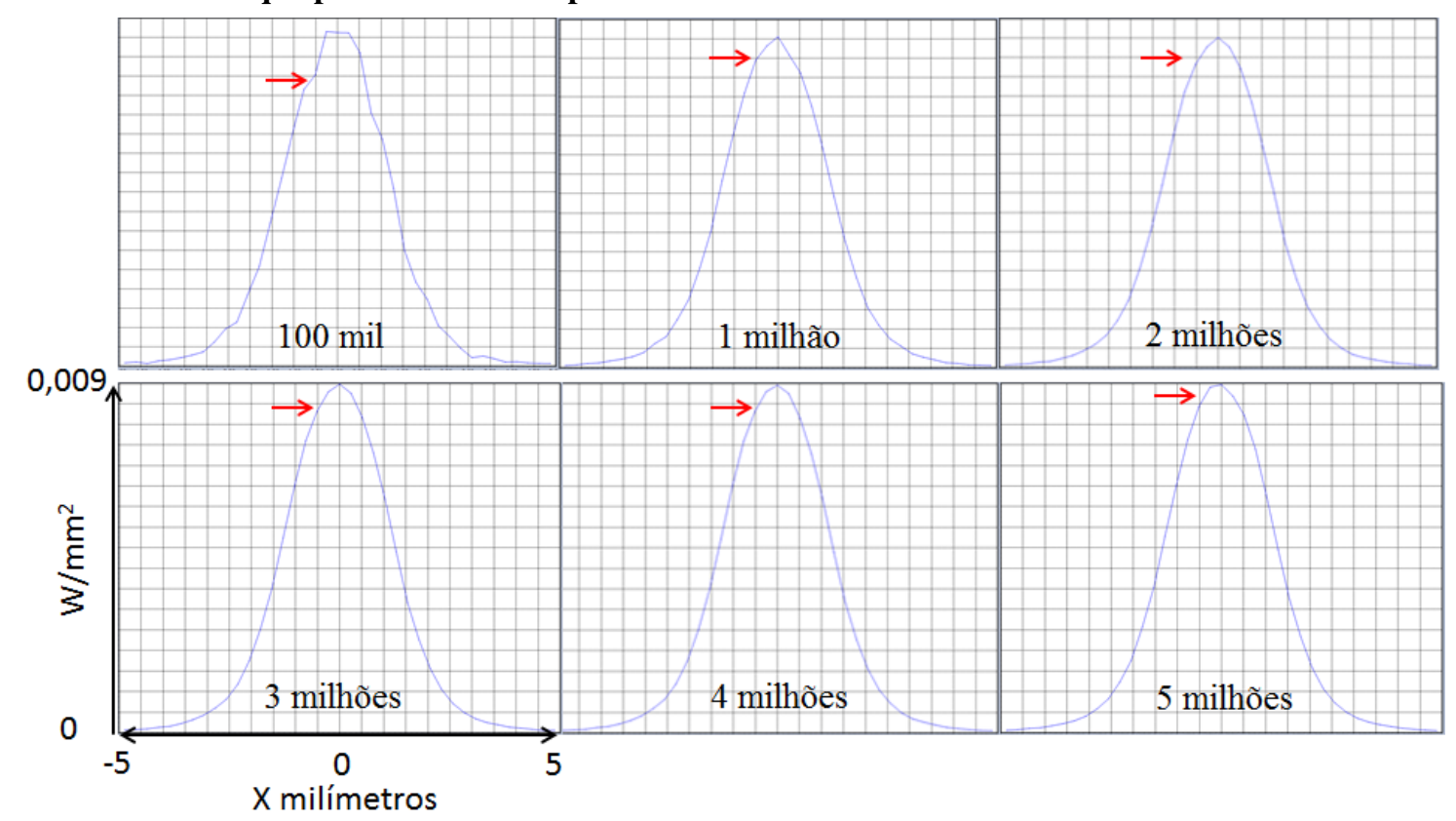

Fonte: Autoria própria.

para a fotodetecção, com as fontes de luz configuradas para gerarem 3 milhões de raios nesta simulação.

Tabela 5 - Variação da área de fotodetecção.

\begin{tabular}{cccc}
\hline LED & Área $\left(\mathrm{cm}^{2}\right)$ & Quantidade de raios & Fluxo radiométrico total $(\mathrm{W})$ \\
\hline & 10 & 531 & $0,4209507 \times 10^{-5}$ \\
LXML-PW31 & 1 & 53 & $0,4696092 \times 10^{-6}$ \\
& 0,1 & 6 & $0,6180626 \times 10^{-7}$ \\
& 0,01 & 0 & sem resultados \\
& 0,001 & 0 & sem resultados \\
\hline \multirow{3}{*}{ STAR WARM } & 10 & 327 & $0,4066900 \times 10^{-5}$ \\
& 1 & 26 & $0,2945828 \times 10^{-6}$ \\
& 0,1 & 0 & sem resultados \\
& 0,01 & 0 & sem resultados \\
& 0,001 & 0 & sem resultados \\
\hline
\end{tabular}

Fonte: Autoria própria.

Para o traçado de raios há opções de espalhar os raios refletidos pelos métodos determinístico ou estocástico. A dispersão determinística significa que, em geral, para cada raio incidente, haverá a criação de muitos raios refletidos, e, na dispersão estocástica, para cada raio incidente, haverá apenas um raio refletido, sendo esta, uma simulação de Monte-Carlo para o espalhamento dos raios (BREAULT, 2016).

Foi necessário um tempo superior a 24 horas para a geração de 3 milhões de raios por LED, quando acomodados à luminária e inseridos em um cenário. O esforço computacional é 
devido, também, ao método determinístico para a geração dos raios. Por outro lado, gerando 100 mil raios o tempo de processamento é reduzido, porém, a menor quantidade de raios afetou a precisão das avaliações.

Após, foi testada a geração de 1 milhão de raios pelos métodos determinístico e estocástico de Monte-Carlo, disponíveis no $\mathrm{APEX}^{\circledR}$. O tempo para processamento das informações foi de 5 horas e 1 hora, respectivamente. Para efeitos comparativos foi avaliado o fluxo radiométrico em uma superfície circular com $0,71 \mathrm{~cm}^{2}$ de área e sobre uma superfície de $1,0 \mathrm{~m}^{2}$. Verificou-se que a diferença medida entre os métodos foi de $6,6 \mu \mathrm{W}$, o equivalente a $0,76 \%$ para superfície de $0,71 \mathrm{~cm}^{2}$. Para a superfície de $1,0 \mathrm{~m}^{2}$ não houve diferença para o fluxo radiométrico total.

Tabela 6 - Comparativo entre método determinístico e estocástico.

\begin{tabular}{ccc}
\hline Método estatístico & Determinístico & Estocástico (Monte-Carlo) \\
\hline Quantidade de raios & 1 milhão & 1 milhão \\
Tempo de execução & apx. 5 horas & apx. 1 hora \\
Fluxo total radiado pelos 7 LEDs & $2,6 \mathrm{~W}(725,9 \mathrm{~lm})$ & $2,6 \mathrm{~W}(725,9 \mathrm{~lm})$ \\
Distância & $1,0 \mathrm{~m}$ & $1,0 \mathrm{~m}$ \\
Fluxo radiométrico total $0,71 \mathrm{~cm}^{2}$ & $877,9 \mu \mathrm{W}$ & $871,3 \mu \mathrm{W}$ \\
Fluxo radiométrico total $1,0 \mathrm{~m}^{2}$ & $1,927 \mathrm{~W}$ & $1,927 \mathrm{~W}$ \\
\hline
\end{tabular}

Fonte: Autoria própria.

Com essas informações definiu-se que as simulações dos cenários propostos seriam de, no mínimo, 1 milhão de raios, de modo a serem evitadas medidas imprecisas, bem como seria utilizado o método estocástico, tendo em vista que o aumento da quantidade de raios impacta em um aumento significativo em termos de processamento computacional e, consequentemente, o tempo para aquisição de dados.

\subsubsection{Cenário}

O ambiente a ser estudado é indoor para o qual os parâmetros ópticos de refletância foi aplicado às paredes. O piso e a mobília foram considerados como superfícies perfeitamente absorventes, pois são utilizados como sensores. O desempenho de um sistema óptico é dependente do meio no qual está inserido. No caso em estudo o meio de propagação dos raios é o ar, padrão para as simulações adotadas no $\mathrm{APEX}^{\circledR}$.

Como foi aplicada uma expessura de $10 \mathrm{~cm}$ nas paredes com $5 \mathrm{~m}$ de lado cada, a área interna ficou com área total para análise de 23,04 $\mathrm{m}^{2}(4,8 \mathrm{~m}$ x 4,8m). Na face interna das paredes foi aplicada a refletância em função do comprimento de onda apresentada na Tabela 7, que foi elaborada a partir da curva correspondente à parede de gesso da Figura 14 e incluída na biblioteca 
de revestimentos do $\mathrm{APEX}^{\circledR}$. Para realização das simulações a luminária foi disposta no centro de um cenário emulando uma sala como a da Figura 25.

Tabela 7 - Refletância em função do comprimento de onda correspondente às paredes de gesso.

\begin{tabular}{cc}
\hline Comprimento de onda $(\mathrm{nm})$ & Refletância considerada \\
\hline 400 & 0,60 \\
450 & 0,70 \\
500 & 0,75 \\
550 & 0,80 \\
600 & 0,82 \\
650 & 0,82 \\
700 & 0,82 \\
750 & 0,82 \\
\hline
\end{tabular}

Fonte: Adaptado de Lee et al. (2011).

Figura 25 - Cenário montado para as simulações, representando uma sala com as medidas de 4,80 x 4,80 x $2,50 \mathrm{~m}$ e a fonte de luz centralizada na parte superior. As setas indicam a posição da fonte de luz em relação à sala.

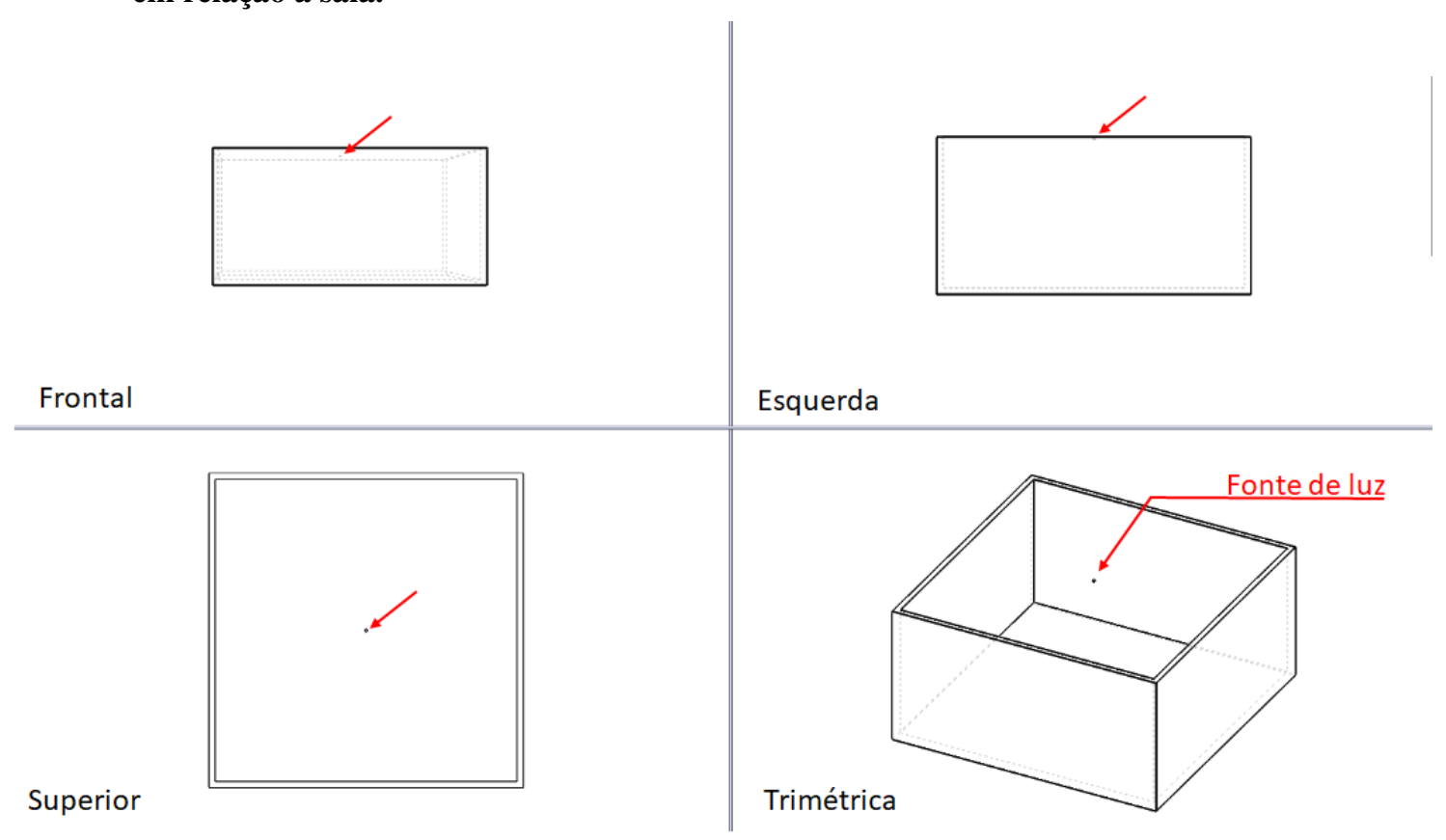

Fonte: Autoria própria. 


\subsubsection{Inclusão de peças na luminária}

A luminária reproduzida no $\mathrm{APEX}^{\circledR}$ é composta por duas peças: a base e o concentrador; e sete LEDs LXML-PW31. Para ilustrar o efeito dessas peças que compõem a luminária, foi realizada uma sequência de simulações com ela posicionada a $2,5 \mathrm{~m}$ do piso e no centro da sala, verificando os respectivos efeitos da inclusão das peças (refletor e concentrador). Em todas as simulações o fluxo radiométrico dos LEDs era de 2,6 W, equivalente a 725,9 $1 \mathrm{~m}$ de fluxo luminoso.

Nas simulações ilustradas pelas Figuras 26 (a) e (b), é desconsiderando o efeito das peças que formam a luminária, contudo a disposição das fontes de luz LED é a mesma utilizada nas simulações subsequentes. Na primeira simulação (a) o revestimento das paredes e do piso foram configurados como perfeitamente absorventes e o fluxo radiométrico total no piso foi de 1,595 W. O efeito da atribuição da refletância nas paredes (Tabela 7) pode ser observado pela Figura 26 (b). Quando é aplicada a refletância há mudança nos níveis de irradiância detectados no piso, em razão da composição dos raios diretos e indiretos (refletidos), e o fluxo radiométrico total no piso passou a $2,251 \mathrm{~W}$.

As Figuras 26 (c) e (d), foram geradas após ser adicionada a base na qual as sete fontes de luz LED são acomodadas. Nesse caso foram parametrizados dois diferentes revestimentos internos da base, com refletância de $80 \%$ (fundo branco) e $95 \%$ (especular); e desconsiderados os elementos concentradores. Ao ser incluída a base o efeito esperado é o de redirecionamento em direção ao piso dos raios que se propagam na direção horizontal. Nessas simulações não foi aplicada refletância nas paredes da sala. Foram obtidos $1,668 \mathrm{~W}$ com refletância de $80 \%$ e $1,693 \mathrm{~W}$ com refletância de $95 \%$, de modo que o redirecionamento dos raios aumenta o fluxo radiométrico total no piso se comparado à simulação somente com os LEDs na montagem (sem refletância nas paredes). A superfície especular aumentou em $25 \mathrm{~mW}$ o fluxo radiométrico total, o equivalente a cerca de $0,065 \mathrm{~dB}$ de ganho nessa simulação. 
Figura 26 - Perfil de irradiância obtido no piso: (a) Somente LEDs e paredes sem refletância: irradiância mínima de 16,66 $\mathrm{nW} / \mathrm{mm}^{2}$ e máxima de $163,72 \mathrm{nW} / \mathrm{mm}^{2}$; (b) Somente LEDs e paredes com refletância: irradiância mínima de 50,24 nW/mm² e máxima de 183,34 nW/mm²; (c) Inclusão da base com refletãncia de $80 \%$ : irradiância mínima de $16,62 \mathrm{nW} / \mathrm{mm}^{2}$ e máxima de 162,49 nW/mm ${ }^{2}$; e (d) Inclusão da base com refletãncia de 95\% : irradiância mínima de 16,91 nW/mm ${ }^{2}$ e máxima de $162,49 \mathrm{nW} / \mathrm{mm}^{2}$.

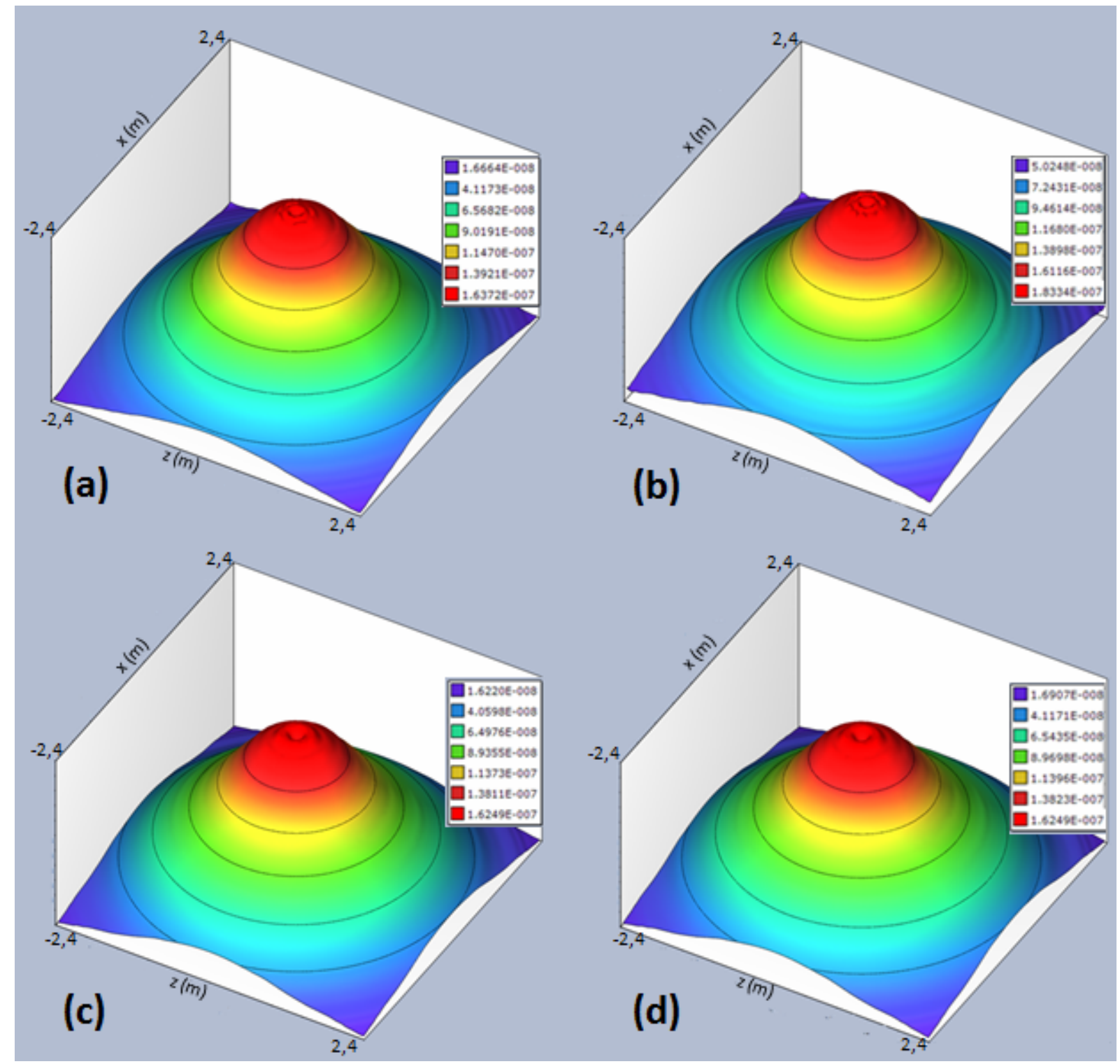

Fonte: Autoria própria.

A composição da luminária é finalizada com o concentrador detalhado nas Figuras 19 e 20. Com ele a cobertura da radiométrica do piso da sala sofre grande redução, fato que deve ser considerado em projetos de luminotécnica, porém, ocorre a concentração de energia na área do sensor, que é fator importante para a melhoria de desempenho em sistemas VLC, como pode ser observado pela Figura 27. Nesta simulação não foi aplicada refletância nas paredes da sala. 
Figura 27 - Distribuição de potência no piso: (a) representação tridimensional pela qual pode ser observada a concentração de potência na parte central; e (b) detalhamento dos níveis de irradiância que varia de $7,37 \mathrm{nW}$ a $\mathbf{1 , 7 6} \mu \mathrm{W} / \mathrm{mm}^{2}$.
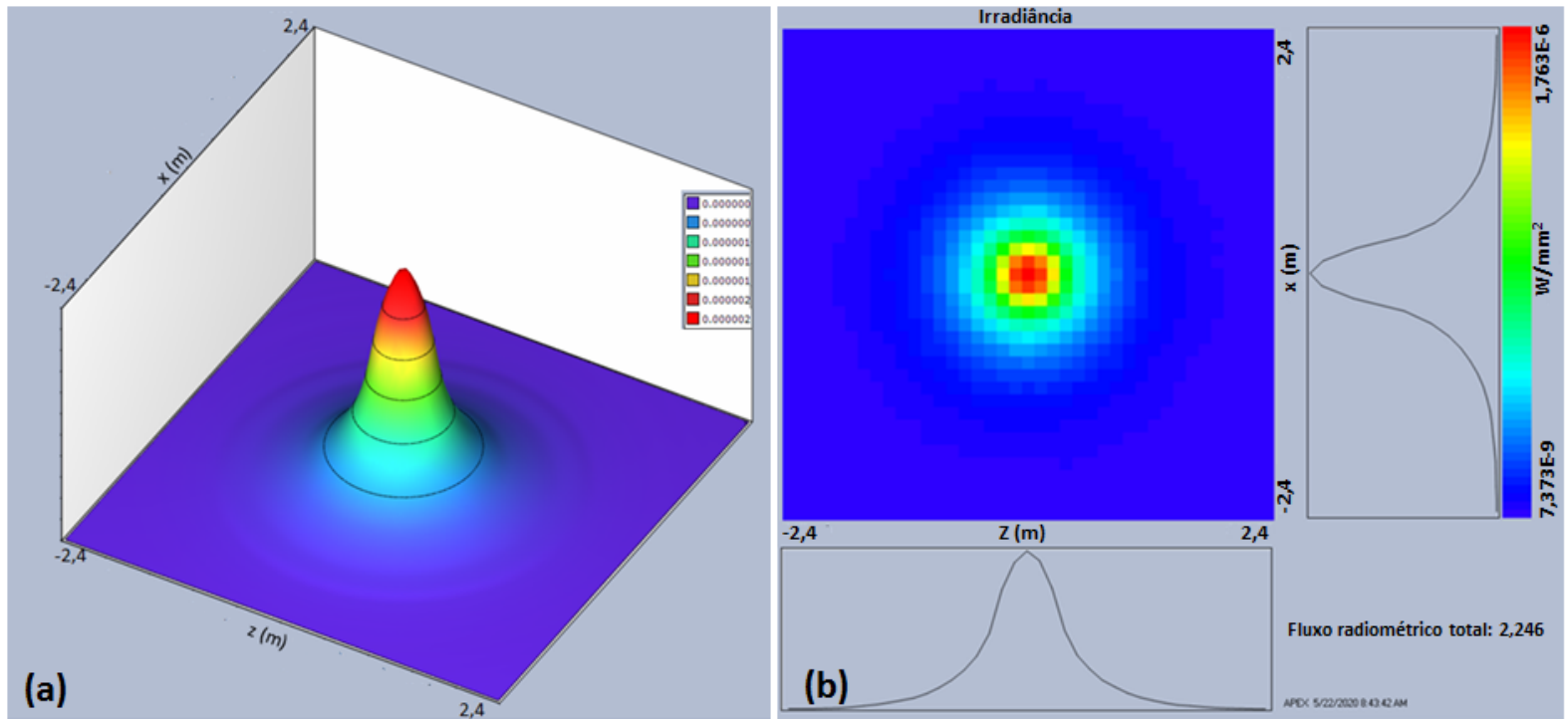

Fonte: Autoria própria.

\subsubsection{Variação da distância de detecção}

Inicialmente foram realizadas simulações sem a aplicação da refletância nas superfícies internas da sala. À base da luminária aplicou-se refletância de $80 \%$ e ao concentrador o material PCARB. Foi, então, variada a distância de afastamento de outra superfície representando uma mesa quadrada $\left(1 \times 1 \mathrm{~m}^{2}\right)$ tendo, no centro, um ressalto circular de área de $0,71 \mathrm{~cm}^{2}$ com revestimento perfeitamente absorvente, servindo como sensor nessas simulações.

Figura 28 - Elementos utilizados para simulação. No centro da sala é disposta uma superfície quadrada (mesa) com variação da distância em relação à luminária (eixo y). Elementos: (1) Luminária; (2) Mesa; e (3) detalhe do ressalto circular no centro da mesa.

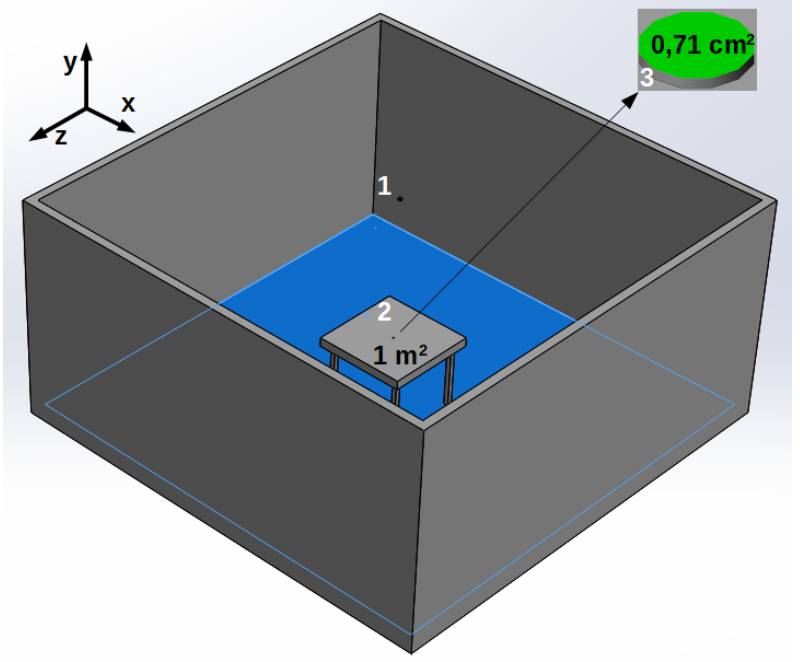

Fonte: Autoria própria. 
A Figura 29 apresenta a maneira como são realizadas as detecções e a obtenção do valor para o fluxo radiométrico na superfície. O resultado dessas simulações sobre uma superfície de $0,71 \mathrm{~cm}^{2}$ é ilustrado pelo gráfico na Figura 30. Nessas simulações os 7 LEds da luminária foram ajustados para emissão de dois diferentes $\Phi_{e}$ : (i) $2,6 \mathrm{~W}(725,90 \mathrm{~lm})$ e (ii) $736,05 \mathrm{~mW}(205,5$ lm). Na mesma figura são plotadas as curvas teóricas (Equação 30) de referência, considerando: $\mathrm{m}=60$ e $\mathrm{A}=0,71 \mathrm{~cm}^{2}$.

Figura 29 - Exemplo de detecção do fluxo radiométrico por superfície sensora de $0,71 \mathrm{~cm}^{2}$. (a) Fluxo radiométrico total de $47,86 \mathrm{~mW}$ para superfície distante $20 \mathrm{~cm}$ da luminária. (b) Fluxo radiométrico de 318,50 $\mu \mathrm{W}$ para superfície distante $1,70 \mathrm{~m}$ da luminária

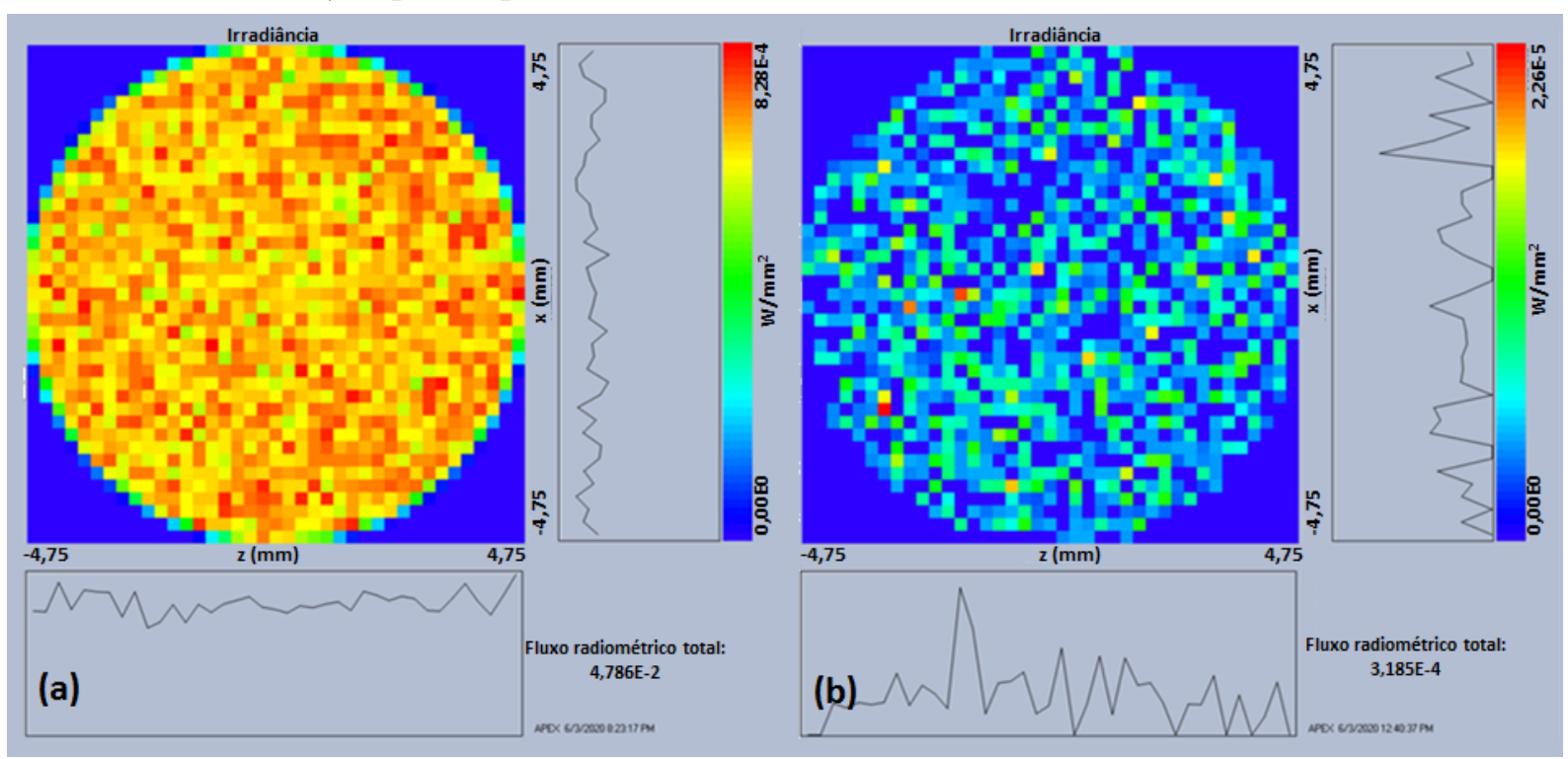

Fonte: Autoria própria.

O material do elemento concentrador foi alterado de policarbonato (PCARB) para acrílico (PMMA). Estes materiais são aplicados como meios ópticos (polímeros) e estão disponíveis na biblioteca do $\mathrm{APEX}^{\circledR}$. Foi realizada a variação da refletância do revestimento da base de $80 \%$ para 95\% e efetuada a troca do PCARB pelo PMMA no elemento concentrador, mantendo-se a refletância da base de $80 \%$. 
Figura 30 - Potência detectada em uma superfície circular com $0,71 \mathrm{~cm}^{2}$ de área em função do afastamento em relação à luminária. As linhas tracejadas indicam o resultado teórico.

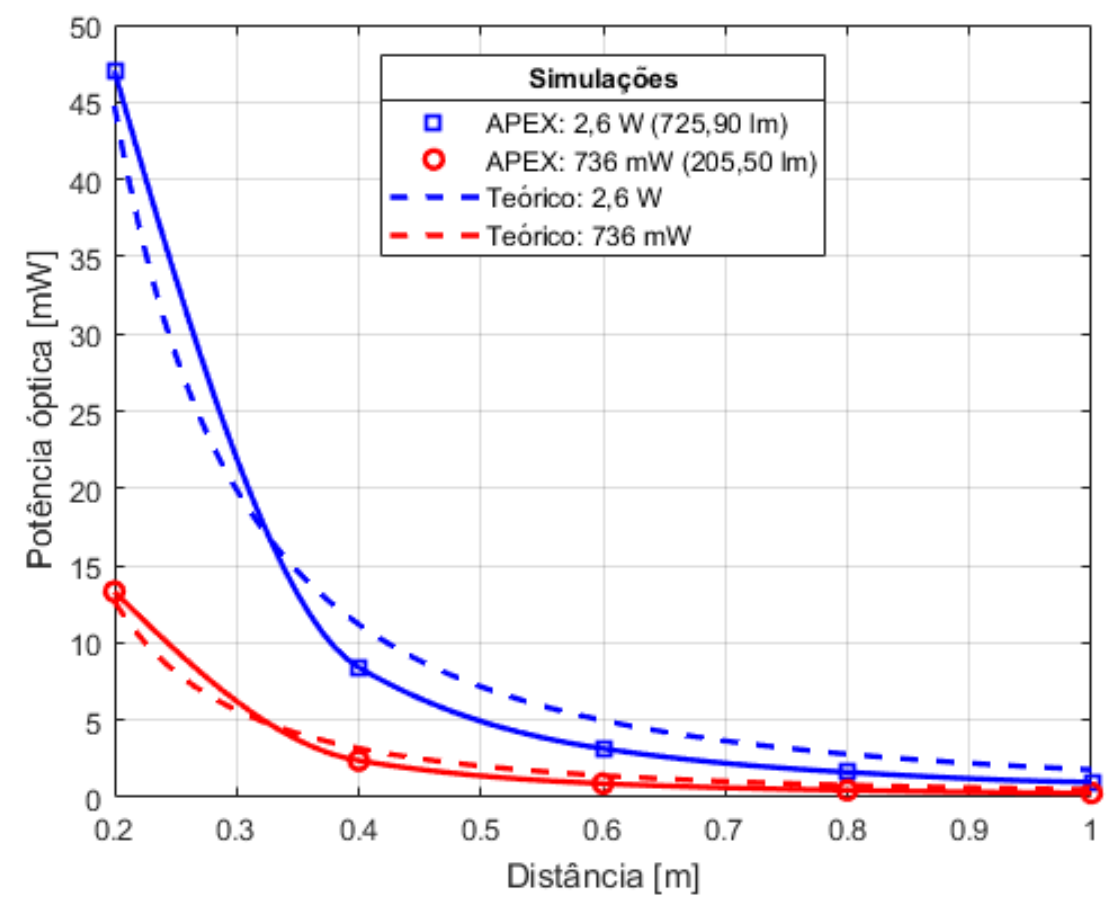

Fonte: Autoria própria.

À distância de 1,70 m foram obtidos os fluxos radiométricos incidentes sobre a superfície sensora de $0,71 \mathrm{~cm}^{2}$ :

- 85,81 $\mu \mathrm{W}$ - Concentrador em PCARB e base com 80\% de refletância (205,50 lm).

- 303,1 $\mu \mathrm{W}$ - Concentrador em PCARB e base com 80\% de refletância (725,90 lm).

- 318,5 $\mu \mathrm{W}$ - Concentrador em PCARB e base com 95\% de refletância (725,90 lm).

- 306,8 $\mu$ W - Concentrador em PMMA e base com 80\% de refletância (725,90 lm).

Com a variação da distância entre a luminária e a superfície sensora de $0,71 \mathrm{~cm}^{2}$, obtemse as curvas conforme associada à detecção do fluxo radiométrico total (Figura 31), porém, esta não evidenciou diferenças entre as variações realizadas. 
Figura 31 - Variação da refletância e do material do elemento concentrador.

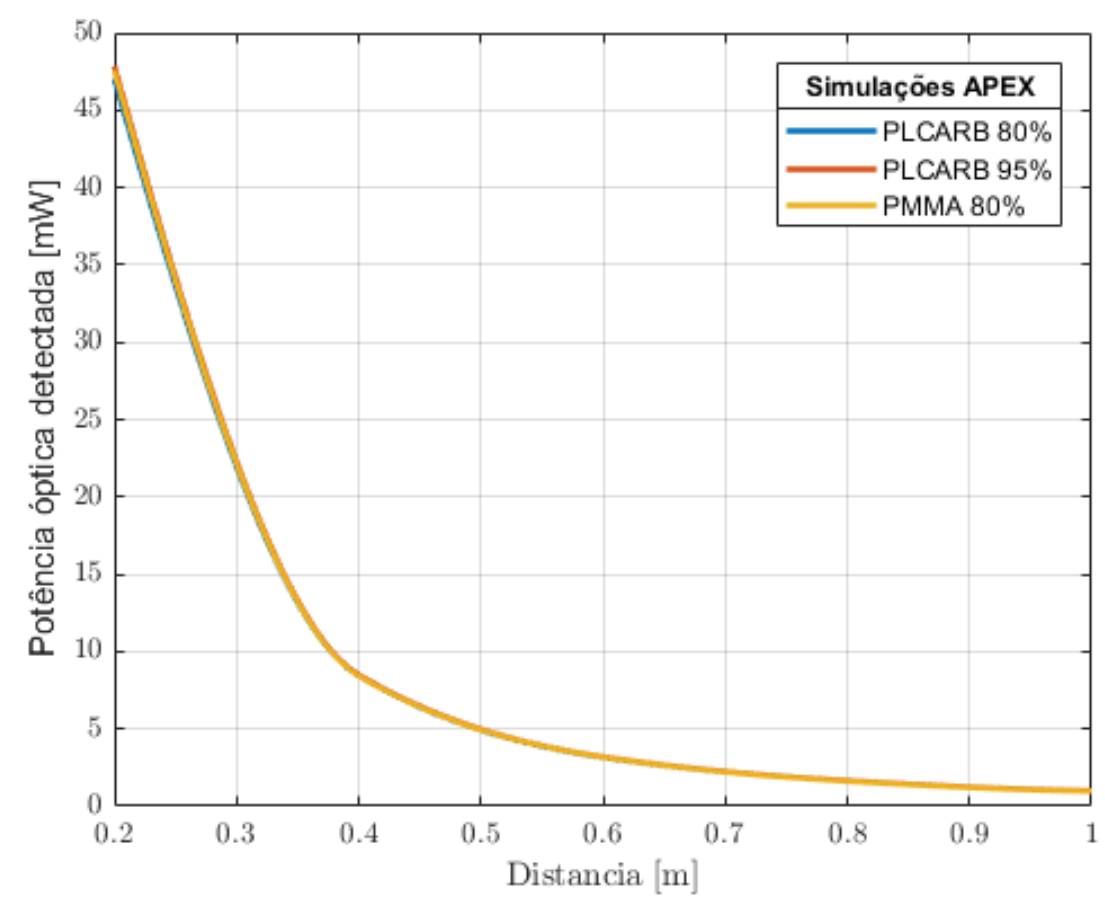

Fonte: Autoria própria.

A distribuição da iluminação sobre a mesa (lux) também foi simulada e é ilustrada nas Figuras 32 e 33. Nelas são plotados os resultados para 2,6 W e para 736,05 mW. Nas bordas da superfície, ocorrem os pontos de menor iluminância estimados pelo software em 80,23 lx para $\Phi_{e}$ de 2,6 W e 21,79 lx para $\Phi_{e}$ de 736,05 mW. No centro, a máxima iluminância estimada é, respectivamente, de 1351,59 lx e 382,60 lx. O efeito devido ao ressalto de 0,71 $\mathrm{cm}^{2}$ é percebido centro da distribuição. Como referência, de acordo com a Norma ABNT, em áreas de trabalho de bibliotecas e escritórios a iluminância mínima deve ser de 500 lx. 
Figura 32 - Distribuição da iluminância em uma superfície de $1 m^{2}$ ( $\Phi_{v}$ de $\mathbf{7 2 5 , 9 0 ~ l m}$ ).

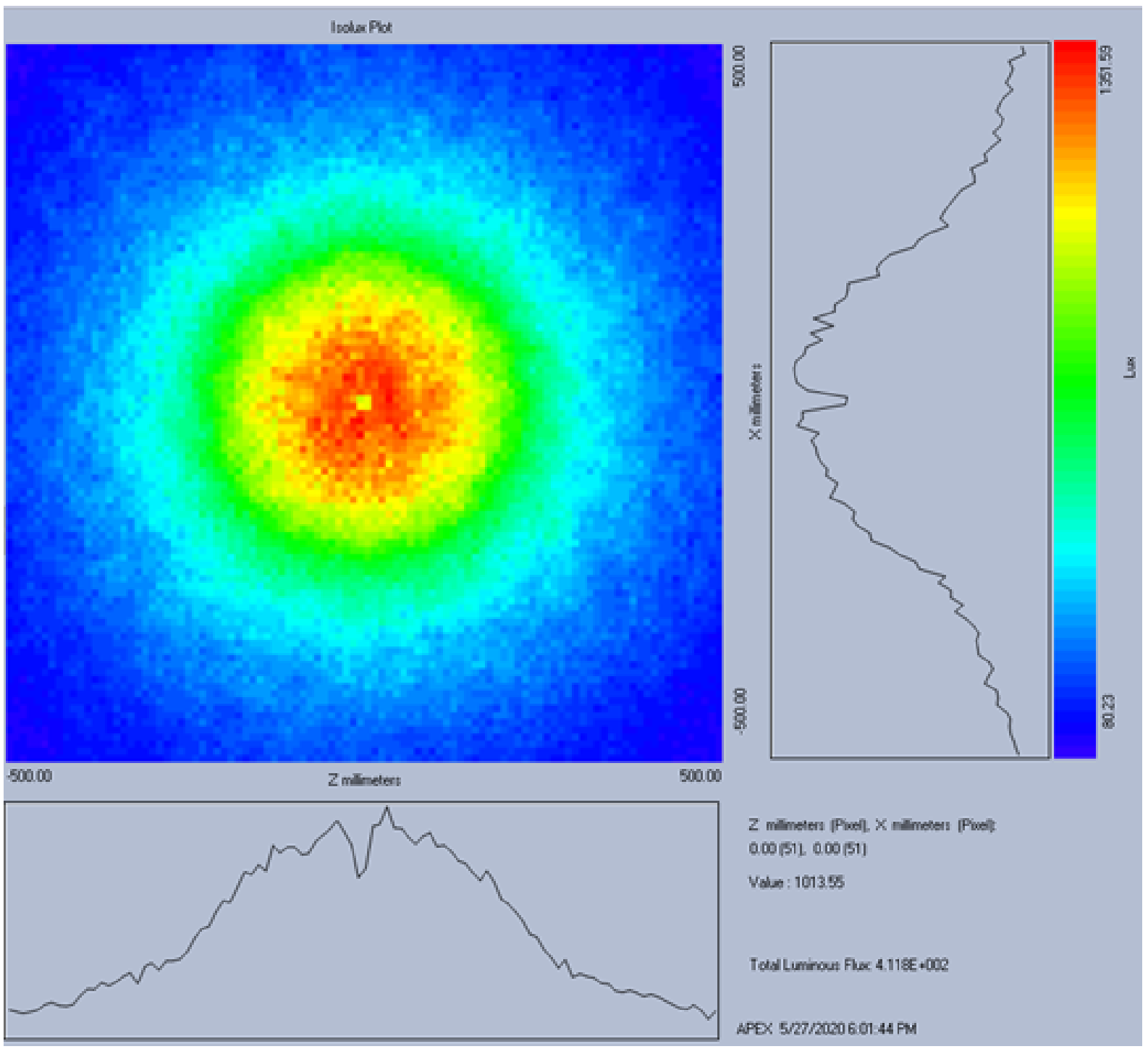

Fonte: Autoria própria. 
Figura 33 - Distribuição da iluminância em uma superfície de $1 m^{2}\left(\Phi_{v}\right.$ de $\mathbf{2 0 5 , 5 0} \mathbf{l m}$ ).

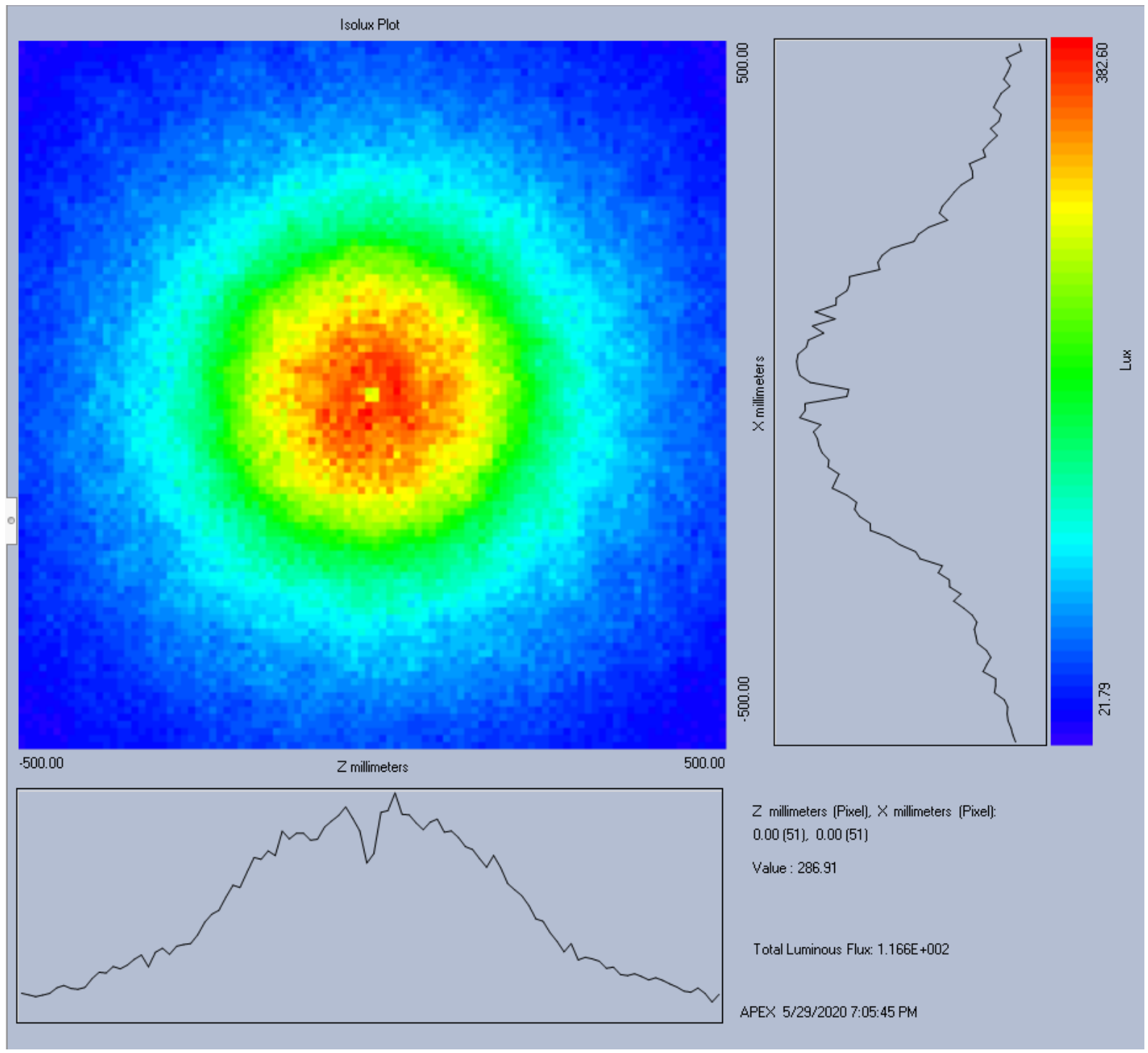

Fonte: Autoria própria.

\subsubsection{Múltiplas luminárias}

Na sala foram distribuídas nove luminárias a 2,5 m de altura. As luminárias estão afastadas de 1,20 m entre si. A Figura 34 ilustra esse novo cenário composto com cinco mesas, distantes $1,70 \mathrm{~m}$ do teto e utilizadas para verificação dos níveis de fluxo radiométrico e fotométrico incidentes em áreas de trabalho. Com o aumento da quantidade de luminárias a potência total do sistema foi recalibrada para 23,4 W (9 x 2,6 W). Nota-se pela Figura 34 o efeito de reflexão dos raios nas paredes devido à inclusão de refletãncia (parede de gesso).

A análise inicial foi feita sem considerar a presença das mesas no cenário para obtenção dos fluxos radiométricos e fotométricos incidentes no piso. A distância vertical entre o piso e as luminárias é de 2,5 m. O resultado para a irradiância distribuída no piso é apresentado pelas 
Figura 34 - Distribuição das luminárias numeradas de 1 a 9 e das mesas (A, B, C, D e E) no cenário. Vista superior (esquerda) e vista isométrica (direita).
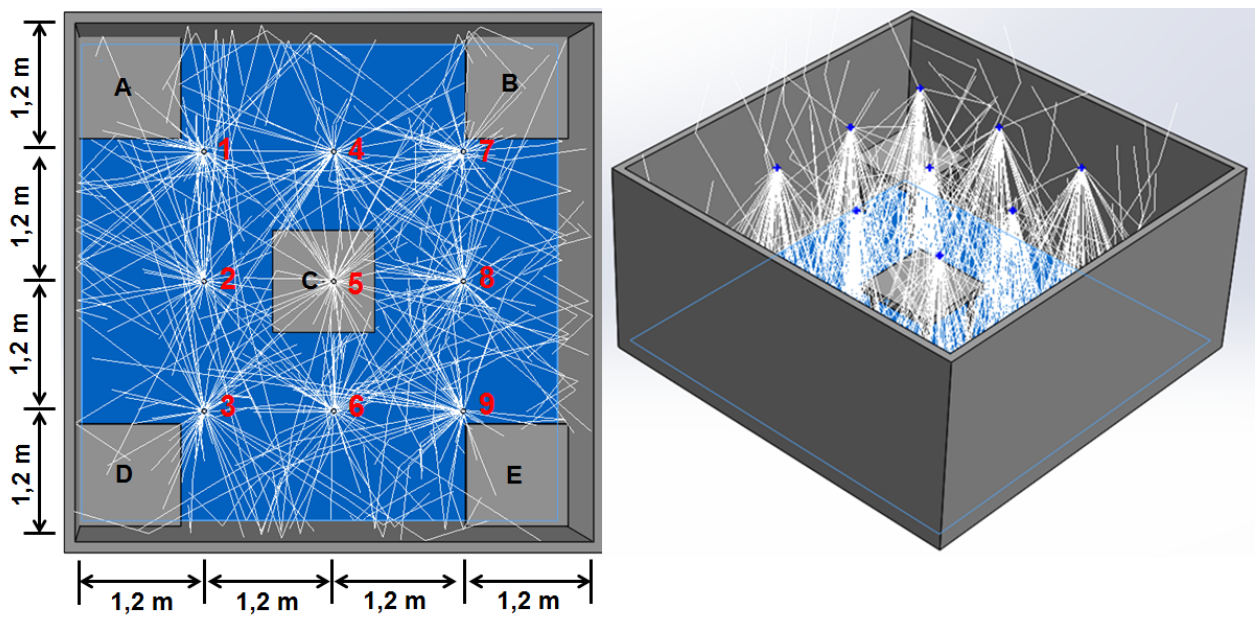

Fonte: Autoria própria.

Figura 35, obtendo-se o nível de irradiância de até 2,62 $\mu \mathrm{W} / \mathrm{mm}^{2}$ nessa simulação.

Figura 35 - Distribuição da Irradiância incidente no piso da sala com o uso de nove luminárias. Os níves de variam entre $104 \mathrm{nW} / \mathrm{mm}^{2}$ e $2,62 \mu \mathrm{W} / \mathrm{mm}^{2}$. No detalhe é apresentada a visualização tridimensional da distribuição da irradiância.

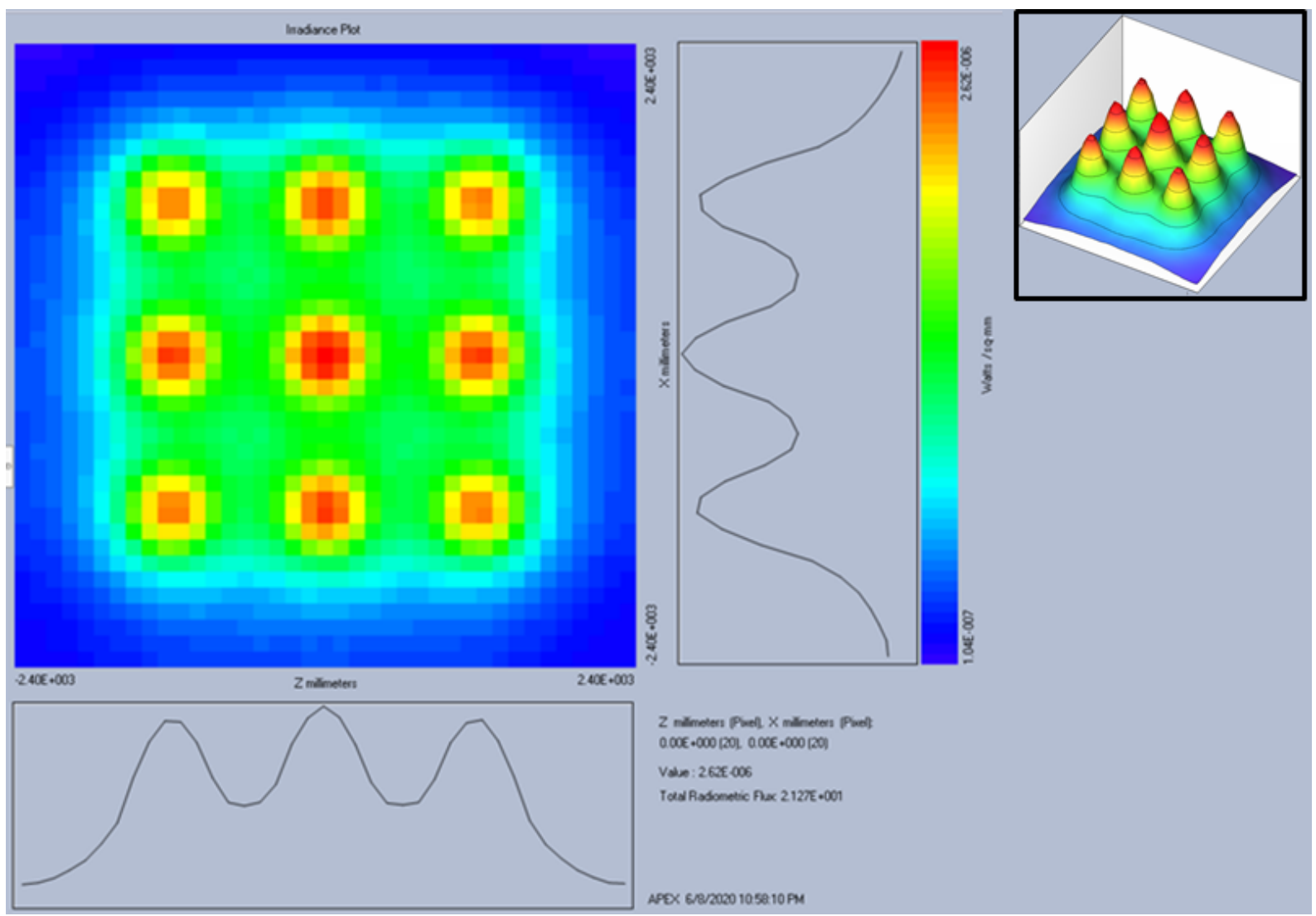

Fonte: Autoria própria.

Os resultados para a iluminância distribuída no piso é apresentada pela Figura 36. Foram obtidos níveis mínimos de iluminância de 29,17 lx nos cantos da sala e níveis máximos de 734,05 
lx nessa simulação.

Para análise da distribuição da iluminância sobre planos de trabalho foram consideradas as mesas que distam de 1,70 $\mathrm{m}$ do teto. Uma mesa foi posicionada no centro da sala e as demais nos cantos. Estas mesas também possuem no centro da superfície superior um ressalto circular com $0,71 \mathrm{~cm}^{2}$ de área para emular uma superfície sensora do fluxo radiométrico incidente.

A Tabela 8 contém os valores obtidos para as mesas. Devido a sucessivos erros de processamento e reinicializações do Solidworks, não foi possível a aquisição de valores para a mesa E, contudo, devido ao seu posicionamento na sala, os resultados devem ser próximos aos obtidos nas mesas A, B e D.

Figura 36 - Distribuição da iluminância incidente no piso da sala com o uso de nove luminárias. Os níves de variam entre $104 \mathrm{nW} / \mathrm{mm}^{2}$ e $2,62 \mu \mathrm{W} / \mathrm{mm}^{2}$.

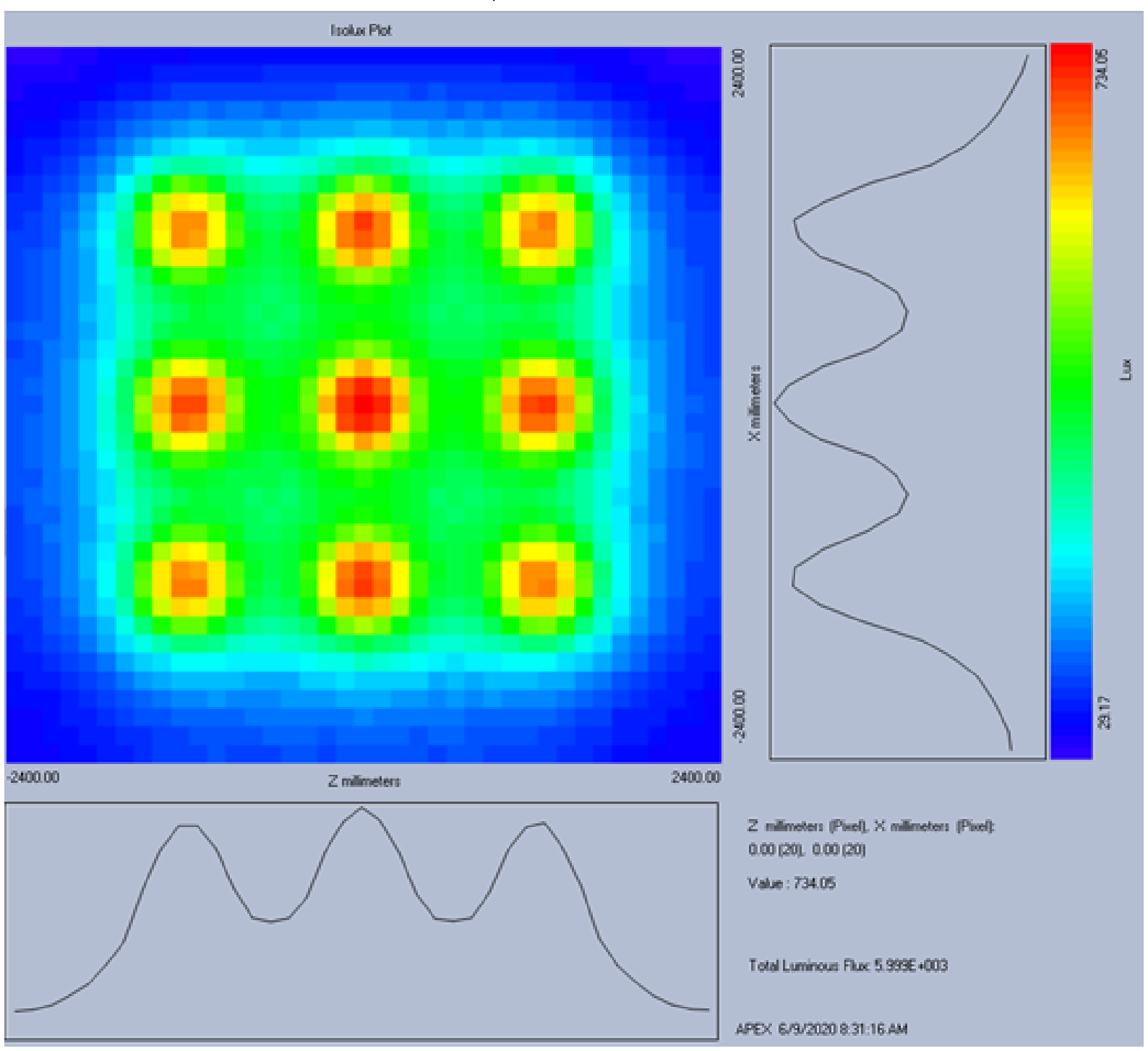

Fonte: Autoria própria. 
Tabela 8 - Análise da iluminância sobre as mesas da sala e do fluxo radiométrico incidente sobre as respectivas superfícies sensoras com $0,71 \mathrm{~cm}^{2}$.

\begin{tabular}{cccc}
\hline Mesa & $\Phi_{e}(\mathrm{~W})-0,71 \mathrm{~cm}^{2}$ & $E_{v}(\mathrm{~lx})$ mínimo & $E_{v}(\mathrm{~lx})$ máximo \\
\hline $\mathrm{A}$ & $14,96 \mu$ & 8,33 & 493,44 \\
$\mathrm{~B}$ & $11,34 \mu$ & 8,85 & 470,00 \\
$\mathrm{C}$ & $339,80 \mu$ & 263,04 & 1386,28 \\
$\mathrm{D}$ & $13,93 \mu$ & 12,00 & 503,20 \\
\hline
\end{tabular}

Fonte: Autoria própria.

\subsection{ENSAIOS PARA CARACTERIZAÇÃO DA LUMINÁRIA}

O conjunto da luminária foi montado sobre uma mesa óptica e alimentada por uma fonte variável de corrente contínua. Entre a fonte variável e a luminária é disposto um circuito de controle (driver) devido à necessidade de acoplamento com a interface microaxial da luminária. O circuito permite a polarização dos sinais a serem modulados. Nesse ensaio de caracterização não foi realizada modulação de informações na luminária, portanto o referido circuito não produz outros efeitos, senão o de permitir a polarização e o ajuste da corrente de alimentação em corrente contínua da luminária. Com esse mesmo arranjo, ilustrado pela Figura 37, foram realizadas medidas de:

- Comprimento de onda de operação com espectrômetro de banda CCS200.

- Potência óptica com fotodiodo S121C.

- Iluminância com luxímetro Criffer Flex.

Figura 37 - Montagem do setup para medidas de laboratório. $\mathrm{O}$ arranjo de medidas pode ser modificado pela alteração da posição da fonte de luz (luminária) e dos instrumentos de medida sobre a mesa óptica.

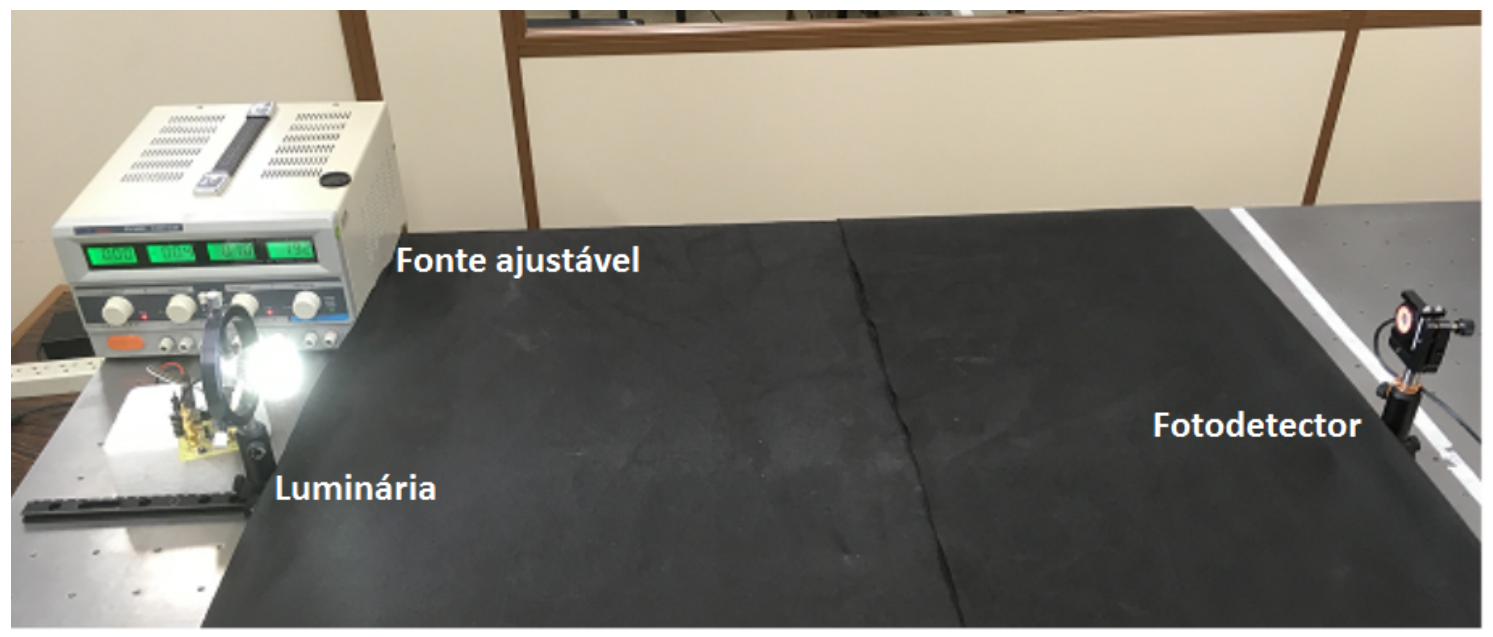

Fonte: Autoria própria. 
Inicialmente foi verificada a distribuição da potência espectral da luminária com espectrômetro de banda modelo CCS200 da Thorlabs ${ }^{\circledR}$, pelo qual foi detectado pico de potência óptica em $580 \mathrm{~nm}$. Com isso foi ajustado o ponto de operação para aquisição das medidas do fotodiodo S121C (THORLABS, 2016) em $580 \mathrm{~nm}$.

Figura 38 - Picos de emissão na faixa da cor azul e amarela detectados pelo analisador. O pico à esquerda $(454 \mathrm{~nm})$ demonstra a emissão no espectro de cor azul. $O$ pico à direita $(580 \mathrm{~nm})$ encontra-se na faixa a cor amarela.

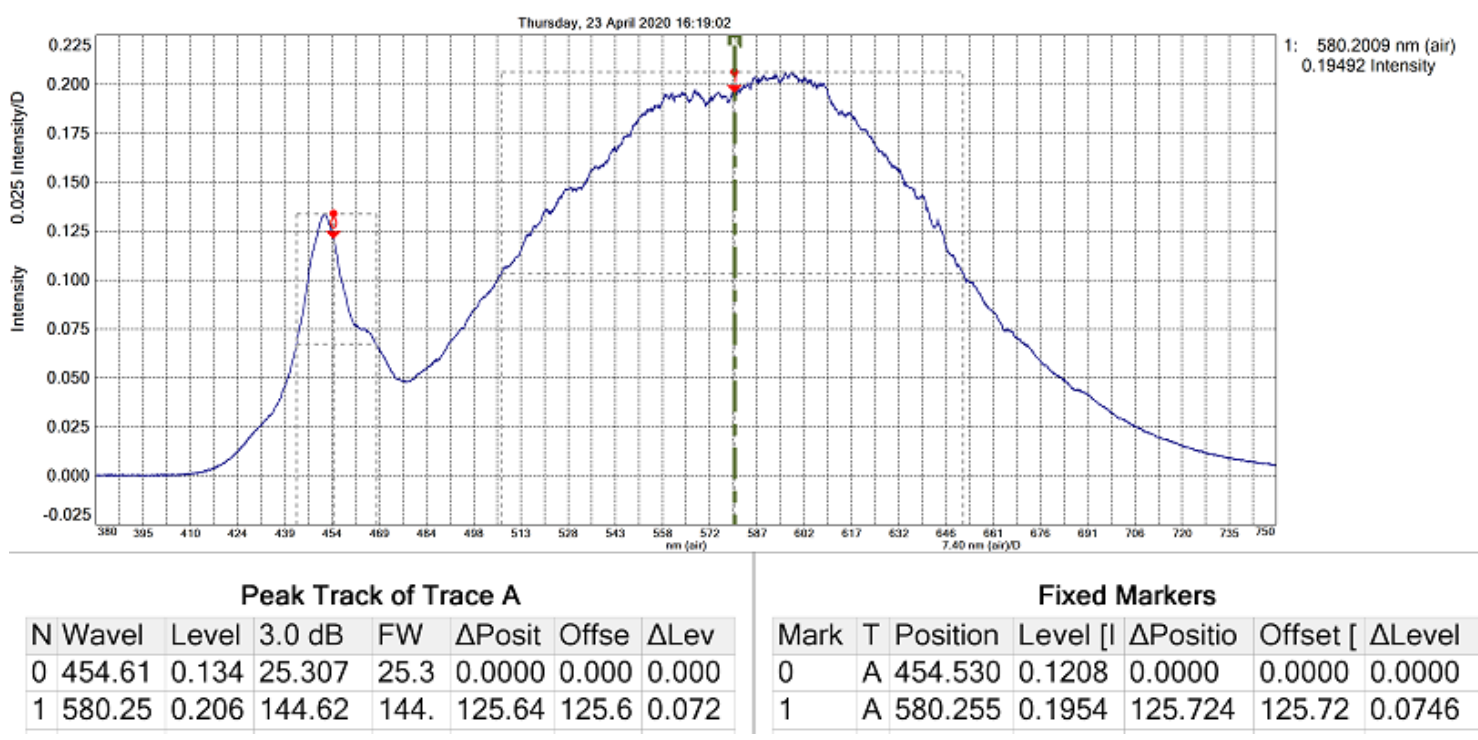

Fonte: Autoria própria.

A razão entre os valores de fotocorrente e de potência medidos pelo sensor de potência permitem a obtenção da responsividade efetiva do fotodiodo S121C. De maneira análoga, a razão entre os valores de potência e de irradiãncia medidos permitem a obtenção da área efetiva de fotodetecção. Assim, foram obtidas a responsividade de 3,19 mA/W, ligeiramente inferior à curva de responsividade fornecida pelo fabricante (Figura 39), e área efetiva de fotodetecção de de $0,71 \mathrm{~cm}^{2}$ para o fotodiodo $\mathrm{S} 121 \mathrm{C}$.

Observa-se que a superfície de fotodetecção do dispositivo fotodiodo S121C é menor que a superfície de emissão da luminária. Esse fator é considerado importante, pois afeta a caracterização da potência de saída junto à luminária em uma avalização do tipo back-to-back, que não foi executada.

Foi utilizada uma capa na cor preta para cobrir a mesa óptica fabricada em aço inox. Uma das medidas realizadas apontou diferença de 5,6 $\mu \mathrm{W}$, equivalente a $0,15 \mathrm{~dB}$, entre a medida com e sem a cobertura da bancada, $163,9 \mu \mathrm{W}$ e 169,5 $\mu \mathrm{W}$, respectivamente. Nessa análise a distância entre os dispositivos era de $1 \mathrm{~m}$. A luz ambiente, proveniente das lâmpadas do laboratório, onde não há incidência de radiação solar no fotodiodo, promovem um acréscimo de 
Figura 39 - Curva de responsividade do fotodiodo S121C disponibilizada pela ThorLabs ${ }^{\circledR}$.

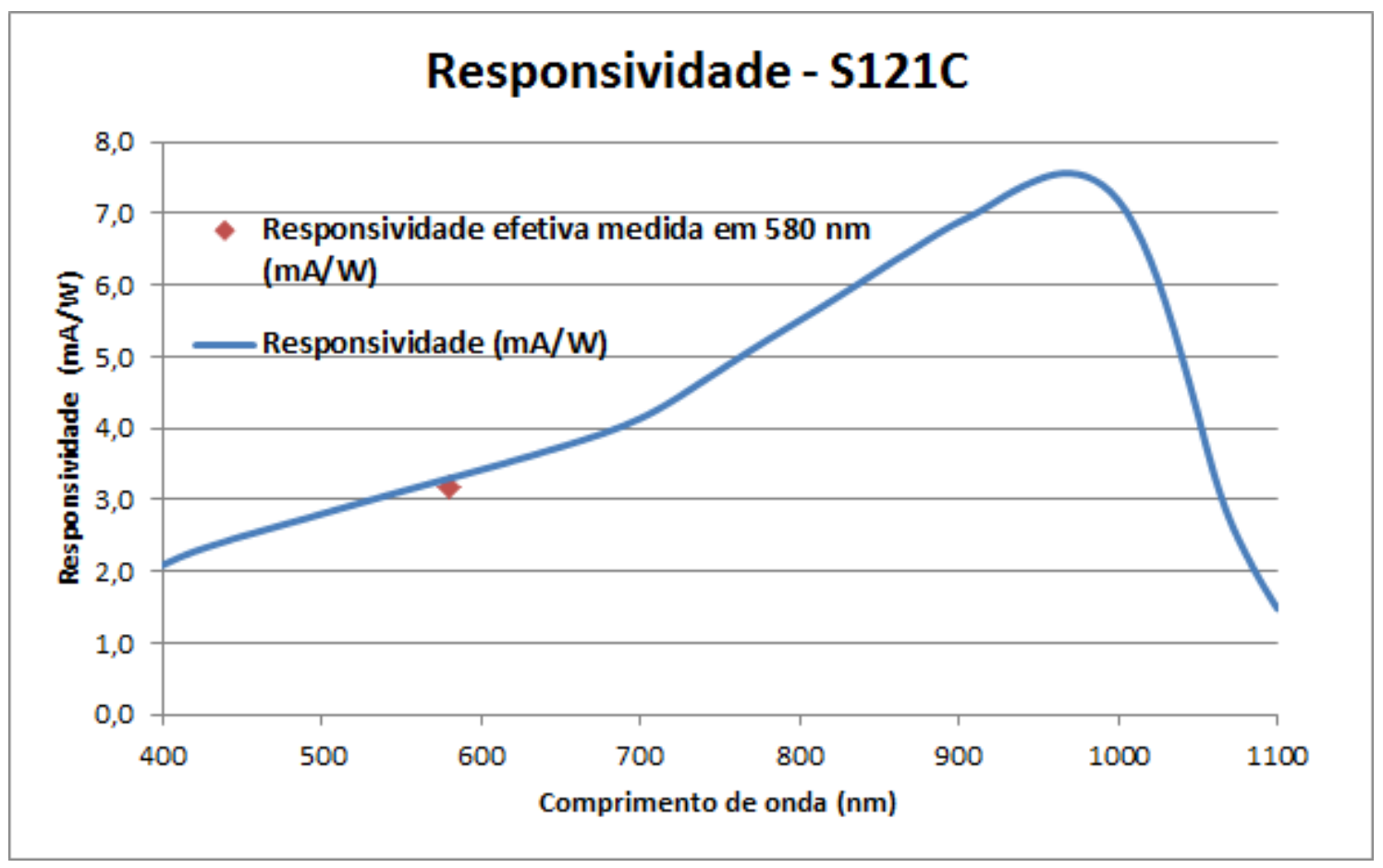

Fonte: Adaptado de Thorlabs (2016).

47,9 $\mu \mathrm{W}$ na potência média detectada ao serem ligadas. Devido a estas contribuições as medidas foram realizadas com o uso da capa sobre a mesa e com a luz ambiente apagada.

\section{Variação da corrente de alimentação fornecida pela fonte:}

No primeiro experimento, a luminária foi mantida afastada de $1 \mathrm{~m}$ dos dispositivos de detecção (fotodiodo S121C e luxímetro) e com o concentrador encaixado à luminária, para realização de medidas radiométricas (potência óptica) e fotométricas (iluminância). A corrente $\mathrm{CC}$ fornecida pela fonte variável foi ajustada em passos de $10 \mathrm{~mA}$, partindo de $10 \mathrm{~mA}$ (LEDs ainda apagados) até o valor máximo de $280 \mathrm{~mA}$, obtendo-se as variações da potência elétrica consumida pela luminária, a potência óptica medida (recebida) pelo fotodetector e a Iluminância medida pelo luxímetro. Os resultados podem ser visualizados na Figura 40.

No segundo experimento a luminária foi mantida a $1,70 \mathrm{~m}$ de distância e realizada a variação da corrente CC fornecida pela fonte variável. Nesse experimento foram realizadas medidas com e sem o dispositivo concentrador encaixado na luminária. Os resultados são apresentados na Figura 41.

Pelas medidas realizadas pode-se observar, a condição de operação dos LEDs ainda na região linear. A Figura 41 demonstra o efeito provocado pela inclusão do concentrador óptico na luminária. 
Figura 40 - Potência óptica e Iluminância medidas em função da variação da potência elétrica consumida pela luminária a $1 \mathrm{~m}$ de distância.

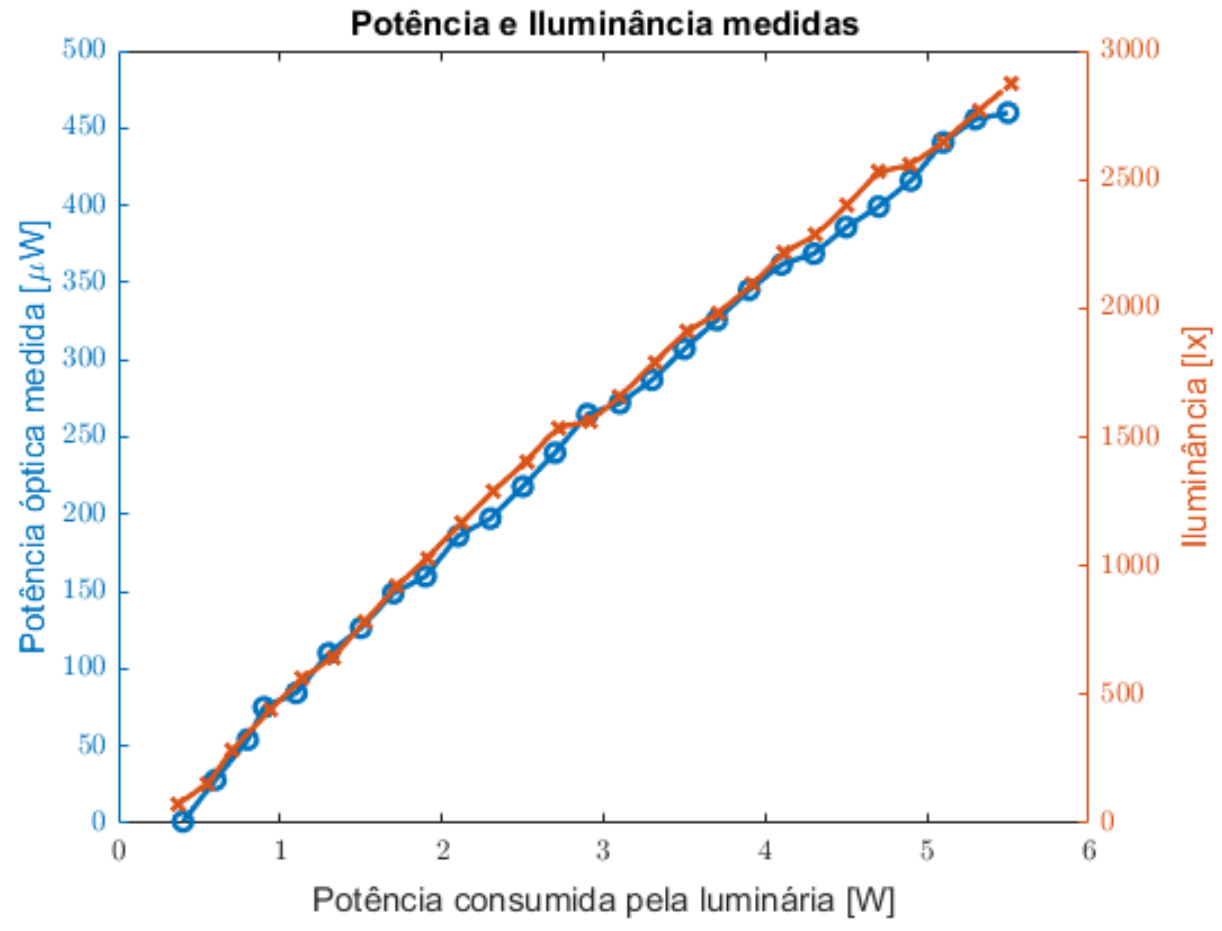

Fonte: Autoria própria.

Figura 41 - Potência óptica função da variação da potência elétrica consumida pela luminária a mantida a 1,70 m de distância. Nesse experimento foram medidos valores com e sem o concentrador.

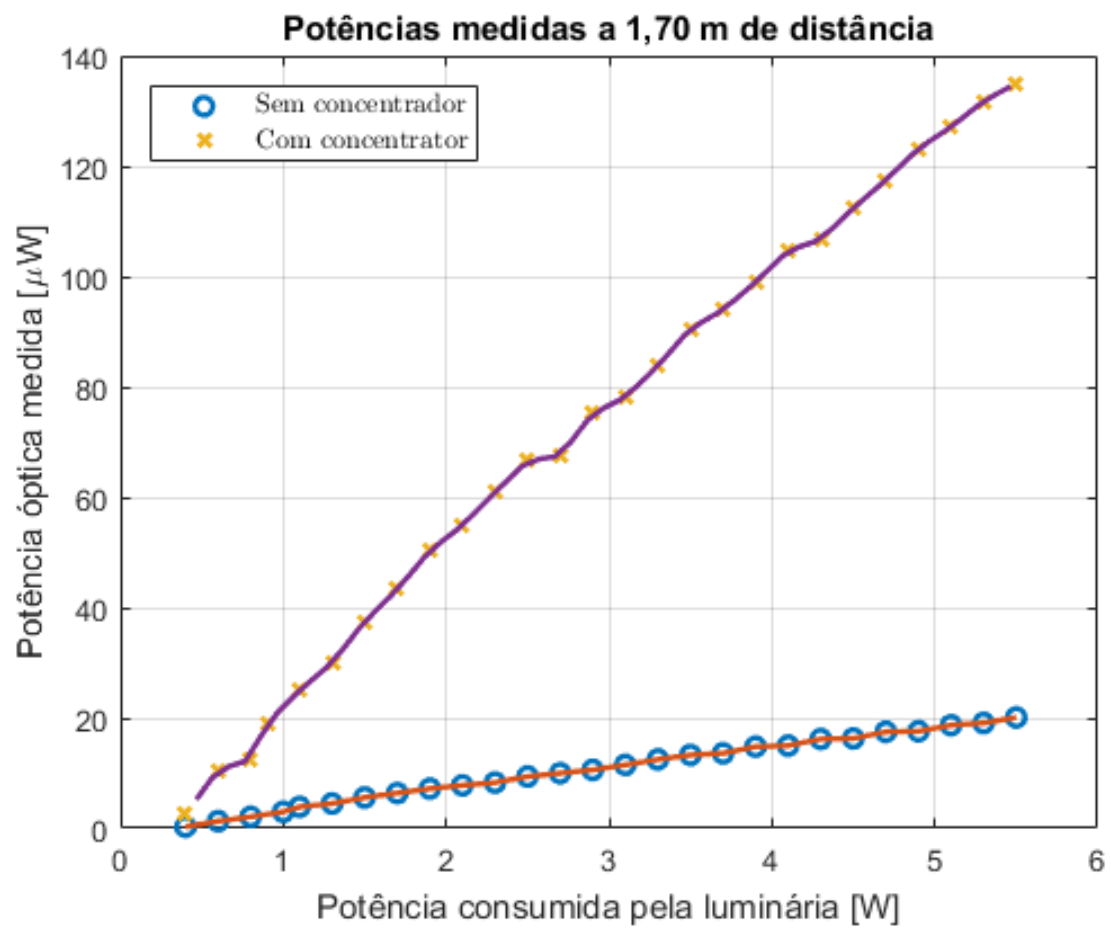

Fonte: Autoria própria. 


\section{Variação da distância entre o fotodetector e a luminária:}

Com o concentrador encaixado à luminária e o fotodiodo S121C alinhado ao eixo central da luminária, foi variada a distância entre os dispositivos. A distância mínima foi de $20 \mathrm{~cm}$ e a máxima de $1,0 \mathrm{~m}$, variando a cada $20 \mathrm{~cm}$ a distância, obtendo-se nese procedimento medidas para cinco diferentes potências consumidas pela luminária. Este procedimento é ilustrado pela Figura 42 e os resultados das medições são apresentados pela Figura 43.

Figura 42 - Procedimento para variação da distância durante a execução do experimento.

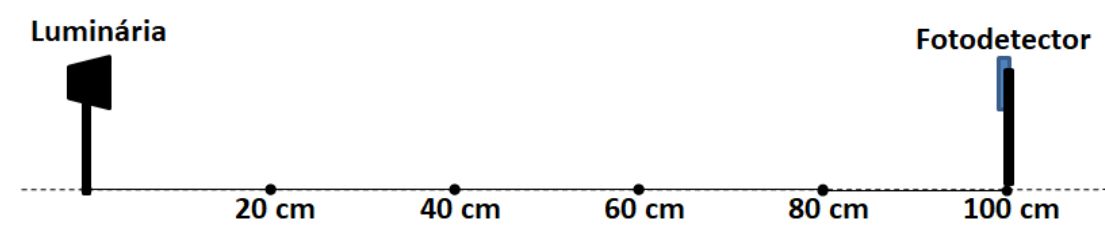

Fonte: Autoria própria.

Figura 43 - Potência medida no fotodetector em função da distância de afastamento em relação à luminária.

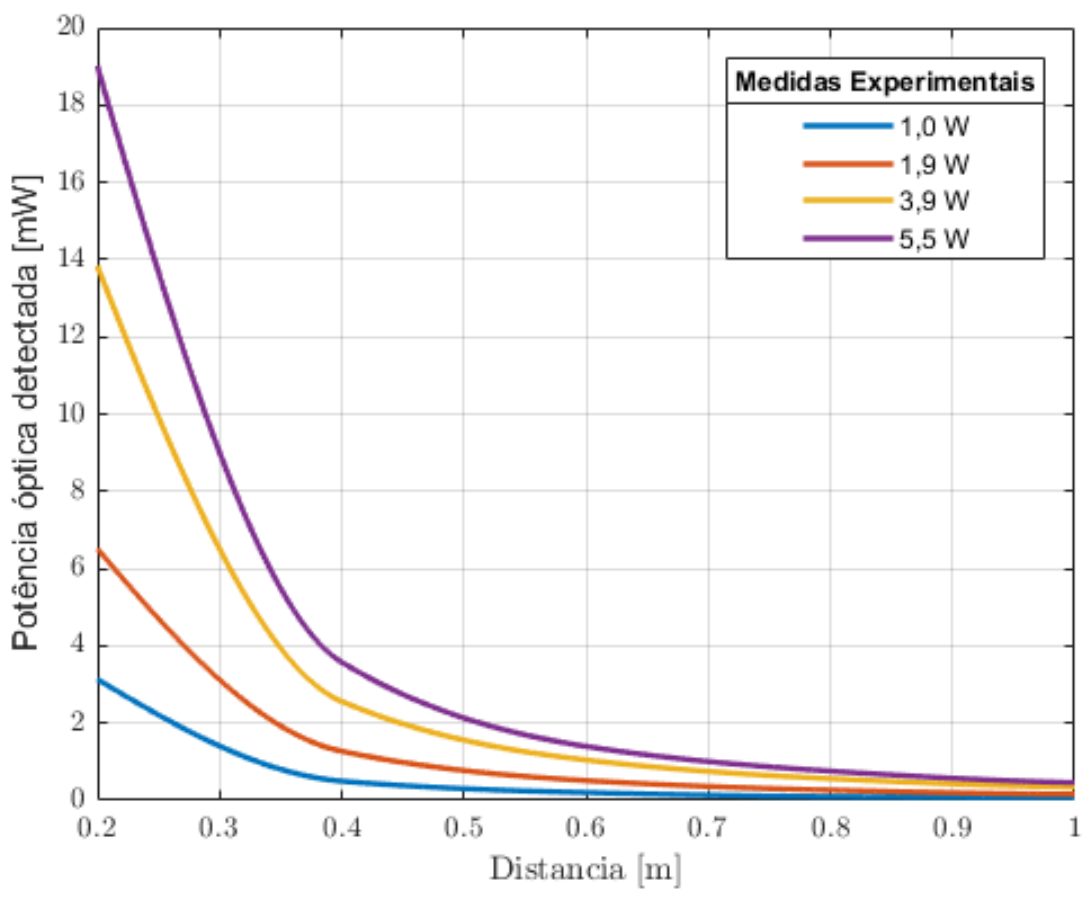

Fonte: Autoria própria. 


\section{Desalinhamento do fotodetector:}

O dispositivo fotodetector foi desalinhado lateralmente em relação ao eixo central da luminária em passos de $5 \mathrm{~cm}$ até atingir a distância de $45 \mathrm{~cm}$ do eixo de alinhamento, conforme ilustra a Figura 44. O ângulo de recepção do fotodetector não foi alterado, permanecendo com o mesmo apontamento em relação à horizontal.

A Figura 45 apresenta os resultados das potências ópticas medidas em função do deslocamento lateral. Verificou-se que, quando utilizado o concentrador óptico, a metade da potência ocorre quando o deslocamento lateral é de aproximadamente $15,30 \mathrm{~cm}$, ou seja, o ângulo de meia potência é de 8,7 . Desse modo, obtem-se pela Equação 24 a ordem lambertiana da emissão: $m=60$.

Nas medidas sem o concentrador não foi atingido o nível de meia potência óptica devido à limitação da mesa para realização do deslocamento lateral. No entanto, observou-se que, de acordo com a análise teórica, a ordem lambertiana $\mathrm{m}=6$ acomoda-se sobre os valores obtidos experimentalmente. Essa ordem equivale ao ângulo de meia potência de $27^{\circ}$.

Nessa medida também é possível verificar o ganho proporcionado pelo elemento concentrador que, no eixo central (axial), é de 8,59 dB.

Figura 44 - Desalinhamento lateral do fotodetector a cada $5 \mathrm{~cm}$ em relação ao eixo de alinhamento entre luminária e fotodetector.

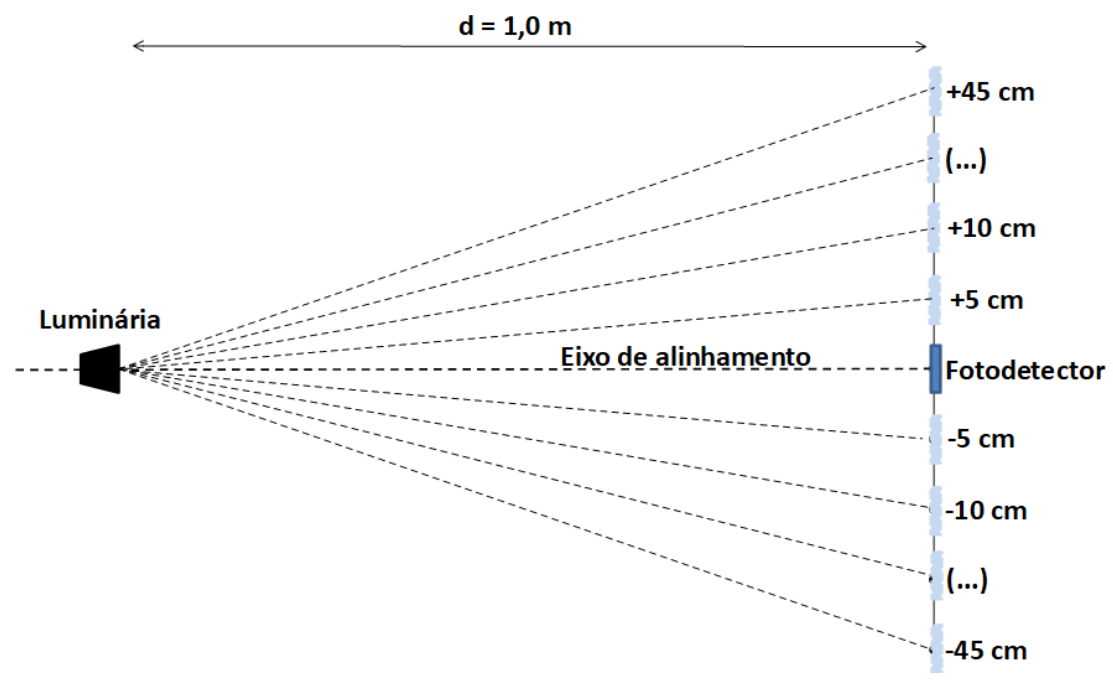

Fonte: Autoria própria. 
Figura 45 - Potência medida no fotodetector em função do desalinhamento lateral em relação ao eixo de alinhamento da luminária.

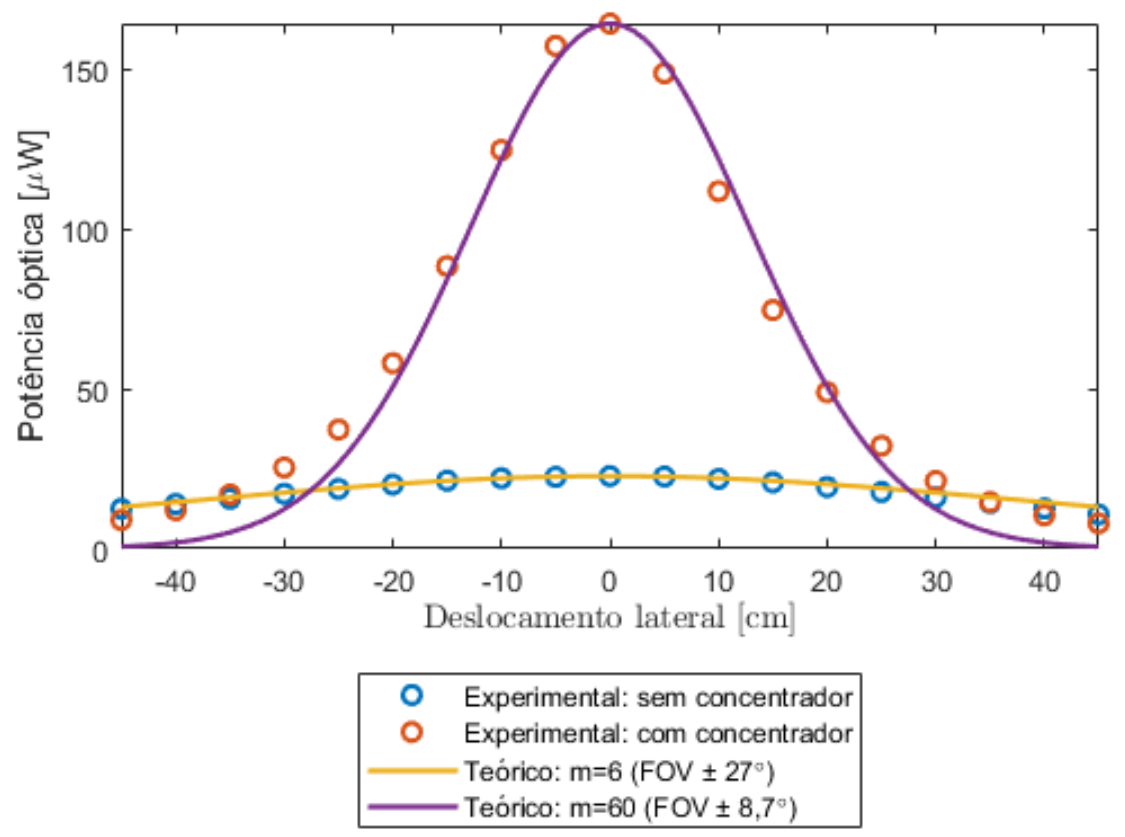

Fonte: Autoria própria.

\section{Distribuição da iluminância:}

Nessa medida foi realizada a distribuição da iluminância sobre uma superfície (parede) distante de 1,70 m, que é comum na configuração de iluminação de interiores, considerando a altura entre o teto e área de trabalho. Foi demarcada na parede uma área de $1 \times 1 \mathrm{~m}^{2}$, equivalente a uma atto-célula. Essa superfície foi subdividida em 16 partes, sendo tomadas 16 medidas no centro dessas subdivisões e uma no centro geométrico do quadrado, totalizando 17 pontos medidos pelo luxímetro (Figura 46).

Com as medidas realizadas pelos luxímetro foram obtidos locais de máxima Iluminância no ponto central de 248 lx e 689 lx, com 1,9 W e 5,5 W, respectivamente, sendo consumidos pela luminária. Os mínimos valores de Iluminância obtidos foram de 33 lx (1,9 W) e 106 lx (5,5 W) e estavam localizados nas bordas da superfície, subdivisões 01 e 13, respectivamente. Níveis de iluminância mínimo necessários para atendimento à Norma ABNT em áreas de trabalho de bibliotecas e escritórios (500 lx) são obtidos na parte central da superfície quadrada ao utilizar-se uma potência consumida de 5,5 W. Com esta mesma potência, a iluminância verificada nas bordas da superfície são superiores às mínimas necessárias para saguões de entrada (100 lx) e teatros e salas de concerto (200 lx). Com a potência consumida de 1,9 W os níveis de iluminância na parte central atendem os caso em que a superfície de trabalho necessite de, no mínimo, 100 lx. 
Figura 46 - Subdivisões da distribuição das medições de iluminância em uma superfície de $1 \mathbf{m}^{2}$.

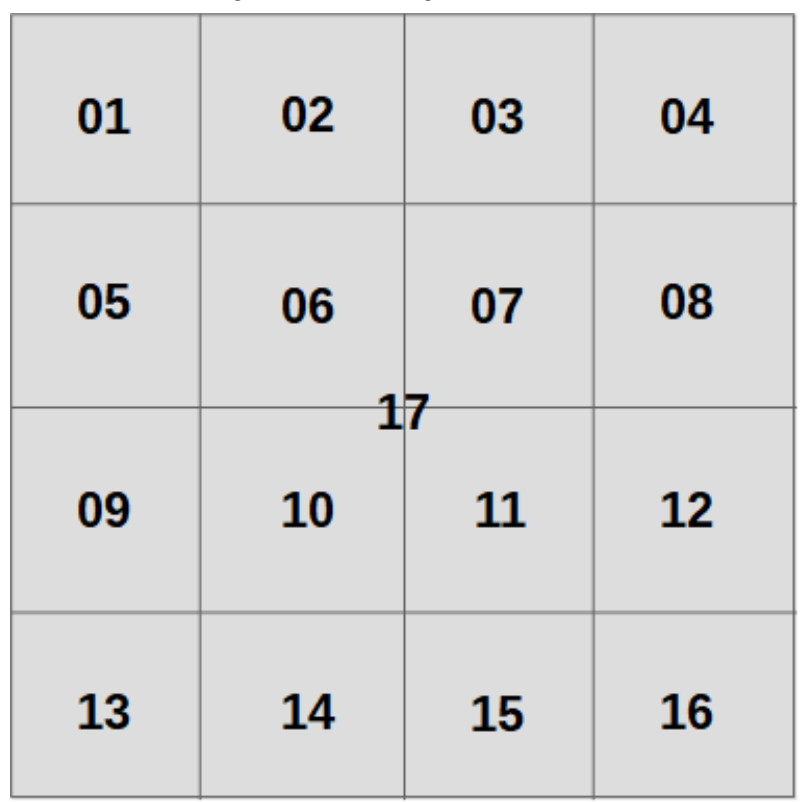

Fonte: Autoria própria.

Figura 47 - Distribuição das medições de iluminância em uma superfície de $1 \mathrm{~m}^{2}$. Nas figuras pode ser observada a concentração da iluminância na região central. As medidas foram realizadas com as potências consumidas pela luminária de $1,9 \mathrm{~W}$ e 5,5 W.
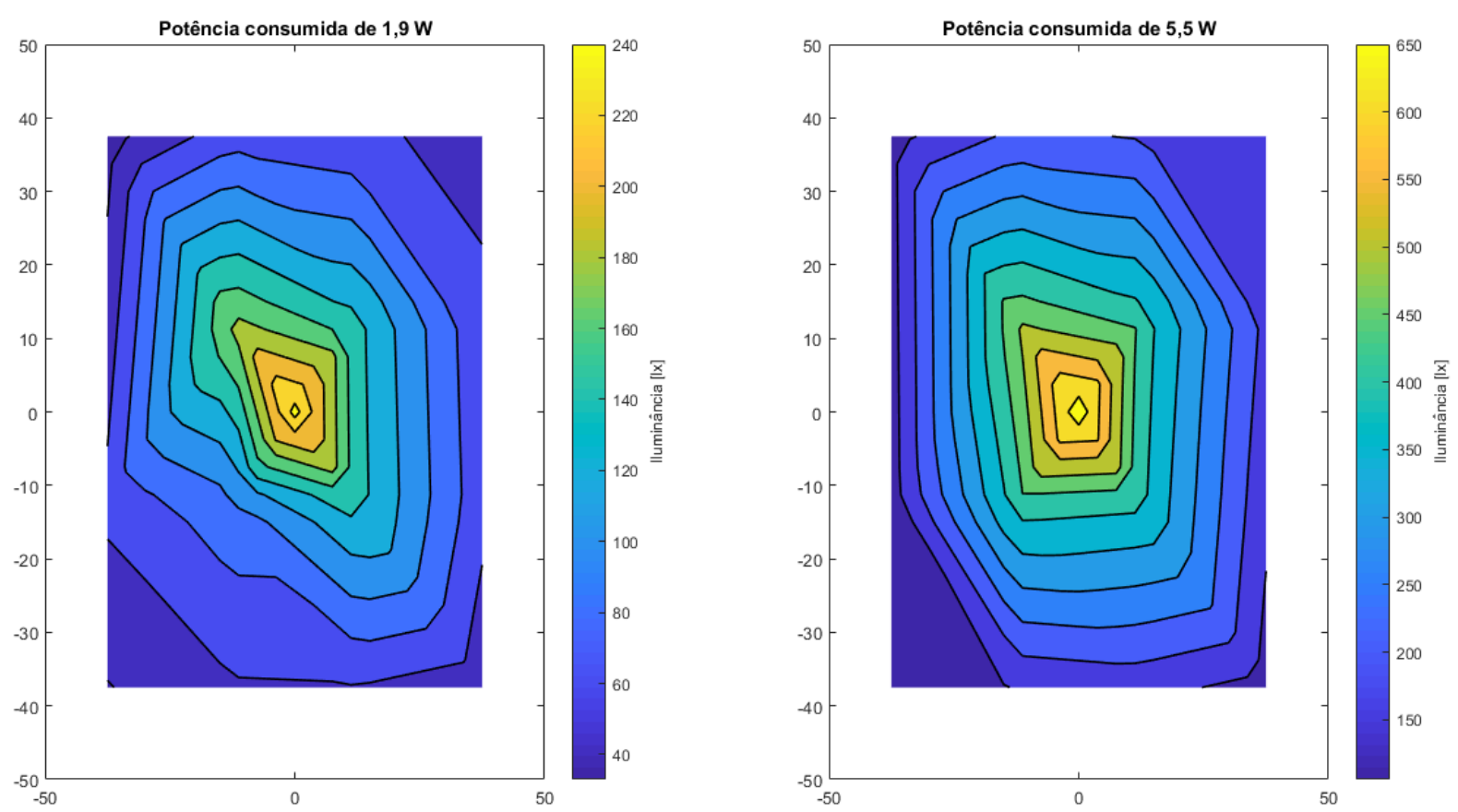

Fonte: Autoria própria. 


\section{RESULTADOS E DISCUSSÃO}

Como resultados das simulações foram realizadas avaliações de desempenho de comunicação em função dos valores medidos em laboratório e pelas simulações no APEX ${ }^{\circledR}$. As situações em análise devem considerar que: (a) os resultados experimentais são obtidos em função das potências elétricas consumidas pelos LEDs da luminária e as respectivas potências ópticas medidas pelo fotodiodo S121C. (b) os resultados das simulações do APEX ${ }^{\circledR}$, são obtidos em função dos fluxos radiométricos emitidos pelos LEDS da luminária, pré-ajustados no software, e as respectivas potências ópticas detectadas pela superfície sensora circular com 0,71 $\mathrm{cm}^{2}$ de área.

Além dos valores máximos de potência ajustados experimentalmente e nas simulações com o $\mathrm{APEX}^{\circledR}$, foram considerados valores intermediários, menores que os máximos, para estimativa de desempenho em condições de operação de baixa luminosidade emitida pela luminária.

No $\mathrm{APEX}^{\circledR}$ as superfícies que recebem o fluxo radiométrico funcionam como sensores. Foi, então, desenhada uma peça circular com área de $0,71 \mathrm{~cm}^{2}$ posicionada no eixo de alinhamento com a luminária para realização de medidas do fluxo radiométrico sobre esta superfície. Os sete LEDs foram calibrados no software para emissão total nas potências de 2,6 W e 736,05 $\mathrm{mW}$, sendo obtidos dois diferentes fluxos luminosos, 725,9 $\mathrm{lm}$ e 205,50 $\mathrm{lm}$, respectivamente. As medidas da potência óptica foram tomadas nas distâncias de $20 \mathrm{~cm}, 40 \mathrm{~cm}, 60 \mathrm{~cm}, 80 \mathrm{~cm}$ e 100 cm para a mesma superfície de $0,71 \mathrm{~cm}^{2}$. Em outra simulação, a superfície foi afastada a $1,70 \mathrm{~m}$ de distância, emulando o distanciamento típico entre mesas de trabalho e luminárias de teto.

De acordo com o resultado experimental dado pela curva apresentada na Figura 40, mesmo com a máxima potência de alimentação aplicada, os LEDs da luminária ainda se mantiveram na região de operação linear e, portanto, este nível também foi considerado para as estimativas da SNR. Para cálculo da SNR (Equação e 36), são considerados os fatores de ruído (Equações 33, 34 e 35), com os parâmetros descritos na Tabela 9.

As equações são retomadas aqui para melhor visualização da aplicação dos parâmetros da Tabela 9:

$$
N=\sigma_{\text {térmico }}^{2}+\sigma_{\text {balistico }}^{2}+\gamma^{2} P_{r I S I}^{2}
$$




$$
\begin{gathered}
\text { sigma }_{\text {térmico }}^{2}=\frac{8 \pi k T_{k}}{G} \eta_{c} A I_{2} B^{2}+\frac{16 \pi^{2} k T_{k} \Gamma}{g_{m}} \eta_{c}^{2} A^{2} I_{3} B^{3}, \\
\text { sigma }_{\text {balistico }}^{2}=2 q \gamma\left(P_{r \text { Sinal }}+P_{r I S I}\right) B+2 q I_{b g} I_{2} B \\
S N R=\frac{\gamma^{2} P_{r}^{2}}{N} .
\end{gathered}
$$

Tabela 9 - Parâmetros para cálculo da SNR

\begin{tabular}{ccc}
\hline Parâmetro & Símbolo & Valor \\
\hline Temperatura ambiente & $\mathrm{T}_{k}$ & $300 \mathrm{~K}$ \\
Ganho de malha aberta do circuito de fotodeteç̧ão & $\mathrm{G}$ & 10 \\
Capacitância fixa & $\eta_{c}$ & $12 \mathrm{pF} / \mathrm{cm}^{2}$ \\
Área efetiva do fotodiodo & $\mathrm{A}$ & $0,71 \mathrm{~cm}^{2}$ \\
Fator de ruído & $\mathrm{I}_{2}$ & 0,562 \\
Fator de ruído & $\mathrm{I}_{3}$ & 0,0868 \\
Fator de ruído equivalente & $\mathrm{B}$ & $100 \mathrm{MHz}$ \\
Fator de ruído do canal FET & $\Gamma$ & 1,5 \\
Transcondutância do FET & $\mathrm{g}_{m}$ & $30 \times 10^{-3} \mathrm{~S}$ \\
Carga do elétron & $\mathrm{q}$ & $1,602 \times 10^{-19} \mathrm{C}$ \\
Responsividade do fotodiodo & $\gamma$ & $0,54 \mathrm{~A} / \mathrm{W}$ \\
Interferência intersimbólica (100 Mbps) & $\mathrm{P}_{I S I}$ & $10 \mathrm{nW}$ \\
Fotocorrente devido à luz ambiente & $\mathrm{I}_{b g}$ & $5,1 \mathrm{~mA}$ \\
Ganho do filtro na recepção & $\mathrm{T}_{s}(\beta)$ & $0 \mathrm{~dB}(\mathrm{unitário})$ \\
Ganho da lente na recepção & $\mathrm{g}(\beta)$ & $3,82 \mathrm{~dB}$ \\
\hline
\end{tabular}

Fonte: Autoria própria.

Para possibilitar a comparação entre os resultados experimentais e os obtidos nas simulações , foi elaborada a Figura 48, na qual os níveis de emissão de potência dos LEDs da luminária são ajustados para o mesmo valor $(736,05 \mathrm{~mW})$. Verificou que, mesmo com o ajuste por meio de calibração da potência dos LEDs utilizados nas simulações, ainda há diferença entre os níveis obtidos experimentalmente com os simulados no APEX $^{\circledR}$ e calculados teoricamente. No entanto, a Figura 48 demonstra que os resultados experimentais e os simulados no APEX ${ }^{\circledR}$, apesar de apresentarem níveis diferentes, guardam uma correlação no comportamento da curva entre as distâncias de $0,2 \mathrm{~m}$ e $0,4 \mathrm{~m}$.

A razão dessa diferença entre os valores simulados e teóricos com os valores obtidos experimentalmente pode ser justificada por não ter sido considerada nas simulações a atenuação provocada pelo material utilizado no elemento concentrador (PCARB).

Considerando o comparativo entre os resultados experimentais e simulados, apresentados pela Figura 48, foi plotada a curva de estimativa da BER em função da SNR (Figura 49). Nesse caso, as distâncias variam entre 0,2 m e $1 \mathrm{~m}$ e, como a máxima distância considerada é de 
Figura 48 - Comparação entre resultados experimentais, simulados pelo APEX $^{\circledR}$ e teóricos.

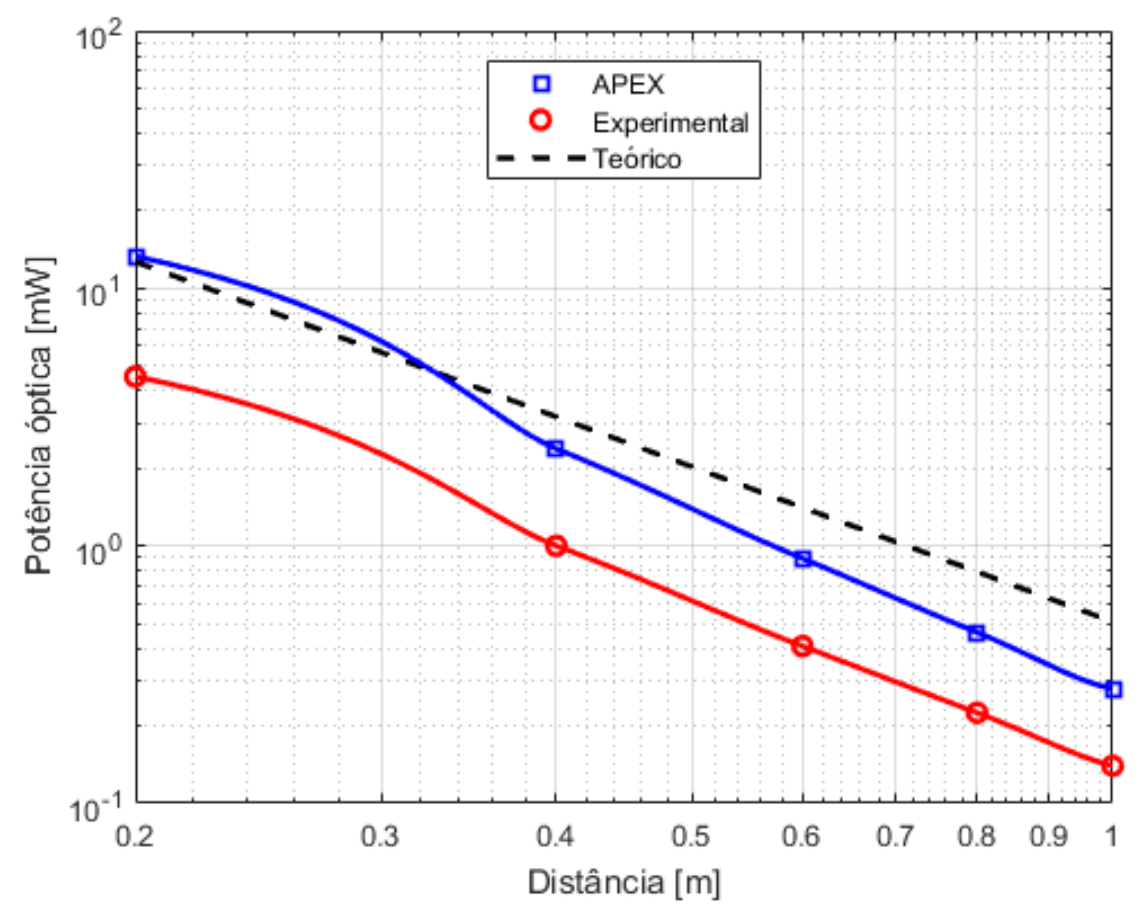

Fonte: Autoria própria.

$1 \mathrm{~m}$, este é o ponto que apresentará o pior desempenho na estimativa de BER, devido à menor SNR. As curvas teóricas são plotadas e servem de referência, pois iniciam justamente na máxima distância considerada, em que a SNR é de 8,75 dB. Observa-se que os resultados experimentais e simulados pelo APEX apresentam desempenhos de BER abaixo de $10^{-2}$ a partir de $1 \mathrm{~m}$ de distância, nessa condição de baixa luminosidade $(736,05 \mathrm{~mW})$.

Utilizando os resultados experimentais da potência óptica medida, foi estimada a SNR com e sem aplicação de ganhos de recepção. Ao ser considerado um ganho de 3,82 dB (2,41 vezes) atribuído a $\mathrm{g}(\beta))$, lente na recepção, há melhora significativa da $\mathrm{SNR}$, conforme pode ser verificado pela Figura 50, na qual as curvas tracejadas foram obtidas sem a aplicação de ganho na recepção $(\mathrm{g}(\beta)=0 \mathrm{~dB})$. Os parâmetros para o cálculo do ruído são os apresentados na Tabela 9, onde o fator de ruído dominante nesses cálculos foi a interferência intersimbólica. Nela também são plotados dois resultados das simulações do $\mathrm{APEX}^{\circledR}$, nos quais a estimação da BER é mais otimista. Nesta simulação, as estimativas de SNR para as medidas experimentais considera as potências elétricas consumidas pelos LEDs da luminária em quatro situações diferentes: 1,0 $\mathrm{W}, 1,9 \mathrm{~W}, 3,9 \mathrm{~W}$ e 5,5 W. As estimativas referentes às simulações do APEX consideram dois diferentes ajustes de $\Phi_{e}$ emitidos pelos LEDs da luminária: (i) 2,6 W (725,90 lm) e (ii) 0,736 W $(205,5 \mathrm{~lm})$. 
Figura 49 - Estimativas de SNR e BER para diferentes modulações, na condição de baixa luminosidade $(205,50 \mathrm{~lm})$.

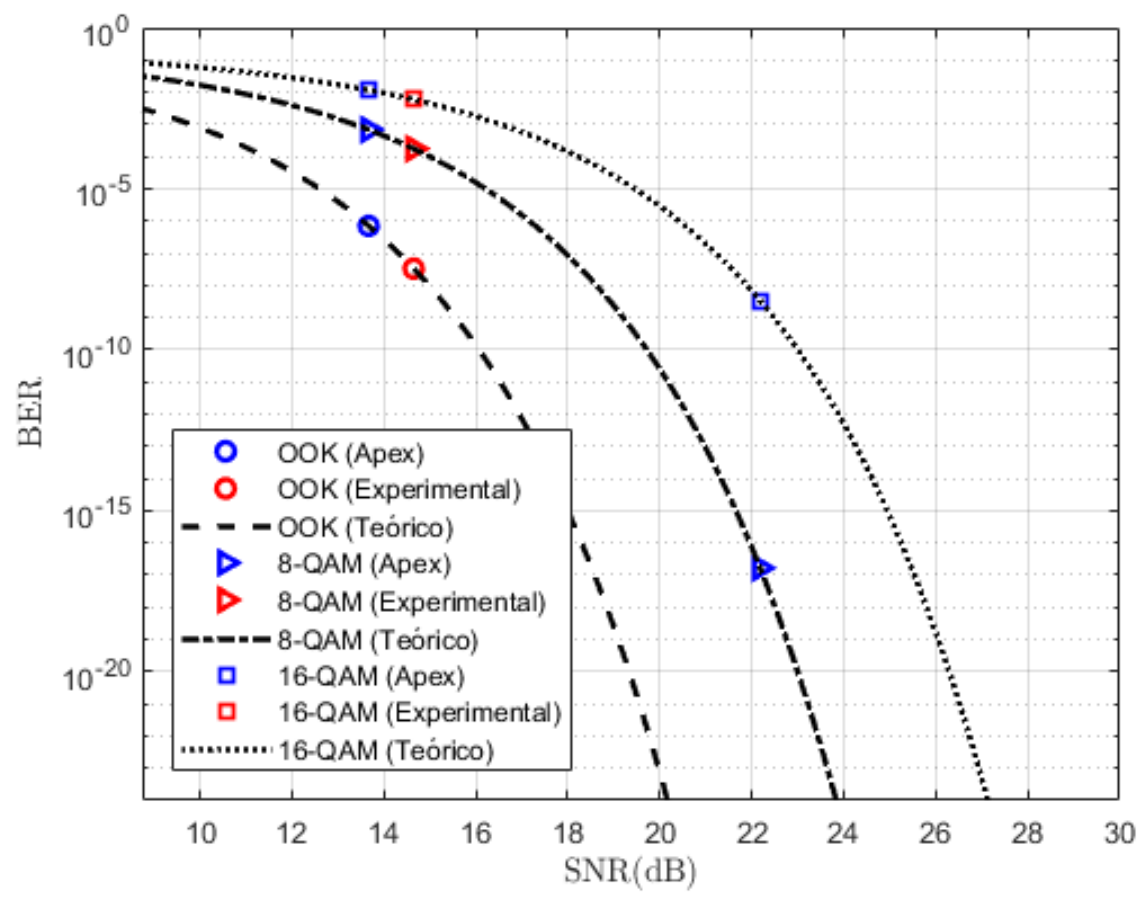

Fonte: Autoria própria.

Figura 50 - Variação da SNR em função da distância. As linhas tracejadas demonstram a SNR sem a aplicação de ganho na recepção. Os resultados experimentais consideram as potências elétricas consumidas pela luminária.

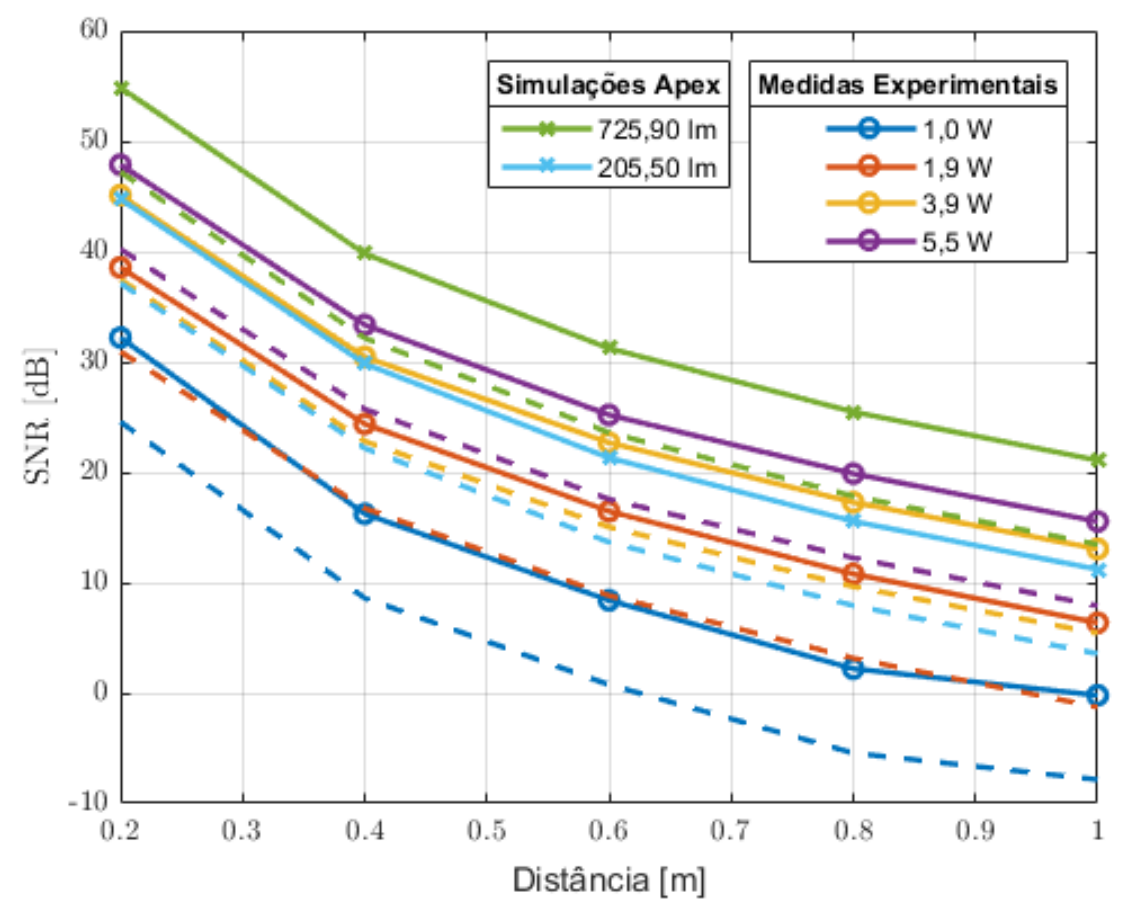

Fonte: Autoria própria. 
A Figura 51 apresenta o desempenho das modulações OOK, 8-QAM e 16-QAM em função do desalinhamento lateral entre os dispositivos ( $1 \mathrm{~m}$ de distância e consumo de 1,9 W). A inclusão do elemento concentrador permite a obtenção de BER próximas a $10^{-2}$ para a modulação OOK, que não são alcançadas sem ele. Nesse caso, também há aplicação de ganho de 3,82 dB na recepção $(g(\beta))$.

Figura 51 - Variação da BER para as modulações OOK e M-QAM devido ao desalinhamento lateral do fotodiodo em relação à luminária distante $1 \mathrm{~m}$ quando alinhada ao eixo central $(\mathrm{g}(\beta)=3,82 \mathrm{~dB})$.

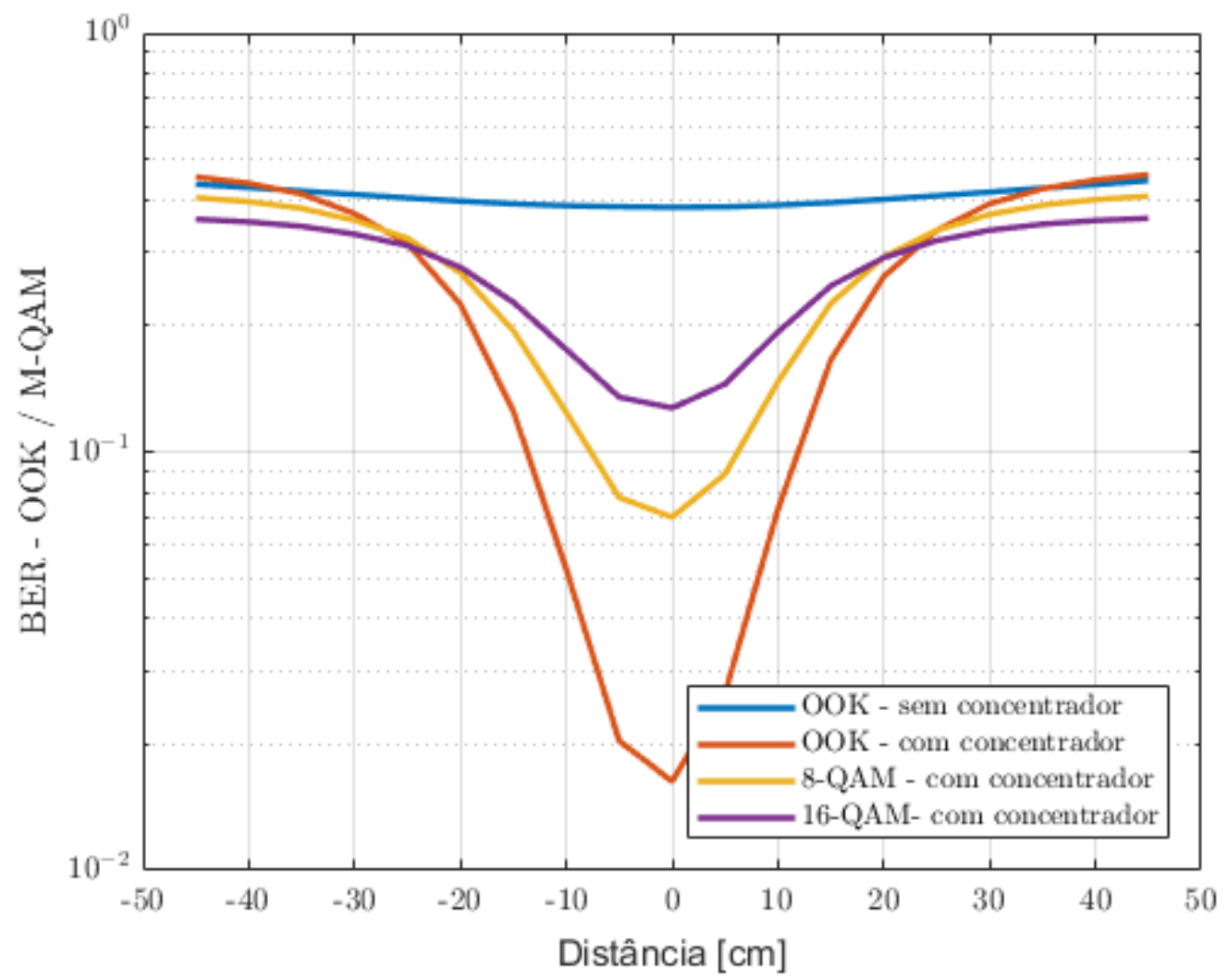

Fonte: Autoria própria. 
Para a análise de desempenho de comunicação na área de trabalho distante 1,70 m, foram utilizadas as simulações com o $\mathrm{APEX}^{\circledR}$ para estimar o fluxo radiométrico em uma área de detecção de $0,71 \mathrm{~cm}^{2}$, em quatro diferentes situações:

(i) PCARB / $\mathrm{r}=80 \%$. LEDs calibrados para emissão de: $\Phi_{e}=736,05 \mathrm{~mW}\left(\Phi_{v}=205,50 \mathrm{~lm}\right)$ luminosidade reduzida.

(ii) PCARB / $\mathrm{r}=80 \%$. LEDs calibrados para emissão de: $\Phi_{e}=2,6 \mathrm{~W}\left(\Phi_{v}=725,90 \mathrm{~lm}\right)$.

(iii) PCARB / $\mathrm{r}=95 \%$. LEDs calibrados para emissão de: $\Phi_{e}=2,6 \mathrm{~W}\left(\Phi_{v}=725,90 \mathrm{~lm}\right)$.

(iv) PMMA / r $=80 \%$. LEDs calibrados para emissão de: $\Phi_{e}=2,6 \mathrm{~W}\left(\Phi_{v}=725,90 \mathrm{~lm}\right)$.

Para efeitos de comparação entre os resultados das simulações com o APEX ${ }^{\circledR}$, foram considerados os resultados das medidas experimentais de potência óptica recebida quando a luminária consumia 1,9 W e 5,5 W, realizadas, também, a 1,70 m de distância e considerando o uso do concentrador na luminária:

(v) Potência óptica medida de 50,3 $\mu \mathrm{W}$. Potência elétrica consumida pela luminária de 1,9 W.

(vi) Potência óptica medida de $135 \mu \mathrm{W}$. Potência elétrica consumida pela luminária de 5,5 W.

Os resultados das estimativas de BER são apresentados pelas Tabelas 10 e 11, e, comparado-as, verificas-e que sem a inclusão de ganho na recepção as performances de BER para as modulações OOK e M-QAM são piores que a ordem de $10^{-3}$. Contudo, ao considerar-se um ganho para o front - end na recepção, são obtidas performances de BER melhores que $10^{-3}$ para a modulação OOK nos casos ii, iii e iv.

Tabela 10 - Estimativas de SNR e BER para diferentes modulações com superfície sensora alinhada à luminária e distante de $1,70 \mathrm{~m}$ ( $\operatorname{sem}$ ganho na recepção - $\mathrm{g}(\beta)=0 \mathrm{~dB}$ ).

\begin{tabular}{cccccc}
\hline Condição & $\Phi_{e}(\mathrm{~W})$ & SNR $(\mathrm{dB})$ & BER OOK & BER 8-QAM & BER 16-QAM \\
\hline i & $85,81 \mu$ & $-6,68$ & $32,15 \times 10^{-2}$ & $32,82 \times 10^{-2}$ & $31,34 \times 10^{-2}$ \\
ii & $303,10 \mu$ & 4,28 & $5,08 \times 10^{-2}$ & $12,24 \times 10^{-2}$ & $17,41 \times 10^{-2}$ \\
iii & $318,50 \mu$ & 4,71 & $4,29 \times 10^{-2}$ & $11,24 \times 10^{-2}$ & $16,59 \times 10^{-2}$ \\
iv & $306,80 \mu$ & 4,38 & $4,88 \times 10^{-2}$ & $11,99 \times 10^{-2}$ & $17,20 \times 10^{-2}$ \\
\hline v & $50,30 \mu$ & $-11,32$ & $39,30 \times 10^{-2}$ & $37,01 \times 10^{-2}$ & $33,87 \times 10^{-2}$ \\
vi & $135,00 \mu$ & $-2,75$ & $23,30 \times 10^{-2}$ & $27,29 \times 10^{-2}$ & $27,92 \times 10^{-2}$ \\
\hline
\end{tabular}

Fonte: Autoria própria.

A mesma estimativa de SNR e BER foi realizada para os resultados da simulação disponíveis na Tabela 8 , e, para cada superfície sensora de $0,71 \mathrm{~cm}^{2}$, foi considerado um ganho de 3,82 dB na recepção. 
Tabela 11 - Estimativas de SNR e BER para diferentes modulações com superfície sensora alinhada à luminária e distante de $1,70 \mathrm{~m}$ (com ganho na recepção - $\mathbf{g}(\beta)=\mathbf{3 , 8 2} \mathrm{dB})$.

\begin{tabular}{cccccc}
\hline Condição & $\Phi_{e}(\mathrm{~W})$ & SNR $(\mathrm{dB})$ & BER OOK & BER 8-QAM & BER 16-QAM \\
\hline i & $85,81 \mu$ & 0,96 & $13,21 \times 10^{-2}$ & $20,03 \times 10^{-2}$ & $23,16 \times 10^{-2}$ \\
ii & $303,10 \mu$ & 11,92 & $4,00 \times 10^{-5}$ & $4,20 \times 10^{-3}$ & $29,20 \times 10^{-3}$ \\
iii & $318,50 \mu$ & 12,34 & $1,73 \times 10^{-5}$ & $2,90 \times 10^{-3}$ & $24,00 \times 10^{-3}$ \\
iv & $306,80 \mu$ & 12,02 & $3,27 \times 10^{-5}$ & $3,90 \times 10^{-3}$ & $27,80 \times 10^{-3}$ \\
\hline v & $50,30 \mu$ & -3.68 & $25,64 \times 10^{-2}$ & $28,80 \times 10^{-2}$ & $28,86 \times 10^{-2}$ \\
vi & $135,00 \mu$ & 4,89 & $3,95 \times 10^{-2}$ & $10,78 \times 10^{-2}$ & $16,20 \times 10^{-2}$ \\
\hline
\end{tabular}

Fonte: Autoria própria.

Tabela 12 - Estimativas de SNR e BER para diferentes modulações com superfícies sensoras de $0,71 \mathbf{c m}^{2}$ distribuídas na sala (com ganho na recepção - $\mathbf{g}(\beta)=\mathbf{3 , 8 2} \mathrm{dB}$ ).

\begin{tabular}{cccccc}
\hline Mesa & $\Phi_{e}(\mathrm{~W})$ & SNR $(\mathrm{dB})$ & BER OOK & BER 8-QAM & BER 16-QAM \\
\hline A & $14,96 \mu$ & $-14,21$ & $42,28 \times 10^{-2}$ & $38,73 \times 10^{-2}$ & $34,90 \times 10^{-2}$ \\
B & $11,34 \mu$ & $-16,62$ & $44,13 \times 10^{-2}$ & $39,78 \times 10^{-2}$ & $35,53 \times 10^{-2}$ \\
C & $339,80 \mu$ & 12,92 & $4,89 \times 10^{-6}$ & $1,60 \times 10^{-3}$ & $18,00 \times 10^{-3}$ \\
D & $13,93 \mu$ & -14.83 & $42,81 \times 10^{-2}$ & $39,03 \times 10^{-2}$ & $35,08 \times 10^{-2}$ \\
\hline
\end{tabular}

Fonte: Autoria própria.

Quanto aos requisitos para iluminação, para uma área de trabalho quadrada de $1 \mathrm{~m}^{2}$, a luminária que foi objeto de estudo permite a obtenção de iluminâncias mínimas de 106 lx obtidos nos experimentos de laboratório enquanto a luminária consumia $5,5 \mathrm{~W}$ de potência elétrica. Nas simulações realizadas no APEX $^{\circledR}$ a iluminância mínima obtida foi de 80,23 lx quando o fluxo luminoso calibrado no software era de 725,90 $\mathrm{lm}$ (2,6 W radiados). Considerando os níveis mínimos necessários para uma área de leitura (500lx), verifica-se que não são acançados os níveis mínimos nas bordas, devido ao efeito de concentração do feixe de luz no centro da área de trabalho, onde os níveis de iluminância atendem aos requisitos da Norma ABNT, conforme os 689 lx obtidos experimentalmenmte e 1351,59 lx obtidos nas simulações. Contudo, em um saguão de entrada, no qual a iluminância mantida deve ser de, no mínimo 100 lx, essa configuração de luminária atenderia os requisitos da norma, desde que realizada a distribuição dos pontos de luz na região a ser iluminada.

Nas simulações do $\mathrm{APEX}^{\circledR}$ pôde ser verificada a possibilidade de otimização dos projetos de luminotécnica associados às necessidades de análise de projetos de comunicação VLC. Criando cenários e situações para análise das condiçoes de iluminação de determinadas áreas de trabalho e dispondo de elementos sensores ao longo do ambiente para estimação da SNR e, consequentemente, das BER associadas às variadas técnicas de modulação empregadas nos projetos. 


\section{CONCLUSÕES E PERSPECTIVAS}

A busca por reprodução de sistemas mais realistas nas simulações de estudo de canal e de desempenho para os sistemas VLC são necessárias, não só para melhor entendimento das suas características, mas, também, para a verificação das dificuldades que devem ser suplantadas em projetos de cobertura desses sistemas.

Os Softwares SolidWorks ${ }^{\circledR}$ e APEX ${ }^{\circledR}$ demonstraram possibilidade de aplicação prática na montagem e análise de cenários na caracterização de desempenho de comunicações VLC, desde que observadas as variantes de natureza elétrica dos elementos transmissores e receptores, além de características ópticas dos materiais empregados.

A necessidade de uso de um LED diferente do utilizado no experimento devido à limitação da biblioteca do $\mathrm{APEX}^{\circledR}$, que no início foi um ponto de dificuldade, tornou-se fator importante para o aprendizado nos ajustes das características dos emissores nas simulações. As comparações indicam a necessidade de ser observada a calibração de potência dos LEDs para aplicação em sistemas práticos.

Observa-se, no entanto, que a execução do traçado de raios introduz custo de processamento computacional que não deve ser desprezado. Uma simulação mais complexa como a do cenário com múltiplas luminárias levou cerca de 48 horas para ser executado com a configuração de hardware disponível no computador do LATE. Não obstante, as simulações de cenários mais complexos apresentaram falhas sucessivas durante a geração de raios e aquisição de resultados. Portanto, realizar ajustes dos modelos estatíscos sem prejudicar a acurácia das simulações é fator central para aplicação em estudos de predição.

Os resultados ressaltam a importância do detalhamento das características ópticas dos materiais empregados nas simulações, bem como a necessidade de calibração de potência dos LEDs. Nas simulações realizadas a 1,70 m de distância foram obtidos níveis de iluminância de até 1351,59 lx e estimativas de BER de: $4,88 \times 10^{-2}$ (OOK); $11,99 \times 10^{-2}(8-\mathrm{QAM})$; e $17,20 \times 10^{-2}$ (16-QAM). Considerando um ganho de 3,82 dB no front - end de recepção, as estimativas de BER melhoram para: $3,27 \times 10^{-5}(\mathrm{OOK}) ; 3,90 \times 10^{-3}$ (8-QAM); e $27,80 \times 10^{-3}$ (16-QAM).

Experimentalmente foi alcançado ganho de até 8,59 dB na transmissão com o uso do concentrador óptico. Por outro lado, a concentração do feixe de luz limita a distribuição da iluminância, devendo ser avaliados os ângulos de meia potência dos elementos concentradores de luz, para melhor aproveitamento das soluções em comunicação VLC aplicadas a projetos de 
luminotécnica.

Nos experimentos ficou evidente a influência da iluminação do ambiente nas medidas de níves de recepção do fotodiodo. Para redução dessa influência deve ser considerada a aplicação de filtros ópticos ou outras técnicas de processamento eletrônico dos sinais na recepção. No caso de uso de luminárias com LEDs brancos à base de fósforo, o uso de filtros passa-faixa operando no comprimento de onda de emissão da cor azul, também pode ser considerado para mitigar os efeitos das componentes lentas da fosforecência.

O estudo de materiais e geometrias dos projetos de luminárias permitem a abertura de novos horizontes nessa área objetivando a associação dos mais diversos projetos de iluminação com sistemas de comunicação VLC.

Como perspectivas para trabalhos futuros, nas simulações com o APEX ${ }^{\circledR}$ devem ser abordadas com maior detalhamento as características ópticas dos materiais empregados na composição de peças utilizadas na montagem da luminária. Outro fator a ser considerado é a inclusão de lentes para concentração do fluxo radiométrico nos sensores da recepção. A criação de cenários mais complexos, contendo obstruções para estudos da propagação da luz sem linha de visada, podem ser avaliados para aplicação em estudos de repetidores ópticos.

O ambiente externo também pode ser considerado em estudos futuros de luminárias utilizadas em vias públicas para comunicação VLC outdoor.

As medidas de laboratório permitem a avaliação quanto aos limiares de detecção que devem ser consideramos em sistemas de recepção para VLC. Os estudos aqui apresentados podem contribuir para o desenvolvimento de circuitos receptores. Certamente, a ampliação dos ensaios de laboratório com uso de modulação são imprescindíveis no avanço desses estudos. 


\section{REFERÊNCIAS}

ABNT. NBR ISO/CIE 8995-1:2013: Iluminação de ambientes de trabalho parte 1: Interior. Rio de Janeiro, 2013.

ANATEL. Resolução no 680, de 27 de junho de 2017. 2017.

ANATEL. Resolução n⿳ 715, de 23 de outubro de 2019. 2019.

ANATEL. Acessos Telefonia Móvel. 2020. Https://www.anatel.gov.br/paineis/acessos/telefoniamovel. Acessado em 22/03/2020.

ANATEL. Radiofrequência. 2020. Acessado em 05/07/2020. Disponível em: www.anatel.gov. br/setorregulado/coordenacao-nacional.

BAO, X; et al. Li-fi: Light fidelity-a survey. Wireless Networks (10220038). 21, 6, 1879-1889, Aug. 2015. ISSN: 10220038., 2015.

BELL, Alexander Graham. The photophone. Science, American Association for the Advancement of Science, os-1, n. 12, p. 130-134, 1880. ISSN 0036-8075. Disponível em: https://science.sciencemag.org/content/os-1/12/130.

BREAULT. 2016. APEX Help - Breault Research Organization.

BREAULT. APEX Features. 2020. Acessado em 10/08/2020. Disponível em: http: //www.breault.com/software/apex-features.

BRO. The ASAP Primer: A basic course of study of asap software, the most powerful set of tools for optical analysis. Tucson, AZ, 2006.

BRO. ASAP Technical Guide: Radiometric analysis. Tucson, AZ, 2007.

BURTON, Andrew; HAIGH, Paul Anthony; CHVOJKA, Petr; GHASSEMLOOY, Zabih; ZVáNOVEC, Stanislav. Filter-less wdm for visible light communications using colored pulse amplitude modulation. Opt. Lett., OSA, v. 44, n. 19, p. 4849-4852, Oct 2019. Disponível em: http://ol.osa.org/abstract.cfm?URI=ol-44-19-4849.

CARRUTHER, J. B.; KAHN, J. M. Angle diversity for nondirected wireless infrared communication. IEEE Transactions on Communications, v. 48, n. 6, p. 960-969, 2000. 
CARVALHO, Luiz Pinto de. Introdução a sistemas de telecomunicações: abordagem histórica. $1^{\text {a }}$. ed. Rio de Janeiro: LTC, 2014.

CELIK, Yasin; ÇOLAK, Sultan Aldırmaz. Quadrature spatial modulation sub-carrier intensity modulation (qsm-sim) for vlc. Physical Communication, v. 38, 2020.

CHEN, C.; IJAZ, M.; TSONEV, D.; HAAS, H. Analysis of downlink transmission in dco-ofdm-based optical attocell networks. p. 2072-2077, 2014.

CHOWDHURY H., Pouttu A. \& Katz M. Performance analysis of visible light communicationsbased hotspots in indoor and outdoor environments. Wireless Pers Commun (2017) 93: 755. 2017. Disponível em: https://doi.org/10.1007/s11277-014-2226-9.

DIMITROV, Svilen; HAAS, Harald. Principles of LED Light Communications. $1^{\text {a }}$. ed. [S.l.]: Cambridge University Press, 2015.

FERREIRA, R. X. G.; XIE, E.; MCKENDRY, J. J. D.; RAJBHANDARI, S.; CHUN, H.; FAULKNER, G.; WATSON, S.; KELLY, A. E.; GU, E.; PENTY, R. V.; WHITE, I. H.; O'BRIEN, D. C.; DAWSON, M. D. High bandwidth gan-based micro-leds for multi-gb/s visible light communications. IEEE Photonics Technology Letters, v. 28, n. 19, p. 2023-2026, Oct 2016. ISSN 1941-0174.

GFELLER, F. R.; BAPST, U. Wireless in-house data communication via diffuse infrared radiation. Proceedings of the IEEE, v. 67, n. 11, p. 1474-1486, 1979.

GHASSEMLOOY, Z.; POPOOLA, W.; RAJBHANDARI, S. Optical Wireless Communications - System and Channel Modelling with MATLAB ${ }^{\circledR}$. Boca Raton, FL: CRC Press - Taylor Francis Group, 2013.

GOLDSMITH, Andrea. WIRELESS COMMUNICATIONS. Stanford University: Cambridge University Press, 2005.

GUERRINI, Délio Pereira. Iluminação - Teoria e Projeto. 2a . ed. São Paulo: Érica, 2008.

GUO, Yujian; ALKHAZRAGI, Omar; KANG, Chun Hong; SHEN, Chao; MAO, Yuan; SUN, Xiaobin; NG, Tien Khee; OOI, Boon S. A tutorial on laser-based lighting and visible light communications: device and technology. Chin. Opt. Lett., OSA, v. 17, n. 4, p. 040601, Apr 2019. Disponível em: http://col.osa.org/abstract.cfm?URI=col-17-4-040601.

HAAS HARALD ; YIN, Liang ; Wang Yunlu ; Chen Cheng. What is lifi? Journal of Lightwave Technology, March15, 2016, Vol.34(6), pp.1533-1544, 2016. 
IEEE. 802.15.7-2011. Part 15.7: Short-Range Wireless Optical Communication Using Visible Light. 2011.

IEEE. 802.15.7-2018. Part 15.7: Short-Range Optical Wireless Communications. 2018.

KARP S. ; O’NEILL, E.L. ; Gagliardi R.M. Communication theory for the free-space optical channel. Proceedings of the IEEE, Oct. 1970, Vol.58(10), pp.1611-1626, 1970.

KARUNATILAKA, Dilukshan; ZAFAR, Fahad; KALAVALLY, Vineetha; PARTHIBAN, Rajendran. Led based indoor visible light communications: State of the art. IEEE Communications Surveys Tutorials, v. 17, p. 1649-1678, 2015.

KHALID, Amir Masood; COSSU, Giulio; CORSINI, Raffaele; CHOUDHURY, Pallab; CIARAMELLA, Ernesto. 1-Gb/s Transmission Over a Phosphorescent White LED by Using Rate-Adaptive Discrete Multitone Modulation. IEEE Photonics Journal, IEEE, v. 4, n. 5, p. 1465-1473, 10 2012. ISSN 1943-0655.

KOMINE, T.; NAKAGAWA, M. Fundamental analysis for visible-light communication system using led lights. IEEE Transactions on Consumer Electronics, v. 50, n. 1, p. 100-107, Feb 2004. ISSN 1558-4127.

LEE, K.; PARK, H.; BARRY, J. R. Indoor channel characteristics for visible light communications. IEEE Communications Letters, v. 15, n. 2, p. 217-219, February 2011. ISSN 2373-7891.

LICHTENEGGER, F.; LEINER, C.; SOMMER, C.; WEISS, A. P.; WENZL, F. P. Ray-tracing based channel modeling for the simulation of the performance of visible light communication in an indoor environment. In: 2019 Second Balkan Junior Conference on Lighting (Balkan Light Junior). [S.l.: s.n.], 2019. p. 1-6.

MCCLUNEY, William Ross. Introduction to Radiometry and Photometry. 2nd. ed. Boston: Artech House, 2014.

MIRAMIRKHANI, F.; UYSAL, M. Channel modeling and characterization for visible light communications. IEEE Photonics Journal, v. 7, n. 6, p. 1-16, 2015.

NARMANLIOGLU, O.; KIZILIRMAK, R. C.; MIRAMIRKHANI, F.; UYSAL, M. Cooperative visible light communications with full-duplex relaying. IEEE Photonics Journal, v. 9, n. 3, p. 1-11, June 2017. ISSN 1943-0647.

NASA. Atmospheric electromagnetic transmittance or opacity. 2007.

Https://pt.wikipedia.org/wiki/Ficheiro:Atmosphericelectromagnetictransmittanceoropacity.jpg. Acessado em 16/08/2020. 
PATHAK PARTH H. ; FENG, Xiaotao ; Hu Pengfei ; Mohapatra Prasant. Visible light communication, networking, and sensing: A survey, potential and challenges. IEEE Communications Surveys \& Tutorials, Fourthquarter 2015, Vol.17(4), pp.2047-2077, 2015.

PETERSON, Gary L. Stray light calculation methods with optical ray trace software. Part of the SPIE Conference on Optical Design and Analysis Software, v. 3780, 1999.

PHILIPS LUMILEDS LIGHTING COMPANY. LUXEON® Rebel Illumination Portfolio. [S.l.], 2009. LUXEON Rebel ANSI Binned Datasheet DS63.

PRäKEL, David. Iluminação. 2a . ed. Porto Alegre: Grupo A, 2015.

RIBEIRO, José Antônio Justino. Comunicações Ópticas. 2a . ed. São Paulo: Érica, 2006.

SADIKU, Matthew N. O. Elementos de Eletromagnetismo. 3a . ed. [S.l.]: Bookman, 2000.

SALEH, Bahaa E. A.; TEICH, Malvin Carl. Fundamentals of Photonics. 2a . ed. New York: Wiley, 2007.

SARBAZI, E.; UYSAL, M.; ABDALLAH, M.; QARAQE, K. Ray tracing based channel modeling for visible light communications. In: 2014 22nd Signal Processing and

Communications Applications Conference (SIU). [S.l.: s.n.], 2014. p. 702-705.

SHI, L.; LI, W.; ZHANG, X.; ZHANG, Y.; CHEN, G.; VLADIMIRESCU, A. Experimental 5g new radio integration with vlc. In: 2018 25th IEEE International Conference on Electronics, Circuits and Systems (ICECS). [S.l.: s.n.], 2018. p. 61-64.

STEVENSON, Michael. Optical software: which program is right for me? 2006.

TANAKA, Y.; HARUYAMA, S.; NAKAGAWA, M. Wireless optical transmissions with white colored led for wireless home links. In: 11th IEEE International Symposium on Personal Indoor and Mobile Radio Communications. PIMRC 2000. Proceedings (Cat. No.00TH8525). [S.l.: s.n.], 2000. v. 2, p. 1325-1329 vol.2.

TANAKA, Yuichi; KOMINE, Toshihiko; HARUYAMA, Shinichiro; NAKAGAWA, Masao. Indoor visible light data transmission system utilizing white led lights. IEICE Transactions on Communications, v. 86, p. 2440-2454, 2003.

THORLABS. S121C - Compact Photodiode Power Head with Silicon Detector. 18358-S01, $\operatorname{Rev}$ C. 2016. https://www.thorlabs.com/newgrouppage9.cfm?objectgroup_id=3328\&pn=S121C. [Online; acessado em 10 de junho de 2020]. 
THORLABS. Radiometric vs. Photometric Units. 2020. https://www.thorlabs.de/ catalogPages/506.pdf. [Online; acessado em 10 de junho de 2020].

TREGENZA, Peter. Projeto de iluminação. Bookman, 2015. ISBN 9788582603352.

Disponível em: http://search.ebscohost.com/login.aspx?direct=true\&db=edsmib\&AN=edsmib. $000007345 \&$ lang $=$ pt-br\&site $=$ eds-live $\&$ scope $=$ site.

TSONEV, Dobroslav; VIDEV, Stefan; HAAS, Harald. Towards a $100 \mathrm{gb} / \mathrm{s}$ visible light wireless access network. Opt. Express, OSA, v. 23, n. 2, p. 1627-1637, Jan 2015. Disponível em: http://www.opticsexpress.org/abstract.cfm?URI=oe-23-2-1627.

VISTNES, Arnt Inge. Physics of Oscillations and Waves: With use of Matlab and Python. Switzerland: Springer Nature Switzerland AG, 2018.

WU, Zi-Yang; GAO, Yu-Liang; WANG, Ze-Kun; YOU, Chuan; YANG, Chuang; LUO, Chong; WANG, Jiao. Optimized dft-spread ofdm based visible light communications with multiple lighting sources. Opt. Express, OSA, v. 25, n. 22, p. 26468-26482, Oct 2017.

XU, Z.; SADLER, B. M. Ultraviolet communications: Potential and state-of-the-art. IEEE Communications Magazine, v. 46, n. 5, p. 67-73, 2008. 
ANEXO 
ANEXO A - DATASHEET LED LXML-PW31 


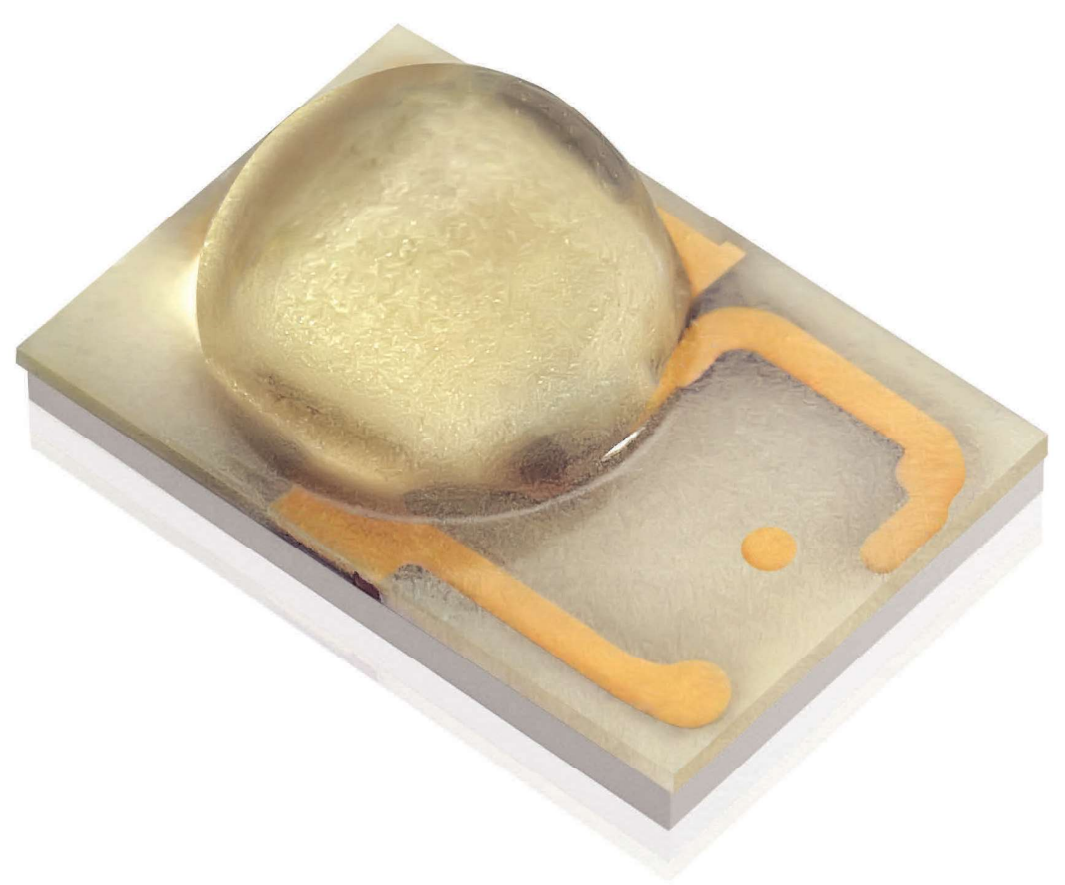

\section{LUXEON Rebel \\ Illumination Portfolio \\ Optimized \\ solutions for \\ illumination applications}

Technical Datasheet DS63

$L U \times E \approx N$

never before possible

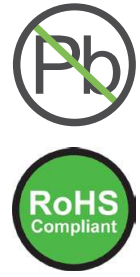

\section{LUXEON ${ }^{\circledR}$ Rebel Illumination Portfolio}

\section{ANSI Binned with Minimum CRI}

\section{Introduction}

The LUXEON ${ }^{\circledR}$ Rebel Illumination Portfolio emitters in this datasheet deliver optimized combinations of light quality and light output needed for today's lighting applications. In addition to delivering specified Correlated Color Temperature and Color Rendering combinations, these parts deliver the efficacy, lifetime and reliability that all LUXEON Rebel LEDs are renowned for. This document contains the performance data needed to design and engineer LUXEON Rebel based applications.

LUXEON Rebel Illumination Portfolio Products

- Specified CCT \& CRI combinations

- ANSI compliant binning

- Exceed ENERGY STAR ${ }^{\circledR}$ lumen maintenance requirements

- High efficacy for sustainable design

- More light delivered at operating temperature. 


\section{Product Selection}

\section{Product Selection for LUXEON Rebel \\ Thermal Pad Temperature $=25^{\circ} \mathrm{C}$}

Table I.

\begin{tabular}{|c|c|c|c|c|c|}
\hline Nominal CCT & $\begin{array}{c}\text { Part } \\
\text { Number }\end{array}$ & $\begin{array}{c}\text { Minimum } \\
\text { CRI }\end{array}$ & $\begin{array}{c}\text { Typical } \\
\text { CRI }\end{array}$ & $\begin{array}{c}\text { Minimum } \\
\text { Luminous } \\
\text { Flux (Im) } \\
\Phi_{\mathrm{v}}\end{array}$ & $\begin{array}{c}\text { Typical } \\
\text { Luminous } \\
\text { Flux } \\
\Phi_{v}\end{array}$ \\
\hline $2700 K$ & LXM3-PW8I & 80 & 85 & 65 & 73 \\
\hline $3000 K$ & LXM3-PW7I & 80 & 85 & 66 & 77 \\
\hline $3000 K$ & LXML-PW7| & 85 & 90 & 50 & 66 \\
\hline $3500 K$ & LXM3-PW6I & 80 & 85 & 67 & 80 \\
\hline $4000 \mathrm{~K}$ & LXML-PW5 I & 60 & 70 & 90 & 105 \\
\hline $4000 \mathrm{~K}$ & LXM3-PW5 I & 80 & 85 & 75 & 85 \\
\hline $5000 \mathrm{~K}$ & LXML-PW3 I & 65 & 70 & 90 & 105 \\
\hline $5700 \mathrm{~K}$ & LXML-PW2I & 65 & 70 & 90 & 105 \\
\hline $6500 \mathrm{~K}$ & LXML-PWII & 65 & 70 & 90 & 105 \\
\hline
\end{tabular}

\section{Notes for Table I:}

I. Philips Lumileds maintains a tolerance of $\pm 6.5 \%$ on luminous flux and \pm 2 on CRI measurements.

2. LUXEON Rebel products with higher performance levels will become available in the future. Please consult Philips Lumileds or Future Lighting Solutions for more information.

3. Test current is $350 \mathrm{~mA}$ for all LXML-PxxI and LXM3-PxxI products. 


\title{
Optical Characteristics
}

\author{
LUXEON Rebel at Test Current ${ }^{[1]}$
}

Thermal Pad Temperature $=25^{\circ} \mathrm{C}$

Table 2.

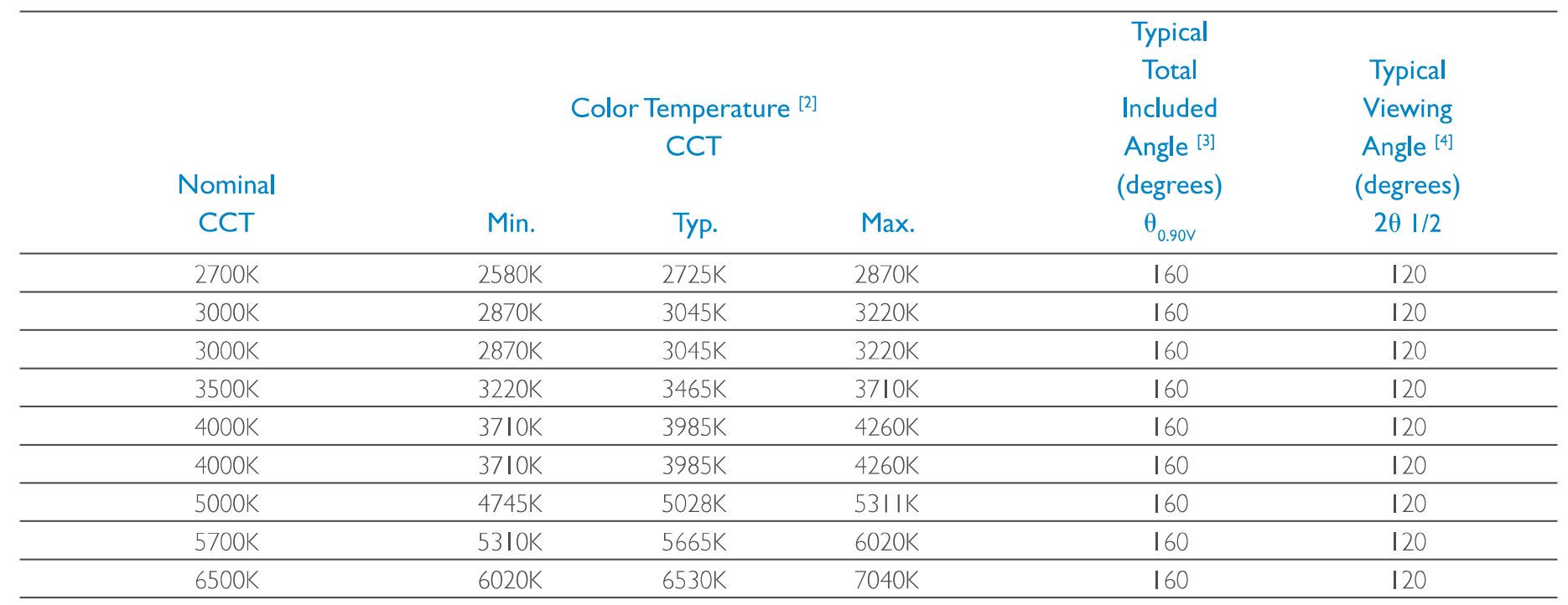

\section{Notes for Table 2:}

I. Test current is $350 \mathrm{~mA}$ for all LXML-PxxI and LXM3-PxxI products.

2. CCT $\pm 5 \%$ tester tolerance.

3. Total angle at which $90 \%$ of total luminous flux is captured.

4. Viewing angle is the off axis angle from lamp centerline where the luminous intensity is $1 / 2$ of the peak value.

5. All white products are built with Indium Gallium Nitride ( $\ln G a N)$. 


\section{Relative Spectral Distribution vs. Wavelength Characteristics, Continued}

\section{LXML-PW3 I (5000K), LXML-PW2I (5700K) and LXML-PWII (6500K)}

at Test Current, Thermal Pad Temperature $=25^{\circ} \mathrm{C}$

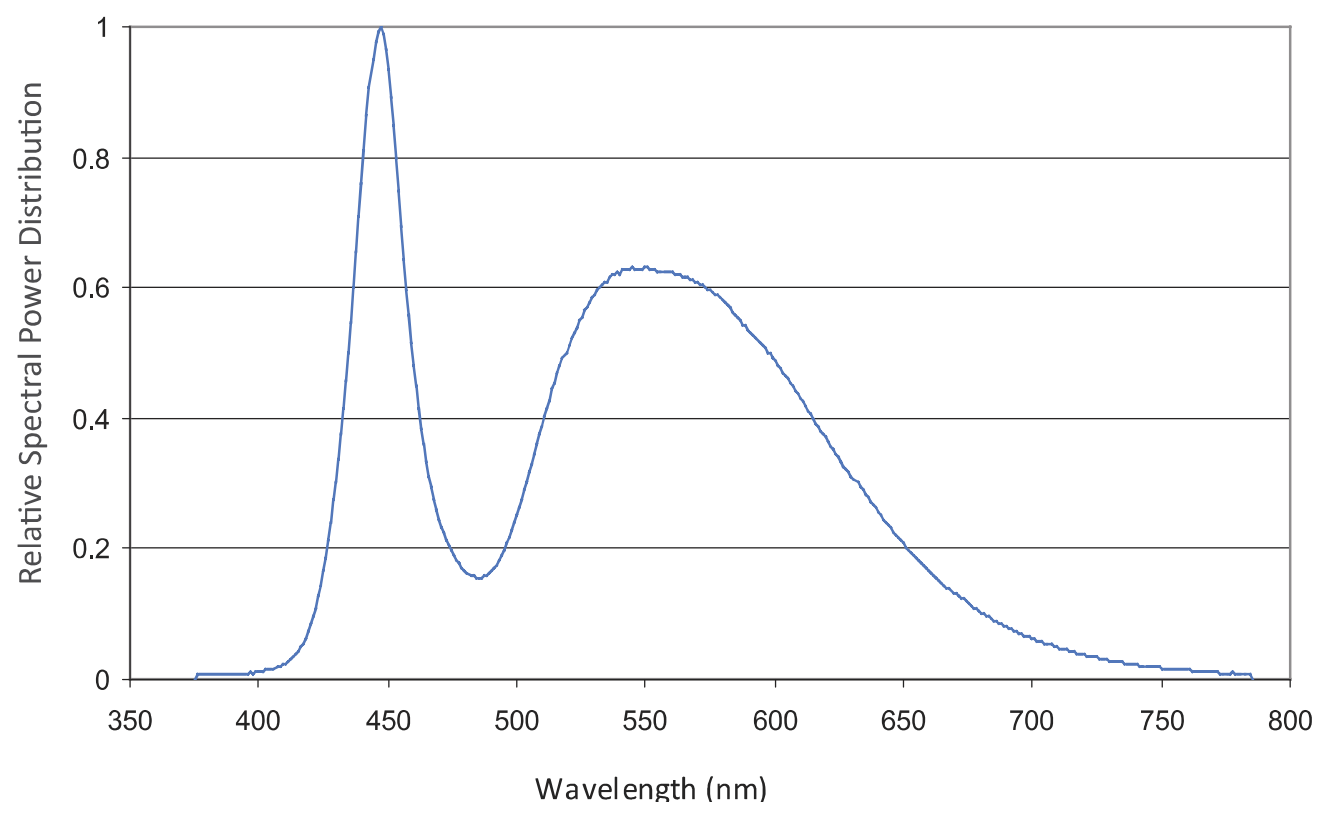

Figure 10. Color spectrum of $5000 \mathrm{~K}, 5700 \mathrm{~K}$ and $6500 \mathrm{~K}$ emitters, integrated measurement. 
ANEXO B - DATASHEET LED LX18-P150 


\section{LUXEON Rebel PLUS}

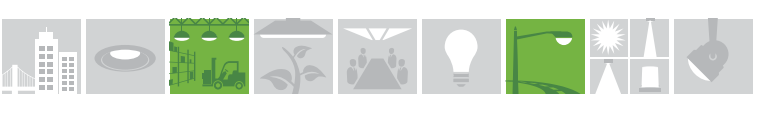

\section{The original high power LED}

LUXEON Rebel PLUS is designed with the highest possible efficacy and light output from an industry standard 4530 package with a $2.5 \mathrm{~mm}^{2}$ dome. With hot testing and color binning, every LUXEON Rebel PLUS is tested and specified at real world operating conditions $-85^{\circ} \mathrm{C}$. Our exceptional color control enables design simplicity for luminaire manufacturers and ensures that they can be confident in color consistency from LED to LED. The superior quality of light, light output, and real world efficacy enable leading performance and efficient solution development in a wide variety of outdoor and industry lighting segments.

\section{FEATURES AND BENEFITS}

3- and 5-step MacAdam ellipse: Freedom from Binning for superior quality of light

Ability to deliver high $\mathrm{Im} / \$$ for Indoor applications

Low typical $V_{f} \sim 2.8 \mathrm{~V}$

Small optical source size

Full range of CCTs in 80CRI minimum

LM-80 test report available

\section{PRIMARY APPLICATIONS}

High Bay \& Low Bay

Outdoor 


\section{Performance Characteristics}

\section{Product Selection Guide}

Table 1. Product performance of LUXEON Rebel PLUS at $350 \mathrm{~mA}$ and $700 \mathrm{~mA}, \mathrm{~T}_{\mathrm{j}}=85^{\circ} \mathrm{C}$.

\begin{tabular}{|c|c|c|c|c|c|c|c|}
\hline \multirow{3}{*}{$\begin{array}{c}\text { NOMINAL } \\
\text { CCT }\end{array}$} & \multirow{3}{*}{$\begin{array}{l}\text { MINIMUM } \\
\text { CRI }^{[1,2]}\end{array}$} & \multicolumn{2}{|c|}{ LUMINOUS FLUX ${ }^{[1]}(\mathrm{Im})$} & \multirow{3}{*}{$\begin{array}{c}\text { TYPICAL } \\
\text { LUMINOUS } \\
\text { EFFICACY (Im/W) }\end{array}$} & \multirow{2}{*}{$\begin{array}{l}\text { TYPICAL } \\
\text { LUMINOUS } \\
\text { FLUX (Im) }\end{array}$} & \multirow{2}{*}{$\begin{array}{c}\text { TYPICAL } \\
\text { LUMINOUS } \\
\text { EFFICACY }(\mathrm{Im} / \mathrm{W})\end{array}$} & \multirow{3}{*}{ PART NUMBER } \\
\hline & & MINIMUM & TYPICAL & & & & \\
\hline & & \multicolumn{2}{|r|}{$350 \mathrm{~mA}$} & & \multicolumn{2}{|c|}{$700 \mathrm{~mA}$} & \\
\hline $2700 K$ & 80 & 80 & 85 & 88 & 156 & 78 & LX18-P127-X \\
\hline $3000 K$ & 80 & 85 & 95 & 98 & 166 & 83 & LX18-P130-X \\
\hline $3500 K$ & 80 & 90 & 98 & 101 & 172 & 86 & LX18-P135-X \\
\hline $4000 \mathrm{~K}$ & 80 & 90 & 103 & 107 & 180 & 90 & LX18-P140-X \\
\hline $5000 \mathrm{~K}$ & 80 & 95 & 106 & 110 & 186 & 93 & LX18-P150-X \\
\hline
\end{tabular}

Notes for Table 1:

Notes for Table 1:
1. Lumileds maintains a tolerance of \pm 2 on CRI and $\pm 6.5 \%$ on luminous flux measurements.

2. Typical CRI is approximately 2 points higher than the minimum CRI specified, but this is not guaranteed.

\section{Optical Characteristics}

Table 2. Optical characteristics for LUXEON Rebel PLUS at $350 \mathrm{~mA}, \mathrm{~T}_{\mathrm{j}}=85^{\circ} \mathrm{C}$.

\begin{tabular}{c|c|c}
\hline PART NUMBER & TYPICAL TOTAL INCLUDED ANGLE ${ }^{[1]}$ & TYPICAL VIEWING ANGLE ${ }^{[2]}$ \\
\hline LX18-P127-X & $160^{\circ}$ & $120^{\circ}$ \\
\hline LX18-P130-X & $160^{\circ}$ & $120^{\circ}$ \\
\hline LX18-P135-X & $160^{\circ}$ & $120^{\circ}$ \\
\hline LX18-P140-X & $160^{\circ}$ & $120^{\circ}$ \\
\hline LX18-P150-X & $160^{\circ}$ & $120^{\circ}$ \\
\hline
\end{tabular}

Notes for Table 2:

1. Total angle at which $90 \%$ of total luminous flux is captured

2. Viewing angle is the off axis angle from the LED centerline where the luminous intensity is $1 / 2$ of the peak value. 


\section{Electrical and Thermal Characteristics}

Table 3. Electrical and thermal characteristics for LUXEON Rebel PLUS at $350 \mathrm{~mA}, \mathrm{~T}_{\mathrm{j}}=85^{\circ} \mathrm{C}$.

\begin{tabular}{|c|c|c|c|c|c|}
\hline \multirow{2}{*}{ PART NUMBER } & \multicolumn{3}{|c|}{ FORWARD VOLTAGE ${ }^{[1]}\left(V_{f}\right)$} & \multirow{2}{*}{$\begin{array}{l}\text { TYPICAL TEMPERATURE } \\
\text { COEFFICIENT OF FORWARD } \\
\text { VOLTAGE }{ }^{[2]}\left(\mathrm{mV} /{ }^{\circ} \mathrm{C}\right)\end{array}$} & \multirow{2}{*}{$\begin{array}{l}\text { TYPICAL THERMAL } \\
\text { RESISTANCE-JUNCTION } \\
\left.\text { TO SOLDER PAD ( }{ }^{\circ} \mathrm{C} / \mathrm{W}\right)\end{array}$} \\
\hline & MINIMUM & TYPICAL & MAXIMUM & & \\
\hline LX18-P127-X & 2.5 & 2.8 & 3.0 & -1.0 to -3.0 & $9.0^{\circ}$ \\
\hline LX18-P130-X & 2.5 & 2.8 & 3.0 & -1.0 to -3.0 & $9.0^{\circ}$ \\
\hline LX18-P135-X & 2.5 & 2.8 & 3.0 & -1.0 to -3.0 & $9.0^{\circ}$ \\
\hline LX18-P140-X & 2.5 & 2.8 & 3.0 & -1.0 to -3.0 & $9.0^{\circ}$ \\
\hline LX18-P150-X & 2.5 & 2.8 & 3.0 & -1.0 to -3.0 & $9.0^{\circ}$ \\
\hline
\end{tabular}

Notes for Table 3:

1. Lumileds maintains a tolerance of $\pm 0.06 \mathrm{~V}$ on forward voltage measurements.

2. Measured between $25^{\circ} \mathrm{C}$ and $110^{\circ} \mathrm{C}$.

\section{Absolute Maximum Ratings}

Table 4. Absolute maximum ratings for LUXEON Rebel PLUS.

\begin{tabular}{|c|c|}
\hline PARAMETER & MAXIMUM PERFORMANCE \\
\hline DC Forward Current ${ }^{[1,2]}$ & $1000 \mathrm{~mA}$ \\
\hline Peak Pulsed Forward Current ${ }^{[1,3]}$ & $1000 \mathrm{~mA}$ \\
\hline LED Junction Temperature ${ }^{[1]}$ (DC \& Pulse) & $150^{\circ} \mathrm{C}$ \\
\hline ESD Sensitivity (ANSI/ESDA/JEDEC JS-001-2012) & < 8000V Human Body Model (HBM) Class 3A JESD22-A114-E \\
\hline Operating Case Temperature ${ }^{[1]}$ & $-40^{\circ} \mathrm{C}$ to $135^{\circ} \mathrm{C}$ \\
\hline LED Storage Temperature & $-40^{\circ} \mathrm{C}$ to $135^{\circ} \mathrm{C}$ \\
\hline Soldering Temperature & JEDEC $020 \mathrm{C} 260^{\circ} \mathrm{C}$ \\
\hline Allowable Reflow Cycles & 3 \\
\hline Reverse Voltage $\left(\mathrm{V}_{\text {reverse }}\right)$ & LUXEON LEDs are not designed to be driven in reverse bias \\
\hline \multicolumn{2}{|c|}{$\begin{array}{l}\text { Notes for Table 4: } \\
\text { 1. Proper current derating must be observed to maintain the junction temperature below the maximum allowable junction temperature. } \\
\text { 2. Residual periodic variations due to power conversion from alternating current (AC) to direct current (DC), also called "ripple," are acceptable if the following conditions are met: } \\
\text { - The frequency of the ripple current is } 100 \mathrm{~Hz} \text { or higher } \\
\text { - The average current for each cycle does not exceed the maximum allowable } \mathrm{DC} \text { forward current } \\
\text { - The maximum amplitude of the ripple does not exceed the maximum peak pulsed forward current } \\
\text { 3. Pulsed operation with the maximum peak pulsed forward current is acceptable if the pulse on-time is } \leq 5 \mathrm{~ms} \text { per cycle and the duty cycle is } \leq 50 \% \text {. }\end{array}$} \\
\hline
\end{tabular}




\section{Characteristic Curves}

\section{Spectral Power Distribution Characteristics}

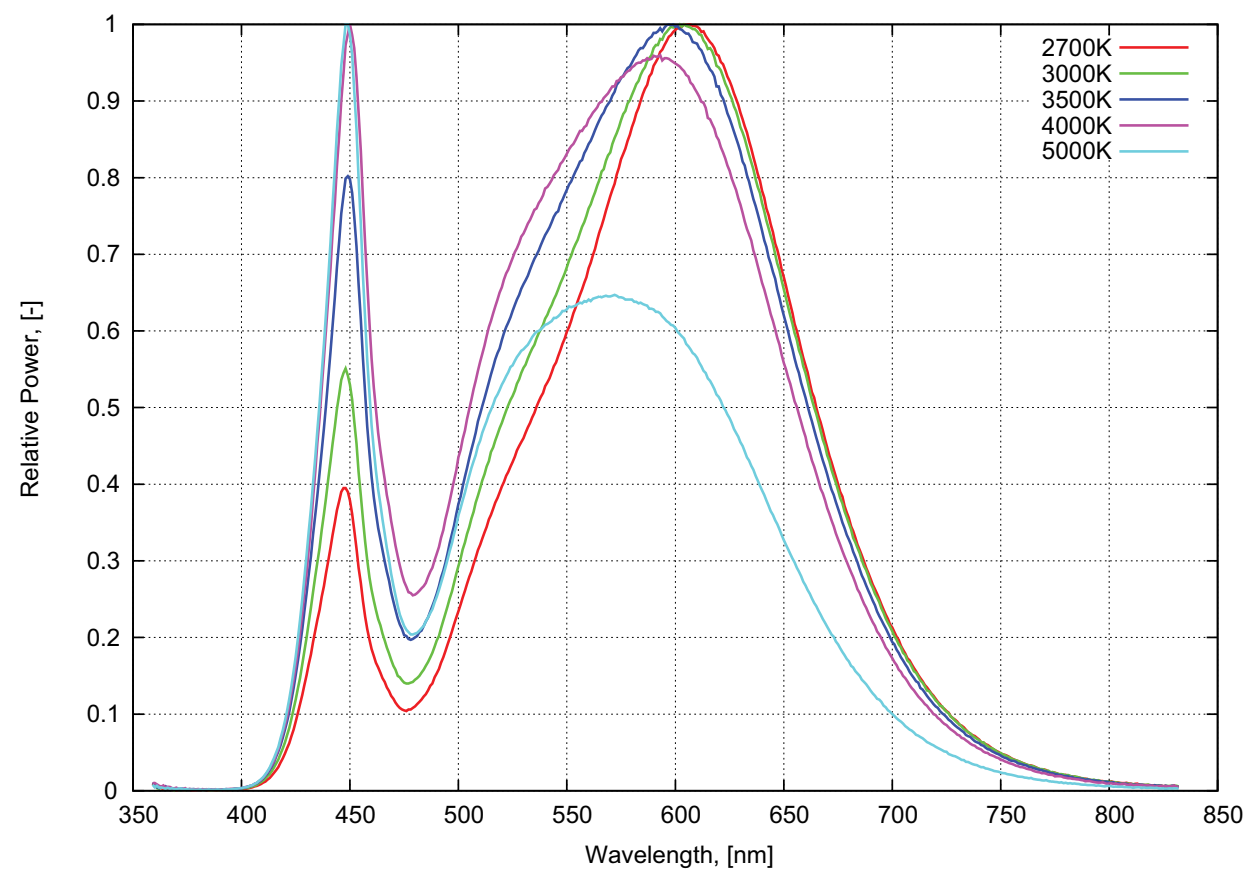

Figure 1. Typical normalized power vs. wavelength for LUXEON Rebel PLUS at test current, $\mathrm{T}_{\mathrm{j}}=85^{\circ} \mathrm{C}$.

\section{Light Output Characteristics}

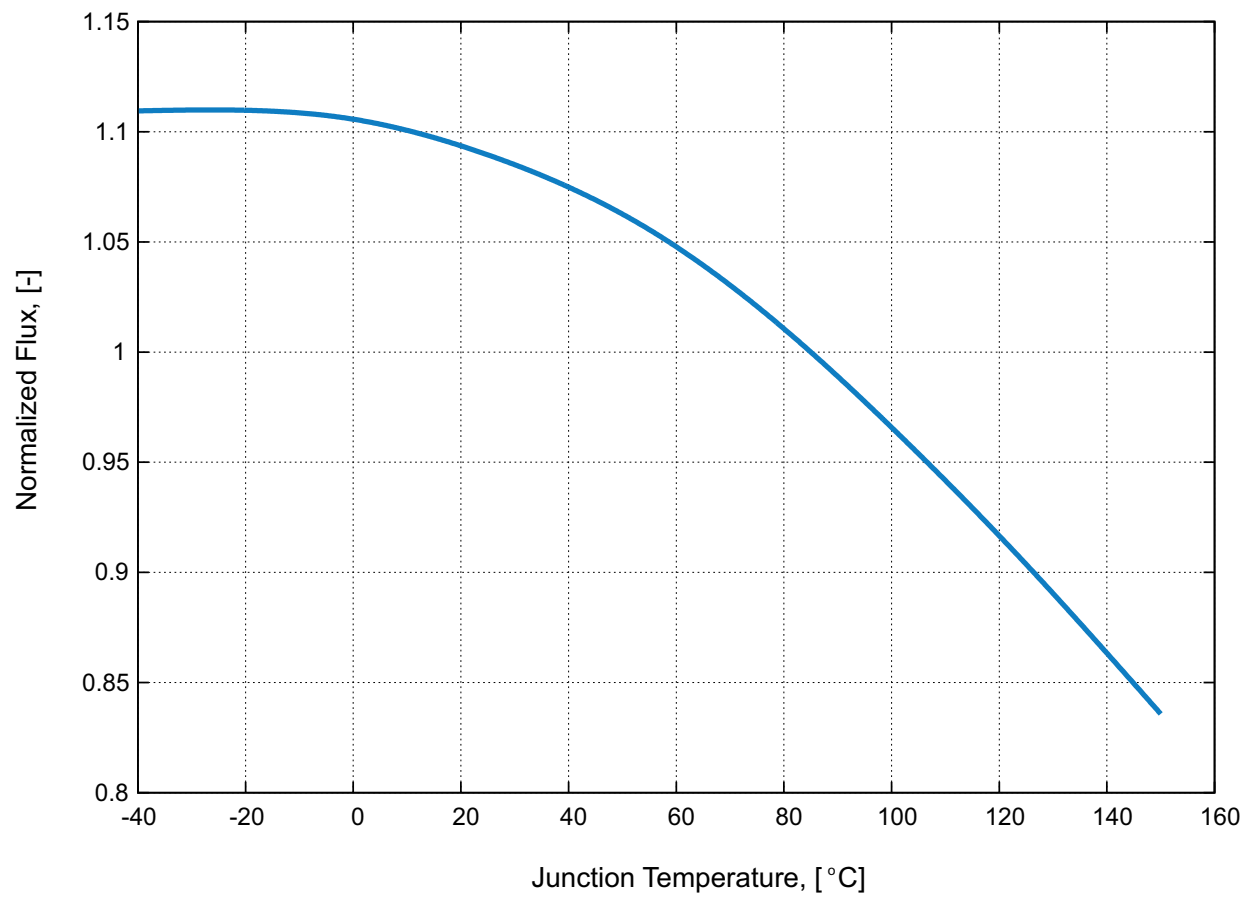

Figure 2. Typical normalized light output vs. junction temperature for LUXEON Rebel PLUS at 350mA. 
ANEXO C - DETALHAMENTO TÉCNICO DO CONCENTRADOR PL121140 


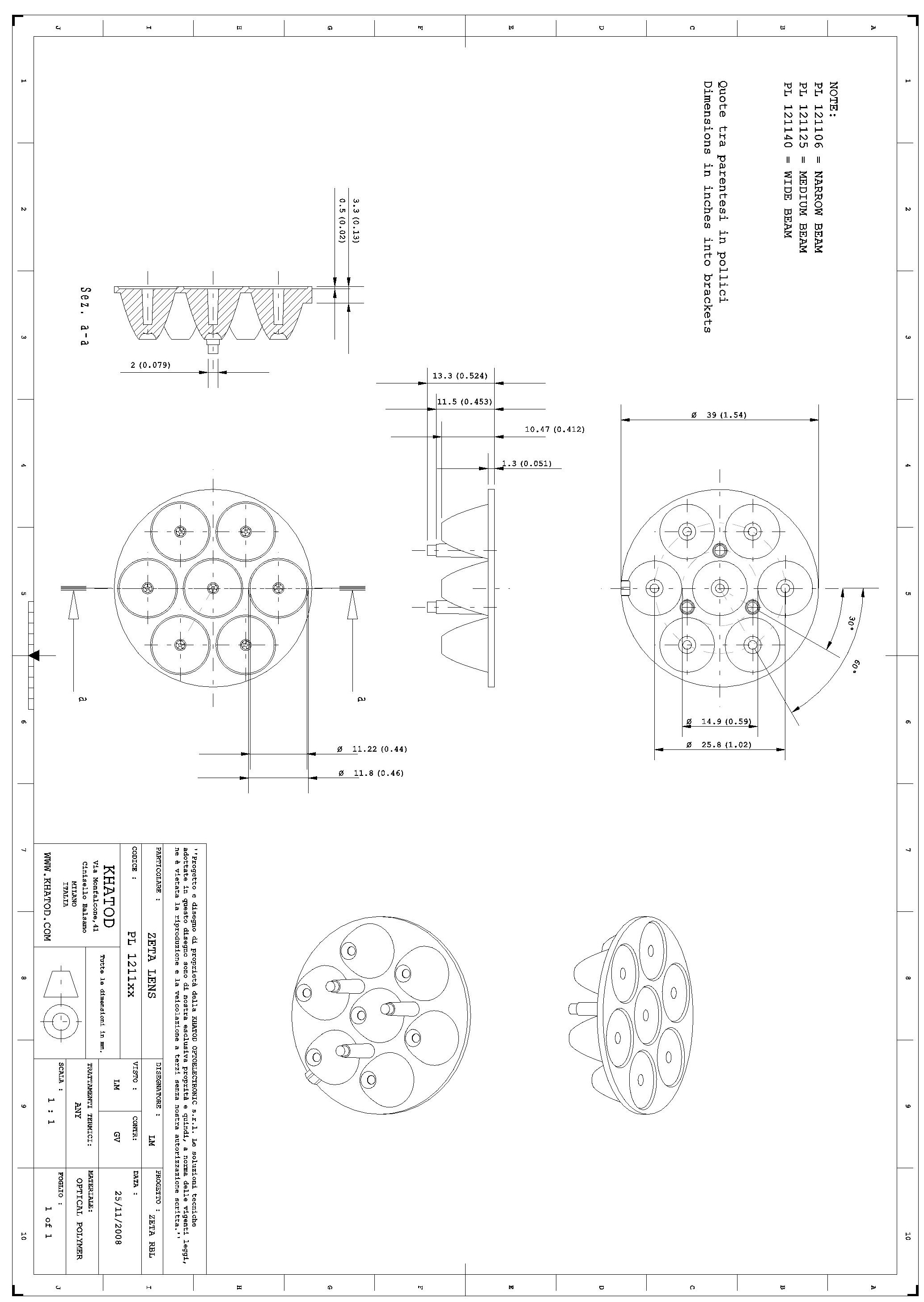

